\title{
MODELO PARA SIMULAÇÃO DA DINÂMICA DA ÁGUA EM SISTEMAS DE DRENAGEM SUBTERRÂNEA E CÁLCULO DO ESPAÇAMENTO ECONÔMICO ENTRE DRENOS
}

\section{JARBAS HONORIO DE MIRANDA}

Engenheiro Agrônomo

Orientador: Prof. Dr. MARCOS VINICIUS FOLEGATTI

Dissertação apresentada à Escola Superior de Agricultura "Luiz de Queiroz", Universidade de São Paulo, para obtenção do título de Mestre em Agronomia, Área de Concentração: Irrigação e Drenagem.

P I R A C I C A B A

Estado de São Paulo - Brasil

Novembro - 1997 
Dados Internacionais de Catalogação na Publicação (CIP) DIVISÃO DE BIBLIOTECA E DOCUMENTAÇÃO - Campus "Luiz de Queiroz"/USP

Miranda, Jarbas Honorio de

Modelo para simulação da dinâmica da água em sistemas de drenagem subterrânea e cálculo do espaçamento econômico entre drenos / Jarbas Honorio de Miranda. - . Piracicaba, 1997.

$89 \mathrm{p.}$

Dissertação (mestrado) - E Escola Superior de Agricultura Luiz de Queiroz, 1997. Bibliografia.

1. Drenagem 2. Espaçamento 3. Simulação automatizada 4. Visual Basic I. Título

CDD 631.6 


\title{
MODELO PARA SIMULAÇÃO DA DINÂMICA DA ÁGUA EM SISTEMAS DE DRENAGEM SUBTERRÂNEA E CÁLCULO DO ESPAÇAMENTO ECONÔMICO ENTRE DRENOS
}

\author{
JARBAS HONORIO DE MIRANDA
}

Aprovada em 20 de Janeiro de 1998

Comissão julgadora:

Prof. Dr. Marcos Vinicius Folegatti ESALQ/USP

Prof. Dr. Sergio Nascimento Duarte ESALQ/USP

Prof. Dr. João Carlos Cury Saad FCA/UNESP

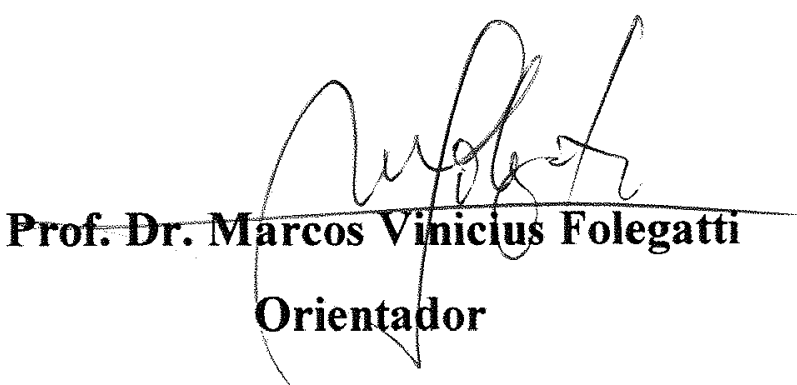


À minha mãe e minhas irmãs OFEREÇO

À memória de meu pai, José Honorio de Miranda, e do meu irmão, José Humberto de Miranda DEDICO 


\section{AGRADECIMENTOS}

À Deus pela força e coragem para superar todas as dificuldades e momentos difíceis durante a realização deste trabalho.

Ao Prof. Dr. Sergio Nascimento Duarte pela orientação e companheirismo, ingredientes que foram de suma importância para a concretização deste trabalho.

Ao Prof. Dr. Marcos Vinicius Folegatti pelo incentivo, pensamento positivo e perseverança em se alcançar um objetivo.

Ao Prof. Dr. João Carlos Cury Saad pelas correções e sugestões feitas durante a defesa deste trabalho.

Ao Prof. Dr. Rogério Teixeira de Faria e ao Prof. Dr. Décio Eugênio Cruciani pelos esclarecimentos e sugestões.

Ao Prof. Dr. Durval Dourado Neto pelo fornecimento do material de estudo e esclarecimentos.

Ao Prof. Dr. José Antonio Frizzone por esclarecimentos e sugestões.

Ao Analista de Sistemas Carlos Fernando Sanches pelos esclarecimentos fornecidos.

Aos colegas de curso de Pós-Graduação, Sérgio Antônio Veronez de Sousa e Vital Pedro da Silva Paz, pela cooperação e esclarecimentos.

A todos os colegas de Pós-Graduação que de alguma forma vieram a contribuir para a realização deste trabalho.

Aos Professores do Departamento de Engenharia Rural pelos ensinamentos.

Aos funcionários do Departamento de Engenharia Rural pela amizade e apoio em todos os momentos.

Às bibliotecárias Eliana M. Garcia Sabino e Kátia M. de Andrade Ferraz pelo eficiente atendimento e pela revisão das referências bibliográficas.

Ao $\mathrm{CNPq}$ pela concessão da bolsa de estudos.

À Escola Superior de Agricultura "Luiz de Queiroz" pelos conhecimentos adquiridos durante a realização do curso. 


\section{SUMÁRIO}

Página

LISTA DE FIGURAS.............................................................. vii

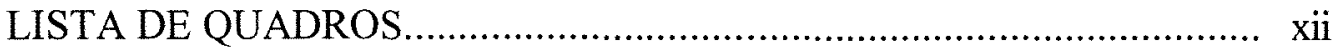

LISTA DE TABELAS............................................................. xiii

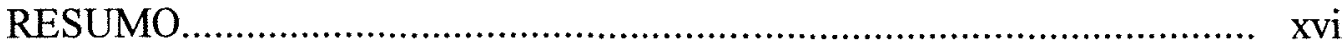

SUMMARY ..................................................................... xviii

1 INTRODUÇÃO.................................................................... 1

2 REVISÃO DE LITERATURA.................................................. 5

2.1 Utilização de modelos para avaliação de desempenho de sistemas de drenagem................................................................. 5

2.2 Análise econômica dos projetos de drenagem................................ 8

3 MATERIAL E MÉTODOS ........................................................ 15

3.1 Desenvolvimento do modelo..................................................... 15

3.1.1 Cálculo da lâmina escoada superficialmente e da infiltrada............... 17

3.1.2 Cálculo do fluxo máximo ascendente....................................... 19

3.1.3 Balanço hídrico na zona radicular........................................... 22

3.1.4 Cálculo da posição do lençol freático............................................ 24

3.1.5 Correção da posição do lençol freático e do armazenamento............. 26

3.1.6 Cálculo da vazão diária........................................................ 26

3.1.7 Cálculo dos índices de desempenho do sistema de drenagem............ 27

3.2 Comparação das simulações realizadas com os modelos....................... 32

4 RESULTADOS E DISCUSSÃO............................................... 36

4.1 Comparações diárias sem escoamento superficial............................. 36

4.1.1 Altura do lençol freático.................................................... 36

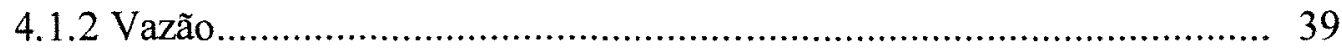

4.1.3 Armazenamento de água na zona radicular............................... 44

4.1.4 Evapotranspiração real........................................................ 44

4.2 Comparações diárias com escoamento superficial............................ 49

4.2.1 Escoamento superficial..................................................... 49 
4.2.2 Altura do lençol freático considerando o escoamento superficial....... 53

4.2.3 Vazão considerando o escoamento superficial.............................. 53

4.2.4 Armazenamento de água na zona radicular considerando o escoamento superficial.......................................................... 57

4.2.5 Evapotranspiração real considerando o escoamento superficial......... 62

4.3 Índices anuais de desempenho em condições de ausência de escoamento superficial....................................................... 62

4.4 Índices anuais de desempenho em condições de existência de escoamento superficial....................................................... 66

4.5 Dimensionamento econômico do sistema de drenagem....................... 72

4.5.1 Estimativa das produtividades médias e prováveis para a cultura do milho em condições de ausência de escoamento superficial............... 72

4.5.2 Estimativa das produtividades médias e prováveis para a cultura do milho em condições de existência de escoamento superficial............. 77

4.5.3 Análise econômica baseada no valor presente................................ 77

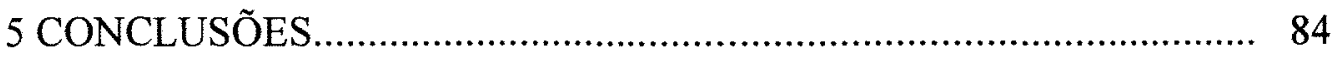

REFERÊNCIAS BIBLIOGRÁFICAS........................................... 85 


\section{LISTA DE FIGURAS}

Página

1 Esquema dos principais componentes de fluxo considerados pelo modelo.

2 Fluxograma do modelo proposto

3 Pluviograma e profundidades do lençol freático simuladas pelo SISDRENA e SIMDRENO comparadas com DRAINMOD, durante o período de julho de 1982 a julho de 1983 , com espaçamento de $50 \mathrm{~m}$ para o solo 2

4 Pluviograma e profundidades do lençol freático simuladas pelo SISDRENA e SIMDRENO comparadas com DRAINMOD, durante o período de julho de 1983 a julho de 1984 , com espaçamento de $80 \mathrm{~m}$ para o solo 1

5 Pluviograma e profundidades do lençol freático simuladas pelo SISDRENA e SIMDRENO comparadas com DRAINMOD, durante o período de julho de 1983 a julho de 1984, com espaçamento de $20 \mathrm{~m}$ para o solo 1

6 Pluviograma e vazões diárias por unidade de área simuladas pelo SISDRENA e SIMDRENO comparadas com DRAINMOD, durante o período de julho de 1983 a julho de 1984, com espaçamento de $80 \mathrm{~m}$ para o solo 2 . 
7 Armazenamento de água na zona radicular simulado pelo SISDRENA e SIMDRENO comparado com DRAINMOD, durante o período de julho de 1984 a julho de 1985 , com espaçamento de $50 \mathrm{~m}$ para o solo 2

8 Evapotranspiração real simulada pelo SISDRENA e SIMDRENO comparada com DRAINMOD, durante o período de julho de 1982 a julho de 1983 , com espaçamento de $80 \mathrm{~m}$ para o solo 2

9 Pluviograma e escoamento superficial simulado pelo SISDRENA e SIMDRENO comparado com DRAINMOD, durante o período de julho de 1983 a julho de 1984 , com espaçamento de $80 \mathrm{~m}$ para o solo 1

10 Pluviograma e escoamento superficial simulado pelo SISDRENA e SIMDRENO comparado com DRAINMOD, durante o período de julho de 1982 a julho de 1983 , com espaçamento de $80 \mathrm{~m}$ para o solo 2

11 Pluviograma e profundidades do lençol freático simuladas pelo SISDRENA e SIMDRENO comparadas com DRAINMOD, durante o período de julho de 1983 a julho de 1984 , com espaçamento de $50 \mathrm{~m}$ para o solo 2 .

12 Pluviograma e profundidades do lençol freático simuladas pelo SISDRENA e SIMDRENO comparadas com DRAINMOD, durante o período de julho de 1983 a julho de 1984 , com espaçamento de $80 \mathrm{~m}$ para o solo 3

13 Pluviograma e vazões diárias por unidade de área simuladas pelo SISDRENA e SIMDRENO comparadas com DRAINMOD, durante o período de julho de 1984 a julho de 1985 , com espaçamento de $50 \mathrm{~m}$ para o solo 2 
14 Armazenamento de água na zona radicular simulado pelo SISDRENA e SIMDRENO comparado com DRAINMOD, durante o período de julho de 1982 a julho de 1983, com espaçamento de $80 \mathrm{~m}$ para o solo 3 ..............

15 Armazenamento de água na zona radicular simulado pelo SISDRENA e SIMDRENO comparado com DRAINMOD, durante o período de julho de 1982 a julho de 1983, com espaçamento de $20 \mathrm{~m}$ para o solo 3

16 Evapotranspiração real simulada pelo SISDRENA e SIMDRENO comparada com DRAINMOD, durante o período de julho de 1983 a julho de 1984, com espaçamento de $50 \mathrm{~m}$ para o solo 3.

17 Gráficos de dispersão do índice $\mathrm{SEW}_{30}$ em torno da reta $\mathrm{X}=\mathrm{Y}$, mostrando o desempenho dos modelos SISDRENA e SIMDRENO em relação ao DRAINMOD, para as simulações realizadas com os solos 1 e 2 .

18 Gráficos de dispersão do índice número de dias secos em torno da reta $\mathrm{X}=\mathrm{Y}$, mostrando o desempenho dos modelos SISDRENA e SIMDRENO em relação ao DRAINMOD, para as simulações realizadas com os solos 1 e 2

19 Gráficos de dispersão da produtividade relativa anual (\%), para a cultura do milho, em torno da reta $\mathrm{X}=\mathrm{Y}$, mostrando o desempenho dos modelos SISDRENA e SIMDRENO em relação ao DRAINMOD, para as simulações realizadas com os solos 1 e 2 . 
20 Gráficos de dispersão do índice $\mathrm{SEW}_{30}$ em torno da reta $\mathrm{X}=\mathrm{Y}$, mostrando o desempenho dos modelos SISDRENA e SIMDRENO em relação ao DRAINMOD, para as simulações realizadas com os solos 1,2 e 3

21 Gráficos de dispersão do índice número de dias secos em torno da reta $\mathrm{X}=\mathrm{Y}$, mostrando o desempenho dos modelos SISDRENA e SIMDRENO em relação ao DRAINMOD, para as simulações realizadas com os solos 1,2 e 3

22 Gráficos de dispersão da produtividade relativa anual (\%), para a cultura do milho, em torno da reta $\mathrm{X}=\mathrm{Y}$, mostrando o desempenho dos modelos SISDRENA e SIMDRENO em relação ao DRAINMOD, para as simulações realizadas com os solos 1,2 e 3 .

23 Produtividades relativas médias, para a cultura do milho, em função do espaçamento entre drenos, obtidas pelo SISDRENA, SIMDRENO e DRAINMOD para os solos 1 e 2 em condições de ausência de escoamento superficial

24 Produtividades prováveis, para a cultura do milho, em função do espaçamento entre drenos, obtidas pelo SISDRENA, SIMDRENO e DRAINMOD para os solos 1 e 2 em condições de ausência de escoamento superficial..

25 Produtividades relativas médias para a cultura do milho em função do espaçamento entre drenos, obtidas pelo SISDRENA, SIMDRENO e DRAINMOD para os solos 1, 2 e 3 em condições de existência de escoamento superficial. 
26 Produtividades prováveis para a cultura do milho em função do espaçamento entre drenos, obtidas pelo SISDRENA, SIMDRENO e DRAINMOD para os solos 1,2 e 3 em condições de existência de escoamento superficial........................................................................ 8 


\section{LISTA DE QUADROS}

\section{Página}

1 Parâmetros físico-hídricos dos solos utilizados nas simulações................... 33

2 Relação dos parâmetros dos três tipos de solos utilizados na simulação, para entrada no modelo de van Genuchten (1980)

3 Valores presentes $\left(\mathrm{R} \$ . \mathrm{ha}^{-1}\right)$ obtidos usando-se produtividades médias para os solos 1 e 2 em ausência de escoamento superficial................................... 82

4 Valores presentes $\left(\mathrm{R} \$ . \mathrm{ha}^{-1}\right)$ obtidos usando-se produtividades prováveis para os solos 1 e 2 em ausência de escoamento superficial

5 Valores presentes obtidos ( $\left.\mathrm{R} \$ . \mathrm{ha}^{-1}\right)$ usando-se produtividades médias para os solos 1, 2 e 3, na presença de escoamento superficial.............................. 82

6 Valores presentes $\left(\mathrm{R} \$ . h \mathrm{~h}^{-1}\right)$ obtidos usando-se produtividades prováveis para os solos 1,2 e 3, na presença de escoamento superficial 


\section{LISTA DE TABELAS}

Página

1 Erros padrões entre as posições diárias do lençol freático simuladas pelo SISDRENA e SIMDRENO, em relação ao DRAINMOD, para diferentes períodos anuais, tipos de solo e espaçamentos, em condições de ausência de escoamento superficial

2 Erros padrões entre as vazões diárias simuladas pelo SISDRENA e SIMDRENO, em relação ao DRAINMOD, para diferentes períodos anuais, tipos de solo e espaçamentos, em condições de ausência de escoamento superficial.

3 Erros padrões do armazenamento de água na zona radicular simulado pelo SISDRENA e SIMDRENO, em relação ao DRAINMOD, para diferentes períodos anuais, tipos de solo e espaçamentos, em condições de ausência de escoamento superficial

4 Erros padrões da evapotranspiração real simulada pelo SISDRENA e SIMDRENO, em relação ao DRAINMOD, para diferentes períodos anuais, tipos de solo e espaçamentos, em condições de ausência de escoamento superficial

5 Erros padrões do volume de escoamento superficial simulado pelo SISDRENA e SIMDRENO, em relação ao DRAINMOD, para diferentes períodos anuais, tipos de solo e espaçamentos, em condições de presença de escoamento superficial 
6 Erros padrões entre as posições diárias do lençol freático simuladas pelo SISDRENA e SIMDRENO, em relação ao DRAINMOD, para diferentes períodos anuais, tipos de solo e espaçamentos, em condições de presença de escoamento superficial.

7 Erros padrões entre as vazões diárias simuladas pelo SISDRENA e SIMDRENO, em relação ao DRAINMOD, para diferentes períodos anuais, tipos de solo e espaçamentos, em condições de presença de escoamento superficial.

8 Erros padrões de armazenamento de água na zona radicular simulado pelo SISDRENA e SIMDRENO, em relação ao DRAINMOD, para diferentes períodos anuais, tipos de solo e espaçamentos, em condições de presença de escoamento superficial.

9 Erros padrões da evapotranspiração real simulada pelo SISDRENA e SIMDRENO, em relação ao DRAINMOD, para diferentes períodos anuais, tipos de solo e espaçamentos, em condições de presença de escoamento superficial.

10 Valores de produtividade relativa média (Ytm), para a cultura do milho, em função do espaçamento entre drenos, obtidos pelos três modelos para o solo $1(\mathrm{Ko}=1 \mathrm{~m} / \mathrm{dia})$ em condições de ausência de escoamento superficial.

11 Valores de produtividade relativa média (Ytm), para a cultura do milho, em função do espaçamento entre drenos, obtidos pelos três modelos para o solo $2(\mathrm{Ko}=0,5 \mathrm{~m} /$ dia $)$ em condições de ausência de escoamento superficial. 
12 Valores de produtividade provável, para a cultura do milho, em função do espaçamento entre drenos, obtidos pelos três modelos para o solo 1 $(\mathrm{Ko}=1 \mathrm{~m} / \mathrm{dia})$ em condições de ausência de escoamento superficial.

13 Valores de produtividade provável, para a cultura do milho, em função do espaçamento entre drenos, obtidos pelos três modelos para o solo 2 $(\mathrm{Ko}=0,5 \mathrm{~m} / \mathrm{dia})$ em condições de ausência de escoamento superficial.

14 Valores de produtividade relativa média (YTm) em função do espaçamento entre drenos, obtidos pelos três modelos para o solo 1 $(\mathrm{Ko}=1,0 \mathrm{~m} / \mathrm{dia})$

15 Valores de produtividade relativa média (YTm) em função do espaçamento entre drenos, obtidos pelos três modelos para o solo 2 $(\mathrm{Ko}=0,5 \mathrm{~m} / \mathrm{dia})$.

16 Valores de produtividade relativa média (YTm) em função do espaçamento entre drenos, obtidos pelos três modelos para o solo 3 $(\mathrm{Ko}=0,1 \mathrm{~m} / \mathrm{dia})$

17 Valores de produtividade provável em função do espaçamento entre drenos, obtidos pelos três modelos para o solo $1(\mathrm{Ko}=1,0 \mathrm{~m} /$ dia $)$.

18 Valores de produtividade provável em função do espaçamento entre drenos, obtidos pelos três modelos para o solo $2(\mathrm{Ko}=0,5 \mathrm{~m} / \mathrm{dia})$.

19 Valores de produtividade provável em função do espaçamento entre drenos, obtidos pelos três modelos para o solo $3(\mathrm{Ko}=0,1 \mathrm{~m} / \mathrm{dia})$ 


\title{
MODELO PARA SIMULAÇÃO DA DINÂMICA DA ÁGUA EM SISTEMAS DE DRENAGEM SUBTERRÂNEA E CÁlCULO DO ESPAÇAMENTO ECONÔMICO ENTRE DRENOS
}

\author{
Autor: JARBAS HONORIO DE MIRANDA \\ Orientador: Prof. Dr. MARCOS VINICIUS FOLEGATTI
}

\section{RESUMO}

Desenvolveu-se um modelo computacional denominado "SISDRENA", que a partir de séries históricas de dados diários de precipitação e evapotranspiração potencial, características fisico-hídricas do solo, dados de sensibilidade da cultura ao excesso e à falta de água, sistema radicular e características do sistema de drenagem, permite simular a posição do lençol freático, a evapotranspiração real e o armazenamento de água na zona radicular, contabilizando ou não o escoamento superficial nas simulações. $O$ escoamento superficial é estimado por uma modificação do método do Número da Curva, que considera também a porosidade drenável do solo e a profundidade do lençol freático. A posição do lençol freático é estimada pela equação de De Zeeuw e Hellinga. $\mathrm{O}$ modelo calcula os índices $\mathrm{SEW}_{30}$, número de dias secos e produtividades relativas esperadas devido ao excesso e déficit de umidade, os quais permitem uma avaliação do comportamento da cultura ao longo do seu ciclo e, a partir daí, estima produtividades relativas anuais. Estas estimativas permitem determinar, realizando-se uma análise econômica, qual o espaçamento entre drenos ideal para cada situação simulada.

O desempenho do modelo SISDRENA foi comparado com o do modelo SIMDRENO, considerando o modelo norte americano DRAINMOD como padrão. O modelo SISDRENA pode corrigir algumas limitações do SIMDRENO, tais como 
contabilizar de forma mais precisa o efeito do fluxo ascendente, sobre o rebaixamento do lençol freático, permitindo simular rebaixamentos do mesmo abaixo da linha dos drenos e considerar o efeito da drenagem subterrânea sobre o escoamento superficial.

Foram comparados resultados relativos a estimativas diárias da altura do lençol freático, armazenamento de água na zona radicular, evapotranspiração real, vazão escoada através dos drenos e escoamento superficial, bem como previsões dos índices de desempenho do sistema de drenagem, produtividades relativas esperadas e espaçamentos entre drenos mais econômicos.

Nas comparações diárias o SISDRENA quando comparado com o SIMDRENO, em relação ao DRAINMOD, apresentou menores erros padrões quanto a estimativa da altura do lençol freático, vazão, evapotranspiração real e escoamento superficial. Os dois modelos obtiveram resultados semelhantes no que diz respeito ao armazenamento de água na zona radicular.

Os índices que permitem a análise do desempenho do sistema de drenagem, simulados pelo SISDRENA foram melhor estimados em relação ao SIMDRENO, quando comparados com o DRAINMOD.

As produtividades médias e prováveis calculadas pelo SISDRENA apresentaram menores desvios do que as estimadas pelo SIMDRENO, principalmente para maiores espaçamentos entre drenos, em relação às obtidas pelo DRAINMOD.

Com relação à estimativa do espaçamento mais econômico entre drenos pode-se verificar que os três modelos apresentaram resultados semelhantes. 


\title{
MODEL FOR SIMULATION OF THE DYNAMICS OF THE WATER IN SYSTEMS OF SUBSURFACE DRAINAGE AND CALCULATION OF THE ECONOMIC DRAIN SPACINGS
}

\author{
Author: JARBAS HONORIO DE MIRANDA \\ Adviser: Prof. Dr. MARCOS VINICIUS FOLEGATTI
}

SUMMARY

SISDRENA is a model developed based on historical series of daily precipitation and potential evapotranspiration, soil physical properties, crop sensitivity to excess and water deficit, root system and drainage system lay-out. It allows to simulate the position of the water table, the real evapotranspiration and the storage of water in the root zone, counting or not the runoff in the simulations. The runoff was calculated by a Curve Number modified method, that also considers the drainable soil porosity and the depth of the water table. The position of the water table is estimated by the equation of De Zeeuw and Hellinga. The model calculates the indexes SEW30, number of dry days and relative productivities expected due to the soil moisture conditions, which allow to evaluate the crop behavior along its cycle and, estimates its annual relative productivities. An economic analysis to determine the ideal drain spacings for each simulated situation was done.

The model SISDRENA was compared to model SIMDRENO, considering the model DRAINMOD as a pattern. The model SISDRENA can correct some limitations of SIMDRENO, such as counting in a more precise way the effect of the ascending flow, on the lowering water table, allowing to simulate lowering below the line of the drains and to consider the effect of the underground drainage on the runoff. 
Relative results were compared to the values estimated daily height of the water table, storage of water in the root zone, evapotranspiration, discharge through the drains and superficial runoff, as well as forecasts of the indexes of the drainage system, expected relative productivities and economic drain spacings.

Daily comparisons of SISDRENA and SIMDRENO, in relation to DRAINMOD, presented smaller standard errors as the estimate of the height of the water table, discharge, real evapotranspiration and superficial runoff. The two models obtained similar results on the water storage at the root zone.

The indexes that allow the analysis of the drainage system, simulated by SISDRENA were better estimated in relation to SIMDRENO, when compared with DRAINMOD.

The medium and the expected productivities calculated by SISDRENA presented smaller deviations than the SIMDRENO, mainly for larger drain spacings, in relation the DRAINMOD.

The economic analysis showed that the three models presented similar results. 


\section{INTRODUÇÃO}

A drenagem para fins agrícolas tem como objetivo a retirada do excesso de água dos solos, permitindo um melhoramento da aeração e das propriedades físicas e químicas, tornando-os mais aptos para o desenvolvimento e produção de culturas. Quando a drenagem natural de um solo não é suficiente para torná-lo propício para o cultivo, métodos de drenagem artificial devem ser utilizados.

Os projetos de drenagem que vêm sendo executados na Região Sudeste do Brasil têm como objetivo incorporar ao processo produtivo várzeas com drenagem natural deficiente. $\mathrm{Na}$ maioria destes projetos, certos aspectos importantes do "lay-out" como o espaçamento entre drenos, muitas vezes vêm sendo definidos não apenas pela aplicação da teoria da drenagem, mas principalmente tomando como base a experiência prática do projetista. Outra característica importante é que na maioria dos casos os espaçamentos utilizados no campo tem sido consideravelmente maiores do que seriam caso fossem obtidos por meio de equações de espaçamento entre drenos e critérios de drenagem tradicionais. Segundo Duarte (1997), ao que tudo indica, os critérios conservadores de dimensionamento fornecem o espaçamento que propicia a produtividade máxima das culturas, mas nem sempre retrata o dimensionamento mais econômico.

A limitada aplicação de procedimentos científicos no dimensionamento dos sistemas de drenagem pode ser atribuída a vários fatores, tais como a complexidade das relações entre a produtividade das culturas e o teor de água no solo, a dificuldade em se prever a distribuição do conteúdo de água no perfil do solo em relação à intensidade da drenagem e o custo das investigações de campo necessárias a um dimensionamento mais racional (Bower, 1974). 
Segundo Bernardo (1986) as principais fontes que colaboram com o excesso de água no solo, são as precipitações, as irrigações e os escoamentos laterais e verticais de posições adjacentes à área de interesse.

Relacionando estes excessos de água com a movimentação do lençol freático (LF), várias técnicas foram desenvolvidas para avaliar a dinâmica da água no solo e procurar relacioná-la com aspectos climáticos, parâmetros físico-hídricos do solo e da cultura e parâmetros geométricos do sistema de drenagem. Estas técnicas são importantes para o dimensionamento racional e implantação de projetos eficientes de drenagem. $O$ desenvolvimento de novos procedimentos de dimensionamento, principalmente os que fazem uso de modelos computacionais, cresceu muito na década de 80, principalmente nos países desenvolvidos onde a drenagem é uma prática agrícola importante como nos Estados Unidos e na Holanda. Alguns desses modelos tornaram-se ferramentas importantes pois permitem quantificar os impactos das práticas agrícolas sobre a produtividade das culturas e o meio ambiente (Sabbagh et al., 1993).

Dentre estes modelos, um dos que vem sendo mais utilizados é o modelo norte-americano DRAINMOD (Skaggs, 1981). O DRAINMOD vem sendo aplicado por técnicos dos Estados Unidos como um método realmente efetivo para dimensionamento dos sistemas de drenagem (Skaggs, 1990).

Este modelo exige como dados de entrada séries históricas de precipitação de vários anos organizadas na forma horária. Este fato dificulta a aplicação do modelo no Brasil, pois como se sabe, são poucas as localidades que dispõem de dados pluviográficos. Além disso, na maioria das vezes estes dados estão dispostos na forma de pluviogramas, necessitando de um trabalho longo para transformá-los em arquivos que possam ser processados pelo DRAINMOD.

Visando contornar esta limitação, Duarte (1997) desenvolveu o modelo SIMDRENO. Este modelo simula a posição do LF e a umidade do solo na zona radicular, a partir de séries históricas de dados diários de precipitação, evapotranspiração, parâmetros físico-hídricos do solo, cultura e geometria do sistema de drenagem. Estima a fração da precipitação que escoa superficialmente empregando o método do Número da Curva, calcula a posição do LF por meio de equações que consideram a recarga 
intermitente do lençol e estima a umidade do solo na zona radicular como base em um balanço hídrico.

Apesar da sua funcionabilidade, o SIMDRENO apresenta algumas limitações quando comparado com o DRAINMOD.

Em ausência de "seepage" vertical e em dias que não ocorrem precipitações o SIMDRENO não contabiliza o efeito do fluxo ascendente devido a evapotranspiração sobre o rebaixamento do LF, nem permite simular este rebaixamento abaixo da linha dos drenos. O SIMDRENO calcula o escoamento superficial independentemente do efeito de variações na umidade do solo e, portanto, não considera a influência da drenagem subterrânea sobre este escoamento.

Ao realizar o dimensionamento econômico dos sistemas de drenagem, o SIMDRENO permite a entrada de apenas 10 valores de espaçamentos a serem submetidos a simulação. Assim, para o usuário atingir a faixa mais econômica, é necessário realizar outra divisão de faixas em precisões maiores até atingir a mais econômica.

Com relação aos aspectos operacionais, o SIMDRENO foi desenvolvido para o sistema operacional DOS, o que o torna dificil de ser operado por usuários que não tenham recebido um treinamento prévio. Além disso este modelo opera, atualmente, com dados de série histórica que são inseridos no programa via teclado, exigindo que sejam criados grandes arquivos com dados de precipitação e evapotranspiração diária anteriormente à realização das simulações.

Diante do exposto, considera-se relevante o desenvolvimento de um novo modelo que supere as limitações do modelo SIMDRENO e que possa atingir uma apresentação a nivel comercial. Assim sendo, os principais objetivos do presente trabalho foram:

a) desenvolver um modelo de simulação de desempenho de sistemas de drenagem subterrânea no qual o efeito do fluxo ascendente seja contabilizado eficientemente sobre o rebaixamento do lençol freático; 
b) implementar no modelo a ser desenvolvido, uma rotina em que a estimativa do escoamento superficial dependa da profundidade do LF no dia corrente, permitindo assim contabilizar o efeito da drenagem subterrânea sobre a drenagem superficial.

c) tornar mais interativa a relação entre o software e o usuário, bem como dotar o programa de uma apresentação comercial, por meio da utilização da linguagem de programação VISUAL BASIC 4.0. 


\section{REVISÃO DE LITERATURA}

\subsection{Utilização de modelos para avaliação de desempenho de sistemas de drenagem}

Devido ao grande número de variáveis que envolvem e dificultam a avaliação de um sistema de drenagem em diferentes situações, a utilização de modelos torna-se desejável pela rapidez, precisão dos resultados obtidos e por permitir que um grande número de fatores e efeitos sejam contabilizados.

A modelagem computacional assume um papel importante pois permite ao projetista prever o desempenho e propor a otimização de sistemas de drenagem agrícola. Este desempenho resulta da complexa interação existente entre condições de clima, solo, planta e do próprio sistema. Um mesmo sistema de drenagem se comporta diferentemente em anos bastante úmidos ou secos influenciando diretamente na produtividade das culturas. Quando se relaciona este comportamento a procedimentos que estimam a resposta da cultura a diferentes condições de umidade do solo, torna-se possível avaliar os efeitos da drenagem sobre o crescimento e a produtividade das culturas (Feddes, 1988).

Um dos parâmetros imprescindíveis para o desenvolvimento das culturas é a umidade do solo em que se encontra a sua zona radicular, pois há uma maior facilidade no transporte através das raízes quando a mesma se encontra em condições ótimas. Quando há umidade excessiva na zona radicular ocorre prejuizo para as culturas. Tal adversidade não corresponde, necessariamente, à presença direta do LF por si só, mas sim, à deficiência de aeração no solo, comprometendo, a absorção de água e nutrientes, o transporte destes através do sistema radicular e tornando as plantas mais susceptíveis às doenças e à deficiência nutricional (Costa, 1994).

A base para dimensionamentos de drenagem subterrânea utilizando a previsão do seu desempenho e que serviu de propósito para o desenvolvimento de 
modelos de simulação foi iniciada por Schilfgaarde (1965), que dispondo de uma série de dados diários de precipitação e evapotranspiração, realizou um balanço hídrico na zona radicular e calculou a porcentagem com que cada chuva iria recarregar efetivamente 0 LF. Realizada a simulação para uma série de anos este autor pode determinar o comportamento da posição do LF, ou seja, durante qual período este permanecia acima de uma dada altura durante determinado número de dias. Os resultados obtidos foram satisfatórios e incentivaram novas linhas de pesquisas visando o desenvolvimento de metodologias de dimensionamento baseadas em simulação a partir de séries de dados climáticos, propriedades do solo e equações de recarga intermitente (Schilfgaarde, 1974). Vários modelos foram então desenvolvidos, alguns baseados na equação de Schilfgaarde e outros na de Kraijenhoff van de Leur, como os modelos de Young e Ligon (1972) e de Minderhoud (1982), respectivamente.

Wiser et al. (1974) utilizando a equação de Schilfgaarde propuseram um modelo para simular a variação temporal do LF e estimar a produtividade para a cultura da alfafa em função desta variação, sendo a relação entre as posições do lençol e a produtividade realizada por um procedimento empírico proposto por Tovey (1964).

Com o passar do tempo os modelos foram sofrendo alterações e melhorias. O escoamento superficial e a retenção de parte da precipitação na zona radicular passaram a ser considerados.

Skaggs (1974) propôs um modelo númerico para simulação da movimentação do lençol freático, no qual o fluxo da zona não saturada foi calculado pela equação de Richards enquanto o fluxo para os drenos foi estimado pela equação de Hooghoudt. Os recursos computacionais da época entretanto, não permitiam que este modelo fosse aplicado para períodos de tempo maiores do que poucos dias.

O modelo DRAINMOD, desenvolvido na Universidade do Estado da Carolina do Norte, foi utilizado primeiramente como uma ferramenta de pesquisa para investigar a performance de sistemas de drenagem e subirrigação e seus efeitos sobre o uso da água, resposta das culturas, uso da terra e movimentos de poluentes nos campos agrícolas. Algumas aplicações do modelo para projetos de drenagem foram feitas na Carolina do Norte no final dos anos 70 (Skaggs, 1981). 
O SWATR - Soil Water and Actual Transpiration Rate, foi desenvolvido na Holanda no final dos anos 70, baseando-se em soluções por diferenças finitas da equação de Richards, abrangendo as zonas saturada e não saturada integradamente. Belmans (1983) renomeou o programa para SWATRE para incluir outras condições de contorno. Dierickx ${ }^{1}$ et al. citado por Workman \& Skaggs (1989) revisou o SWATRE e fez alterações na entrada e saída de dados do modelo. Finalmente a versão final do modelo foi chamada de SWATREN. Workman \& Skaggs (1989), compararam o DRAINMOD com o SWATREN usando série de dados da Carolina do Norte, para simulações de profundidades de lençol freático. Resultados deste trabalho indicam que o SWATREN apresentou maior erro-padrão em relação ao DRAINMOD e que o SWATREN exige muito mais dados de propriedades do solo e parâmetros da cultura $\mathrm{e}$ maior tempo de execução do que o DRAINMOD, para aquelas condições testadas.

Atualmente o SWATREN, é largamente utilizado na Europa para simular os efeitos da drenagem e evapotranspiração no balanço hídrico do solo (Brandyk and Wesseling, 1987).

A distribuição de água no perfil de solos argilosos com muitas rachaduras faz com que o fluxo preferencial acarrete um aumento de infiltração e consequente diminuição do escoamento superficial. Para tanto Jarvis e Leedsharrison (1987) propuseram um modelo denominado PREFLO para estimar a movimentação da água nas zonas saturada e não-saturada nessas condições.

Para que programas de simulação possam ser de utilidade a agricultores é necessário estar sempre atento ao fato de que muitas vezes estes modelos exigem um grande número de dados de entrada, dificultando a sua utilização. Neste sentido o DRAINMOD é um modelo pouco prático pois exige um considerável número de parâmetros de entrada. Visando contornar este problema autores de modelos buscam facilitar a entrada de dados para o usuário de modo que se diminua a possibilidade de erro em parâmetros de entrada. Segundo Bengston et al. (1993), com esta intenção foi

\footnotetext{
${ }^{1}$ DIERICKX, J.C.; BELMANS, C.; PAUWELS, P. SWATRER: a computer package for modeling the field water balance. KU Leuven, Belgium, 1986.
} 
desenvolvido o modelo FWTMOD - Fluctuating Watertable Model, que utiliza a equação de recarga intermitente de De Zeeuw e Hellinga para simular a posição do lençol freático. Este modelo pode ser mais facilmente utilizado pois exige apenas a entrada de dois parâmetros básicos, ou seja, o fator de reação $(\alpha)$ e um coeficiente de recarga para estimar a porcentagem de precipitação que infiltra no solo. Comparações feitas entre DRAINMOD e FWTMOD permitiram concluir que os dois modelos previram igualmente bem a flutuação do lençol freático em sistemas de drenagem convencional.

Em avaliação de campo, onde prevaleceram condições de baixo coeficiente de armazenamento ( $\mathrm{J}$, o SIMDRENO, modelo desenvolvido por Duarte (1997), utilizando a equação de Kraijenhoff, simulou posições do lençol freático com menor erro-padrão do que o DRAINMOD, quando se comparou com os valores medidos. A grande limitação deste modelo entretanto refere-se a sua utilização, pois o usuário se depara com uma trabalhosa operação na entrada de dados devido à linguagem de programação utilizada. A tendência atual dos modelos é permitir que haja uma maior facilidade na obtenção e manuseio dos dados de entrada, principalmente quando se trata das séries históricas de precipitação e evapotranspiração. O DRAINMOD desenvolvido em linguagem Quickbasic, também apresenta uma operação pouco facilitada, no que se refere à manipulação dos arquivos climáticos.

As vantagens das linguagens voltadas para o ambiente "Windows" contornam estas dificuldades pois o tratamento dos dados de entrada reduz a interferência do usuário fazendo com que estes dados possam ser usados pelo modelo de uma forma mais confiável.

\subsection{Análise econômica dos projetos de drenagem}

Para a elaboração de projetos de drenagem deve-se considerar além do lado técnico, outros aspectos importantes para ajudar o projetista a decidir pela implantação do sistema de drenagem. Um desses aspectos é o econômico. O objetivo da drenagem é fazer com que áreas não produtivas possam corresponder a uma expectativa do produtor, seja no sentido de se aproveitar uma área antes não utilizada ou de promover um aumento de sua produtividade. No processo produtivo o lado econômico 
deve sempre ser levado em consideração pois exerce grande influência no processo de decisão.

Para uma situação de campo, é possível que sistemas de drenagem com características diferentes venham gerar respostas semelhantes, em termos de produtividade de uma cultura (Buras, 1974). Do ponto de vista técnico, poder-se-ia definir a intensidade ótima de drenagem como aquela que resulta na produtividade máxima da cultura. Todavia, a instalação de um sistema de drenagem com essa intensidade seria antieconômica, preferindo-se então uma alternativa que resulte em menor custo das obras de drenagem, proporcionando portanto, maior relação beneficio/custo (Ferreira, 1987). Diante disto, a análise econômica dos projetos é um instrumento que facilita a escolha entre várias alternativas ou, simplesmente, permite decidir se é ou não aconselhável se realizar uma determinada aplicação de recursos (Pizarro, 1978).

Um dos aspectos a ser observado na análise econômica é a vida útil do projeto de drenagem. De acordo com recomendações da FAO (1986) a vida útil que deve-se levar em consideração em projetos de drenagem está em torno de 30 anos. $\mathrm{O}$ fator preponderante no aumento da vida útil do projeto é sem dúvida a sua manutenção por parte do agricultor. Segundo Smedema e Rycroft (1983), drenos tubulares com manutenção adequada têm uma vida útil em torno de 50 a 100 anos. Leicht (1983) sugere 20 a 50 anos de duração para drenos tubulares e 25 anos para drenos abertos com manutenção deficiente.

$\mathrm{Na}$ análise econômica de projetos de drenagem os custos e as receitas que ocorrem após 30 anos têm um peso insignificante. Assim, o periodo de análise ou vida econômica de um projeto pode ser da ordem de 20 a 30 anos (Pizarro, 1978; Smedema e Rycroft, 1983; Bornstein et al., 1986).

Quando o projeto passa a ser financiado por uma instituição financeira e há uma condição de pagamento em um determinado número de anos deve ser estimada a chamada vida financeira. Nesse caso a vida financeira costuma ser bem mais curta que a vida útil ou a vida econômica, ou seja, cerca de 10 anos e ao final desse período, o valor 
terminal do projeto deve ser considerado (Smedema e Rycroft, 1983; Carter e Camp, 1994).

Em um projeto de drenagem os seus custos são basicamente despesas com instalação e manutenção. Com relação à instalação podemos citar despesas que envolvem regularização dos cursos d'água, drenos principais e coletores, regularização do terreno, escavação dos emissores, e a manutenção dos drenos propriamente dita. Normalmente, o custo da produção agrícola não é considerado como um dos custos do projeto e é descontado do valor da receita bruta gerada pela produção (Pizarro, 1978).

A variação de custos em projetos de drenagem depende da sua situação de implantação. Em cada região existem peculiaridades que podem fazer com que projetos idênticos possam ter custos diferenciados. Fatores tais como espaçamento e profundidade de instalação dos drenos influenciam nesta variação de custos. Segundo Boumans e Smedema (1986), o custo de um projeto de drenagem varia bastante, em função das diferenças na intensidade de drenagem exigida (espaçamento e profundidade dos drenos), disponibilidade de maquinaria especializada e materiais, escala do projeto, habilidade e custo de mão-de-obra, existência de concorrência entre empreiteiras, etc.

Leitch (1983) calculou, para a região centro-oeste de Minnesota, custos de instalação variando de US\$ 803.ha ${ }^{-1}$ a US\$ 1.551.ha $\mathrm{a}^{-1}$ para drenos tubulares e de US\$ 254.ha ${ }^{-1}$ a US $\$ 452$. ha $^{-1}$ para drenos abertos. Kanwar et al. (1983) encontraram custos variando de US\$ 970.ha ${ }^{-1}$ a US\$2.046. ha ${ }^{-1}$ para drenos fechados no Estado de Iowa. No oeste de Ontário, no Canadá, Jorjani e Vuuren (1991) estimaram custos de US\$744.ha ${ }^{-1}$ para projetos em solos arenosos e US\$ $1.116 . \mathrm{ha}^{-1}$ para projetos em solos argilosos.

No Brasil, segundo Costa (1994), os custos de implantação de 1,0 ha de drenagem subterrânea em função do espaçamento, variaram de US\$ 5.672,91 a US\$ $1.895,24$ para espaçamento de 10 a $30 \mathrm{~m}$ respectivamente. Para o levantamento destes custos foram observados itens como tubos de drenagem, envelope de manta de poliéster, escavação mecânica de valas, acabamento manual de valas, levantamento altimétrico, amarrio da manta de poliéster e aterro mecânico de valas.

De acordo com informações obtidas junto a empresas de saneamento no Estado de São Paulo, para drenagem realizada com drenos abertos e espaçamento 
variando entre 50 e 100 metros, o custo do projeto tem girado em torno de R\$ 1.000 ha $^{-1}$ a R\$ 1.500.ha ${ }^{-1}$ (Duarte, 1997).

Como citado anteriormente a influência da profundidade de instalação de drenos tubulares nos custos por unidade de comprimento, tem um aspecto importante. Geralmente os projetos instalados em regiões úmidas utilizam profundidades de um metro, enquanto nas zonas semi-áridas com risco de salinização as profundidades em torno de dois metros são preferíveis. Além do custo da escavação, maiores profundidades permitem maiores espaçamentos, que implicam em uma maior área de captação e no uso de tubos de maiores diâmetros. Tubos maiores requerem também um maior dispêndio com envelopes (Boumans e Smedema, 1986).

Segundo a CODEVASF o custo internacional médio de drenos tubulares é de cerca de US $\$ 5,00$ por metro. Batista (1992) cita valores variando de US\$ 2,00. $\mathrm{m}^{-1}$ a US\$ 6,50. $\mathrm{m}^{-1}$ dependendo da profundidade de assentamento, tipo de envoltório, tipo de solo e do processo adotado na instalação.

Segundo Duarte (1997), o valor médio por metro de dreno subterrâneo instalado por empresas privadas no interior de São Paulo, gira em torno de US\$ 6,00.

A análise de rentabilidade de um projeto é baseada em custos e receitas, para tanto devem ser observadas duas séries: uma que revela o incremento anual dos custos e, a outra, o incremento anual dos benefícios. A partir destas séries são calculados os índices de rentabilidade (Pizarro, 1978).

Assim, para os cálculos dos índices de rentabilidade, os valores monetários que constituem as séries de incremento de custos e benefícios devem ser transformados em valores correspondentes a um momento de referência (Pizarro, 1978), adotando-se para tal um valor para a taxa de juros anual. Há uma dificuldade em se adotar um valor para esta taxa pois esta influencia diretamente a estimativa dos índices de rentabilidade do projeto. Ao adotar valores mais altos para a taxa de juros, a preservação da área em seu estado natural tende a ficar mais atrativa do que a drenagem, pois o valor presente dos benefícios proporcionados pelo projeto tende a reduzir (Leitch, 1983). Para avaliação de projetos públicos o valor desta taxa normalmente varia de $8 \%$ a $15 \%$ ao ano segundo Pizarro (1978). Autores como Kanwar et al. (1983), sugerem taxas de $12 \%$ a $16 \%$ ao 
ano, principalmente em épocas de instabilidade econômica e se tratando de investimentos de longa duração.

A estimativa da rentabilidade do projeto é feita calculando-se índices econômicos como o valor presente, taxa interna de retorno e relação benefício-custo.

O valor presente de um projeto de drenagem depende do tipo de solo, estado de drenagem da área antes do projeto, grau de intensidade de drenagem exigido, tipo de cultura a ser implantada, clima, etc. É sempre desejável que sejam encontradas grandezas positivas para o valor presente, pois números negativos implicam em perdas, significando que os custos foram maiores que os beneficios no momento em que ambos foram atualizados (Kanwar et al., 1983).

Quando não há produção antes do projeto o valor presente pode ser definido como a diferença entre beneficios e custos. Quando há uma atividade produtiva mesmo sem a drenagem este índice reflete a diferença entre os incrementos nos benefícios e custos, obtidos através da transformação das séries de custos e benefícios correspondentes à vida econômica do projeto para um ano de referência (Smedema e Rycroft, 1983). Matematicamente, este conceito é definido pela expressão:

$$
\mathrm{VP}=\sum_{\mathrm{i}=0}^{\mathrm{i}=\mathrm{n}} \frac{(\mathrm{Ri}-\mathrm{Ci})}{(1+\mathrm{r})^{\mathrm{i}}}-\mathrm{CI}
$$

em que:

$\mathrm{VP}=$ valor presente, $\mathrm{R} \$ \mathrm{ha}^{-1}$;

$R i=$ Receita anual, $R \$ \cdot h a^{-1}$;

$\mathrm{Ci}=$ custo anual de manutenção do projeto de drenagem, $\mathrm{R} \$ . \mathrm{ha}^{-1}$;

$\mathrm{CI}=$ Custo de implantação do projeto de drenagem, $\mathrm{R} \$ . \mathrm{ha}^{-1}$;

$\mathrm{n}=$ vida econômica do projeto, anos; $\mathrm{e}$

$\mathrm{r}=$ taxa de juros anual, decimal. 
Smedema e Rycroft (1983) analisando projetos de drenagem no Estado de Iowa, USA, encontraram valores presentes variando de US\$ $-170 . \mathrm{ha}^{-1}$ a US\$ 4.602. $\mathrm{ha}^{-1}$. Leitch (1983), conduzindo estudo semelhante no Estado de Minnesota, encontrou valores presentes variando de US\$ $-568 . \mathrm{ha}^{-1}$ a US\$ $2.193 \cdot \mathrm{ha}^{-1}$.

A taxa interna de retorno (TIR) é uma taxa de atualização que iguala os valores atualizados das séries de incrementos de custos e benefícios. Matematicamente este índice pode ser calculado iterativamente através da fórmula do valor presente, obtendo-se o valor da taxa de juros que faz com que o valor presente seja nulo (Pizarro, 1978). Após o cálculo da TIR esta deve ser comparada com a taxa de juros anual (r). Se a TIR for maior significa que o investimento é economicamente viável, caso contrário o investimento não será lucrativo (Jorjani e Vuuren, 1991).

Entre os vários índices que expressam a rentabilidade de um projeto, a TIR é considerada o mais adequado (Pizarro, 1978; Bornstein et al., 1986; Jorjani e Vuuren, 1991). Entretanto Duarte (1997), verificou que muitas vezes a receita anual assumia valores negativos. Nessas condições, a taxa interna de retorno não pode ser calculada e a relação benefício-custo não fornece resultados que evidenciem a alternativa mais econômica.

A relação beneficio-custo é um índice de rentabilidade muito utilizado em análise de empreendimentos agrícolas públicos. Esta relação é definida como o quociente do valor atualizado dos beneficios (ou incrementos de beneficios) e dos custos (Pizarro, 1978).

O desejável é que o valor da relação beneficio-custo calculada seja maior que a unidade. Se este valor for inferior a um, significa que a TIR a ser obtida com os capitais investidos é menor que a taxa de juros utilizada. Se este valor for exatamente igual a um, então a taxa de juros utilizada coincidirá com a TIR (Pizarro, 1978).

A relação beneficio-custo está ligada diretamente com a vida econômica do projeto e a taxa de juros. Esta relação tem o seu valor acrescido aumentando-se a vida econômica do projeto e decrescido com o aumento da taxa de juros. 
Leitch et al. (1983) e Kanwar et al. (1983), fazendo avaliações econômicas de projetos de drenagem nos Estados Unidos, encontraram valores para a relação benefício-custo variando de 0,6 a 5,88. 


\section{MATERIAL E MÉTODOS}

\subsection{Desenvolvimento do modelo}

O modelo foi desenvolvido no Departamento de Engenharia Rural da ESALQ/USP em linguagem de programação Visual Basic 4.0, e recebeu a denominação de SISDRENA- Sistema de Drenagem.

O SISDRENA é um modelo unidimensional que contabiliza os principais componentes que afetam o balanço de água em um volume de solo homogêneo e de superficie unitária, localizado equidistante entre dois drenos paralelos e que se estende desde a camada de impedimento até a superficie do solo. Estes componentes são: precipitação, escoamento superficial, infiltração, percolação para o lençol freático, fluxo ascendente do LF para a zona radicular, evapotranspiração, drenagem e "seepage" vertical (Figura 1).

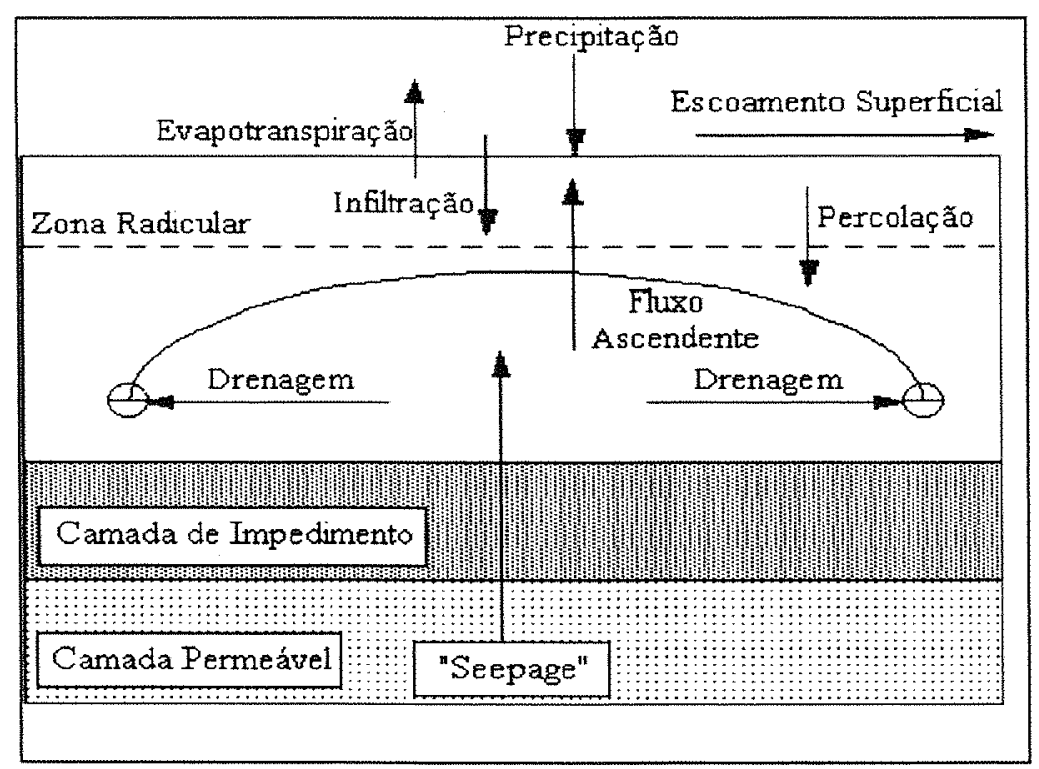

Figura 1 - Esquema dos principais componentes de fluxo considerados pelo modelo. 
Os parâmetros de entrada necessários à simulação são:

- precipitação total diária, mm.dia ${ }^{-1}$;

- evapotranspiração potencial diária, mm.dia ${ }^{-1}$;

- condutividade hidráulica do solo saturado, m.dia ${ }^{-1}$;

- profundidade da camada de impedimento, $\mathrm{m}$;

- valores de espaçamento entre drenos a serem submetidos à avaliação, m;

- "seepage" vertical ascendente diário (opcional), mm.dia"

- profundidade de instalação dos drenos, m;

- raio efetivo do dreno, m;

- curva de retenção de água no solo;

- data de plantio e colheita da cultura;

- variação da profundidade efetiva do sistema radicular ao longo do ano, m;

- fatores diários de sensibilidade da cultura ao excesso e à falta de umidade, adimensional;

- posição do lençol freático acima da linha dos drenos no dia inicial, m; e

- umidade volumétrica do solo no dia inicial, adimensional.

Após a simulação o modelo SISDRENA apresenta os seguintes parâmetros de saída:

- fração da precipitação diária que escoa sobre o solo, mm.dia $^{-1}$;

- fração da precipitação diária que infiltra no solo, mm.dia ${ }^{-1}$;

- altura diária do LF, m;

- lâmina escoada através dos drenos subterrâneos, mm.dia ${ }^{-1}$;

- armazenamento diário de água na zona radicular, mm;

- evapotranspiração real diária; mm.dia ${ }^{-1}$;

- parâmetros que avaliam o desempenho do sistema de drenagem; e

- espaçamento entre drenos mais econômico. 
Resumidamente o SISDRENA abrange as seguintes etapas de processamento:

1) inicialmente separa da precipitação que atinge o solo a fração que infiltra no solo daquela que escoa superficialmente. $\mathrm{O}$ escoamento superficial é estimado por meio de uma modificação do método do Número da Curva (SCS, 1972) e a lâmina infiltrada é considerada como a diferença entre o total precipitado e a fração da precipitação que escoa superficialmente;

2) estima o fluxo ascendente da zona saturada para a zona radicular pela equação de Darcy resolvida por diferenças finitas, utilizando o modelo de van Genuchten (1980) para representar o lugar dos pontos da curva de retenção da água no solo;

3) estima qual a fração da evapotranspiração potencial que será proveniente do LF e qual a que virá da zona radicular;

4) realiza um balanço hídrico diário na zona radicular e calcula, a umidade do solo, a evapotranspiração real e corrige a parcela da precipitação que atinge o LF;

5) calcula a posição do LF, em dias consecutivos, utilizando a fórmula de De Zeeuw e Hellinga

6) corrige a posição do LF em função da evapotranspiração proveniente do LF;

7) calcula a vazão, que escoa para os drenos subterrâneos;

8) calcula os índices de desempenho do sistema de drenagem para o ano e espaçamento correntes;

9) repete as etapas anteriores para toda a série de anos e espaçamentos;

10) realiza finalmente a análise econômica e apresenta qual o espaçamento mais viável.

A seguir serão mostrados todos os passos e fórmulas utilizadas na simulação.

\subsubsection{Cálculo da lâmina escoada superficialmente e da infiltrada}

A primeira etapa após o modelo ter carregado os valores diários de chuva consiste em separar do total precipitado, a parte que foi escoada superficialmente. 
O escoamento superficial é estimado utilizando-se uma modificação do método do Número da Curva (SCS, 1972). Segundo este método o escoamento superficial é calculado pela eq. (2).

$$
E=\frac{(p p t-0,2 S)^{2}}{(p p t-0,8 S)}
$$

em que:

$\mathrm{E}=$ escoamento superficial em mm;

$\mathrm{ppt}=$ precipitação total, $\mathrm{mm}$ e

$\mathrm{S}=$ retenção potencial, $\mathrm{mm}$.

A retenção potencial é função do chamado parâmetro do Número da Curva $(\mathrm{CN})$. O valor do $\mathrm{CN}$ é um dado tabelado e que depende da cobertura do solo, condição hidrológica, tipo de solo e umidade antecedente do solo. Quanto maior o valor de $\mathrm{CN}$, maior é o escoamento superficial e menor a retenção potencial. Por outro lado, quando se diminui o valor deste parâmetro o escoamento decresce e a retenção aumenta.

$\mathrm{O}$ valor do $\mathrm{CN}$ é dividido em 3 classes. $\mathrm{O} \mathrm{CN}$ classe II é o parâmetro de entrada utilizado pelo modelo. Por meio de interpolações determina-se o valor do $\mathrm{CN}$ classe I que é utilizado para calcular a retenção potencial máxima pela eq. (3).

$\mathrm{Smax}=\left(\frac{25400}{\mathrm{CN}_{1}}\right)-254$

em que:

$\mathrm{S}_{\max }=$ retenção potencial máxima, em mm;

$\mathrm{CN}_{1}$ = número da curva classe I, adimensional

A retenção potencial mínima é calculada utilizando o $\mathrm{CN}$ classe III pela eq.(4). 
$\mathrm{S}_{\text {min }}=\left(\frac{25400}{\mathrm{CN}_{3}}\right)-254$

em que:

$\mathrm{S}_{\min }=$ retenção potencial mínima, em mm;

$\mathrm{CN}_{3}=$ número da curva classe III, adimensional

O SISDRENA utiliza uma modificação do método do número da curva, segundo a qual a retenção potencial é calculada pela expressão:

$\mathrm{S}=\mathrm{S}_{\min }+\mu(\mathrm{pd}-\mathrm{h}) \cdot 1000$

em que:

$\mu=$ porosidade drenável, adimensional;

$\mathrm{pd}=$ profundidade do dreno, em $\mathrm{m} ; \mathrm{e}$

$\mathrm{h}=$ altura do lençol freático, em $\mathrm{m}$.

Se $\mathrm{S}$ for maior ou igual a Smax então o modelo assume $\mathrm{S}=$ Smax. Portanto, a retenção potencial está em função da retenção mínima, da profundidade do lençol freático e da porosidade drenável. Segundo Capece et al. (1987), em solos com LF raso, o escoamento superficial se correlaciona melhor com a profundidade do LF do que com a umidade da superficie do solo.

A precipitação efetiva, ou seja, a que infiltrará no solo será a diferença entre a precipitação diária e o escoamento superficial.

\subsubsection{Cálculo do fluxo máximo ascendente}

Nesta etapa, é gerada uma tabela contendo valores do fluxo ascendente máximo para diferentes profundidades do lençol freático, utilizando a equação de Darcy resolvida por diferenças finitas, conforme sugerido por Skaggs (1981). 
A equação utilizada para determinar o fluxo ascendente através de qualquer plano abaixo da zona radicular foi:

$v=-K(\Psi) \frac{d \Psi}{d z}+K(\Psi)$

em que:

$\mathrm{v}=$ fluxo ascendente de água no solo, $\mathrm{cm} \cdot \mathrm{h}^{-1}$;

$\mathrm{K}(\Psi)=$ condutividade hidráulica do meio não saturado, $\mathrm{cm} \cdot \mathrm{h}^{-1}$;

$\Psi=$ potencial matricial, $\mathrm{cm}$ de coluna de água; e

$\mathrm{z}=$ coordenada vertical, positiva para baixo, $\mathrm{cm}$.

Esta equação escrita na forma de diferenças finitas apresenta-se como a expressão (7).

$\psi^{\mathrm{u}+1}=\psi^{\mathrm{u}}+\Delta \mathrm{z}-\mathrm{v} \cdot \frac{\Delta \mathrm{z}}{\mathrm{K}\left(\psi^{\mathrm{u}}\right)}$

Onde " $u$ " representa o número de ordem dos valores de potencial matricial e $\Delta \mathrm{z}$ o incremento de profundidade, considerado igual a $1 \mathrm{~mm}$ na presente versão do modelo.

Para se determinar o fluxo ascendente máximo $\left(\mathrm{v}^{\max }\right)$ em função da profundidade do LF são realizadas as seguintes etapas:

1) obtém-se a função $\theta(\Psi)$ para o solo de interesse, determinada através do modelo de van Genuchten (1980), segundo o qual os pontos de uma curva de retenção podem ser representados pela equação:

$\theta[\Psi]=\theta r+\frac{(\theta s-\theta r)}{\left[1+(\beta \cdot \psi)^{\mathrm{n}}\right]^{\mathrm{m}}}$ 
em que:

$\theta(\Psi)=$ umidade volumétrica, em equilibrio com o potencial matricial $\Psi, \mathrm{cm}^{3} \cdot \mathrm{cm}^{-3}$;

$\theta \mathrm{s}=$ umidade volumétrica, do solo saturado, $\mathrm{cm}^{3} \cdot \mathrm{cm}^{-3}$;

$\theta \mathrm{r}=$ umidade volumétrica residual, do solo saturado, $\mathrm{cm}^{3} \cdot \mathrm{cm}^{-3}$;

m, $\eta$ = parâmetros de regressão da equação; adimensional;

$\beta=$ parâmetro com dimensão igual ao inverso da tensão, $\mathrm{cm}^{-1}$; e

$\psi=$ potencial matricial, $\mathrm{cm}$.

2) entra-se o valor da condutividade hidráulica vertical para o solo em questão;

3) estabelece-se o valor de $v^{\max }$ para o qual será calculada a posição correspondente do lençol freático;

4) estabelece-se como condição de contorno, um valor de umidade baixo junto ao plano que passa pela base da zona radicular. Skaggs (1981) sugere $\Psi^{1}=-100 \mathrm{kPa}$;

5) faz-se $\Psi^{u}=\Psi^{1}$, obtendo-se o valor de $K\left(\Psi^{\prime}\right)$ e calcula-se $\Psi^{2}$ pela eq. (7);

6) fazer $\Psi^{u}=\Psi^{2}$, procedendo do mesmo modo para calcular $\Psi^{3}$ e, assim, sucessivamente;

7) a posição do lençol freático será aquela correspondente a fazer $\Psi=0$.

A função $K(\theta)$ foi obtida a partir da condutividade hidráulica do solo saturado, Ko, e da curva de retenção de água no solo, seguindo o modelo de Mualem (1976).

$K(\theta)=K o \cdot \omega^{l}\left[1-\left(1-\omega^{1 / m}\right)^{m}\right]^{2}$

em que:

$\mathrm{K}(\theta)=$ condutividade hidráulica do solo não saturado, $\mathrm{cm} \cdot \mathrm{h}^{-1}$

$\mathrm{Ko}=$ condutividade hidráulica do solo saturado, $\mathrm{cm} \cdot \mathrm{h}^{-1} ; \mathrm{e}$

$\ell=$ parâmetro empírico, aproximadamente igual a 0,5 , para a maioria dos solos. 
O parâmetro $\omega$ pode ser obtido pela equação:

$$
\omega=\frac{(\theta[\Psi]-\theta r)}{(\theta s-\theta r)}
$$

Depois de se determinar esta tabela de fluxos o modelo interpolará para cada profundidade diária do lençol o fluxo máximo correspondente à posição do lençol do dia corrente.

Em seguida é feita uma comparação entre o fluxo ascendente máximo obtido para a respectiva profundidade do lençol freático e a evapotranspiração potencial. O objetivo desta fase é separar diariamente a fração da evapotranspiração potencial que provém do lençol freático (ETPlf) e a que é oriunda da água da zona radicular (ETPzr). Se o fluxo obtido for maior que a evapotranspiração potencial (ETP), significa que a ETP é suprida integralmente pela ETPlf e a ETPzr é nula. Caso contrário a ETPlf será o próprio fluxo ascendente máximo e a ETPzr será a diferença entre a ETP e o fluxo máximo ascendente, ou seja, uma parte é suprida pela zona radicular.

\subsubsection{Balanço hídrico na zona radicular}

Os cálculos envolvidos nesta etapa tem como objetivo determinar:

- armazenamento diário de água na zona radicular;

- evapotranspiração real diária; e

- precipitação pluvial diária que atinge o lençol freático.

O primeiro passo consiste em verificar o valor da umidade em que se encontra o solo e a profundidade do lençol freático, correspondentes ao final do dia anterior. 
$\mathrm{Na}$ etapa seguinte o modelo determinará o valor dos três parâmetros citados anteriormente conforme a posição do lençol freático:

Posição 1) Se o lençol estiver na superficie ou acima desta o armazenamento corresponde à saturação completa da zona radicular. A evapotranspiração real será igual a evapotranspiração potencial. A precipitação que irá recarregar o LF será o próprio valor da precipitação efetiva para aquele dia.

Posição 2) Se o lençol estiver dentro da zona radicular, o modelo considera que parte da zona radicular ocupada pelo LF está em saturação completa e a fração restante na capacidade de campo. A evapotranspiração real será igual à potencial, e a precipitação potencial diária para recarga do LF será o próprio valor da precipitação efetiva diária.

Posição 3) Se o lençol estiver abaixo da zona radicular o modelo realiza um balanço hídrico na zona radicular e verifica se o armazenamento calculado foi maior que o correspondente ao da capacidade de campo (CC). Em caso afirmativo, ele assumirá o valor da capacidade de campo. A precipitação que percolará para o LF será a diferença entre o armazenamento da capacidade de campo e o armazenamento calculado. A evapotranspiração real (ETR) será igual à ETP. Se o armazenamento calculado for menor que o correspondente ao ponto de murcha permanente (PMP) ele assumirá o valor do próprio PMP. Neste caso a ETR é calculada através de um balanço hídrico, considerando a umidade do dia anterior. A precipitação que recarrega o LF será nula. Se o armazenamento estiver entre a CC e o PMP este será o próprio valor calculado. A evapotranspiração potencial será igual à real e não haverá precipitação potencial diária para recarga do lençol. 
O valor da umidade correspondente à capacidade de campo é estimado diariamente assumindo-se uma condição de equilibrio estático entre o LF e a profundidade média da zona radicular, fazendo-se uso da equação de van Genuchten (1980). A umidade relativa ao PMP é considerada como aquela correspondente a uma tensão de $1500 \mathrm{kPa}$.

\subsubsection{Cálculo da posição do lençol freático}

Primeiramente são calculados alguns parâmetros como a camada equivalente Hooghoudt (deq) e o coeficiente de armazenamento ( $)$.

O cálculo da camada equivalente de Hooghoudt, que é utilizada no cálculo de J, é realizado pela seguintes expressões, propostas por Moody (1967):

$$
\text { deq }=\frac{d}{1+\frac{d}{L\left[\left(\frac{8}{\pi}\right) \ln \left(\frac{d}{\text { rd }}\right)-\rho\right]}} \quad \text { para } 0<\frac{d}{L}<0,3
$$

em que:

$\mathrm{d}$ = distância vertical entre o plano que passa pelos drenos e a camada impermeável, m;

$\mathrm{L}=$ espaçamento entre drenos, $\mathrm{m}$; e

$\mathrm{rd}=$ raio efetivo dos drenos, $\mathrm{m}$.

Esta equação é utilizada quando a relação entre d e $\mathrm{L}$ for menor que $30 \%$. O parâmetro $\rho$ é calculado pela equação:

$$
\rho=3,55-1,6 \frac{d}{L}+2\left(\frac{d}{L}\right)^{2} ; e
$$

$$
\text { deq }=\frac{\mathrm{L} \pi}{8\left[\ln \left(\frac{\mathrm{L}}{\mathrm{rd}}\right)-1,15\right]} \quad \text { para } \frac{\mathrm{d}}{\mathrm{L}} \geq 0,3
$$


$\mathrm{O}$ valor de $\mathrm{J}$ resume as características do solo e de instalação do sistema de drenagem, que afetam o movimento da água em direção aos drenos. Quanto maior o valor de $\mathrm{J}$ maior o tempo de rebaixamento do lençol freático. Este parâmetro é calculado pela seguinte expressão:

$\mathrm{J}=\frac{1}{\pi^{2}} \mu \frac{\mathrm{L}^{2}}{\mathrm{Ko} \cdot \mathrm{D}}$

em que:

$\mathrm{J}=$ coeficiente de armazenamento, dias;

$\mu=$ porosidade drenável;

$L=$ espaçamento entre drenos; $m$

$\mathrm{Ko}=$ Condutividade hidráulica do solo saturado, $\mathrm{m} /$ dia.

O valor de $\mathrm{D}$ é calculado pela seguinte expressão:

$\mathrm{D}=\mathrm{deq}+\frac{\mathrm{pd}}{2}$

A porosidade drenável é calculada pela diferença entre a umidade do solo saturado e a umidade correspondente a uma tensão de $6 \mathrm{kPa}$.

O modelo calcula as alturas do lençol freático empregando a fórmula de De Zeeuw e Hellinga:

$\mathrm{h}=\mathrm{h}_{\mathrm{i}-1} \exp \left(\frac{-1}{\mathrm{~J}}\right)+\frac{\mathrm{rec}}{0,8} \cdot \mathrm{J} \cdot\left(1-\exp \left(\frac{-1}{\mathrm{~J}}\right)\right)$

$\mu$

em que:

$\mathrm{h}=$ altura do lençol calculada diariamente, $\mathrm{m}$;

$\mathrm{h}_{\mathrm{i}-1}=$ altura do lençol do dia anterior, $\mathrm{m}$; $\mathrm{e}$

rec $=$ recarga efetiva do LF, $m \cdot d^{-1}{ }^{-1}$. 
Em caso de existência de "seepage" vertical ascendente na área, o valor da lâmina diária do "seepage" é adicionada à recarga proveniente da fração da precipitação que percolou .

\subsubsection{Correção da posição do LF e do armazenamento}

Nesta etapa corrige-se a profundidade do LF que foi calculada pela fórmula de De Zeeuw e Hellinga descontando-se o efeito da porção da evapotranspiração que provém do LF. Posteriormente o modelo faz uma correção do armazenamento caso o lençol invada a zona radicular. Se a altura do LF atinge a superficie do solo, assume-se o valor do armazenamento como sendo saturado. Caso a altura do lençol calculada atinja apenas parte da zona radicular o modelo assume que a fração que está acima da altura do lençol está na capacidade de campo e o restante está saturado calculando o novo armazenamento baseado em uma ponderação.

\subsubsection{Cálculo da Vazão diária}

O cálculo da vazão diária é realizado usando-se a equação:

$\mathrm{qo}=\frac{8 \cdot \operatorname{Ko} \cdot\left(\mathrm{deq}+\frac{\mathrm{h}}{2}\right)}{\mathrm{L}^{2}} \cdot \mathrm{h}$

em que:

qo = vazão diária, $\mathrm{em} \mathrm{m} /$ dia.

Quando o valor de h supera o valor da profundidade dos drenos, o modelo transforma a diferença em termos de lâmina de água. Esta lâmina é acrescida ao valor da profundidade dos drenos na estimativa do $h$ corrigido. 


\subsubsection{Cálculo dos índices de desempenho do sistema de drenagem}

O modelo determina uma série de índices que irão possibilitar analisar o desempenho do sistema de drenagem. Estes índices irão permitir também a análise econômica do projeto, pois serão extraídos de cada ano da série e para cada tipo de solo, valores de produtividades relativas ao déficit e ao excesso de água, podendo-se calcular produtividades médias anuais totais.

Os valores calculados de profundidade do lençol freático permitem quantificar o índice de estresse $\mathrm{SEW}_{30}$, que representa a soma do valor excedente de água no solo. Este índice permite avaliar o efeito deste excesso de água na produtividade das culturas implantadas sob condições em que o lençol freático atinja a sua zona radicular.

Para o seu cálculo utiliza-se a seguinte expressão:

$\mathrm{SEW}_{30}=\sum_{\mathrm{i}=1}^{\mathrm{n}}(30-\mathrm{h}(\mathrm{i}))$

onde h(i) é a profundidade diária do lençol freático, sendo os termos negativos desprezados. Valores de $\mathrm{SEW}_{30}$ menores que $100 \mathrm{~cm}$.dia durante o ciclo da cultura, podem indicar uma drenagem adequada.

O fluxo ascendente somente é capaz de atender a evapotranspiração

potencial quando o lençol freático está próximo da superfície. À medida que o lençol se rebaixa o fluxo diminui e a evapotranspiração passa a ser compensada em parte pela água vinda da zona radicular. Quando a água da zona radicular atinge um limite mínimo de extração, ou seja, o PMP, a evapotranspiração real passa a ser igual ao valor do fluxo ascendente e pode-se tornar menor que a potencial, caracterizando o chamado "dia seco". Nestas condições, devido a limitações da umidade do solo, a planta passa por um déficit hídrico devido a ação da demanda atmosférica.

Para se obter valores de produtividades relativas o modelo calcula ainda os índices, SDIW e SDID. O índice SDIW é calculado ponderando-se os valores de $\mathrm{SEW}_{30}$ 
por fatores que refletem a sensibilidade da cultura ao excesso de umidade nos diferentes estádios de desenvolvimento.

O SDID é calculado baseando-se na relação entre a evapotranspiração real e a evapotranspiração potencial ponderada por fatores que refletem a sensibilidade da cultura ao déficit hídrico em diferentes estádios de desenvolvimento. É também um fator importante pois será utilizado para estimar a queda da produtividade relativa ao déficit de água.

Para se calcular o SDIW e o SDID, utilizam-se as mesmas equações, empregadas no SIMDRENO, que foram adaptadas de Skaggs (1978).

$\operatorname{SDIW}=\sum_{i=1}^{n}(30-h(i)) \cdot c s W$

$\operatorname{SDID}=\sum_{\mathrm{i}=1}^{\mathrm{n}}\left(1-\frac{\operatorname{ETR}(\mathrm{i})}{\operatorname{ETP}(\mathrm{i})}\right) \operatorname{csd}$

em que:

$\mathrm{csw}=$ fator de sensibilidade da cultura ao excesso de água;

$\operatorname{csd}=$ fator de sensibilidade da cultura ao déficit de água;

ETR(i) = evapotranspiração real diária, $\mathrm{mm}$;

ETP(i) = evapotranspiração potencial diária, $\mathrm{mm}$; e

$\mathrm{n}=$ número de dias do ciclo da cultura.

Os parâmetros obtidos anteriormente servem como base para se calcular as produtividades relativas. Estas produtividades são afetadas tanto pelo excesso quanto pela falta de água, que são representados pelos fatores de sensibilidade da cultura ao excesso e déficit de água cujos valores são de difícil obtenção. As produtividades são estimadas anualmente durante toda a série de simulação. Ao final da simulação obtêm-se para cada tipo de solo, os valores de produtividades que permitem a realização da análise 
econômica, no sentido de se definir qual o espaçamento mais viável para se implantar determinada cultura em uma dada região.

O cálculo da produtividade relativa é realizado da mesma forma que no DRAINMOD e no SIMDRENO, ou seja:

$\mathrm{YT}=\frac{\mathrm{Y}}{\mathrm{Yo}_{\mathrm{O}}}=\mathrm{YRW} . \mathrm{YRD}$

em que:

$\mathrm{YT}=$ produtividade relativa anual, decimal;

$\mathrm{Y}=$ produtividade estimada anual, $\mathrm{kg} \cdot \mathrm{ha}^{-1}$;

Yo $=$ produtividade potencial, $\mathrm{kg} \cdot \mathrm{ha}^{-1}$;

YRW = produtividade relativa esperada, caso ocorra estresse devido ao excesso de água, decimal; e

YRD = produtividade relativa esperada, caso ocorra estresse devido à falta de água, decimal.

A equação que relaciona produtividade relativa com o estresse devido ao excesso de umidade é:

$Y R W=$ YRwMAX - WSLOPE. SDIW

em que:

YRwMAX = intercepto com o eixo vertical no gráfico que relaciona a produtividade relativa ao índice diário de estresse, decimal;

WSLOPE = coeficiente angular da relação entre produtividade relativa e índice diário de estresse, adimensional.

Os parâmetros YRwMAX e WSLOPE são valores obtidos experimentalmente e que dependem da sensibilidade de cada cultura ao excesso de água. 
A seguinte equação permite o cálculo da produtividade relativa para condições de déficit de umidade no solo:

YRD $=$ YRdMAX - DSLOPE . SDID

em que:

YRdMAX = intercepto com o eixo vertical, decimal;

DSLOPE = coeficiente angular da relação entre a produtividade relativa e índice diário de estresse, adimensional.

Os índices YRdMAX e DSLOPE são parâmetros experimentais que dependem da sensibilidade da cultura à falta de água.

Uma vez que a produtividade relativa da cultura tenha sido estimada para cada ano e para cada espaçamento de drenos submetido à simulação, o modelo aponta 0 espaçamento que propicia o maior retorno calculando o índice econômico valor presente, baseando-se no custo do sistema de drenagem e na receita gerada pela cultura. A receita pode referir-se à média das produtividades anuais estimadas para cada espaçamento (Wiser et al., 1974) ou à produtividade esperada com uma dada probablidade de sucesso (Skaggs, 1981). A Figura 2 apresenta o fluxograma resumido do SISDRENA.

Este modelo permite uma grande facilidade de operação devido a utilização de uma linguagem compatível com os atuais softwares desenvolvidos. Uma outra vantagem é o banco de dados que acompanha o programa, no qual há uma facilidade de leitura e gravação, contando ainda com uma maior rapidez na transferência de dados da série histórica para dentro do modelo. O próprio banco de dados do modelo é uma planilha. Isto acontece devido a uma correspondência entre o software e a planilha eletrônica EXCEL 5.0, onde são criados os arquivos de dados de execução do modelo. A planilha permite também a gravação de todos os resultados da simulação, favorecendo muito ao usuário que poderá manusear os dados de saída do SISDRENA utilizando-se de todos os recursos que a planilha the oferece, no sentido de criação de gráficos, emissão de relatórios, ordenação dos resultados etc. 


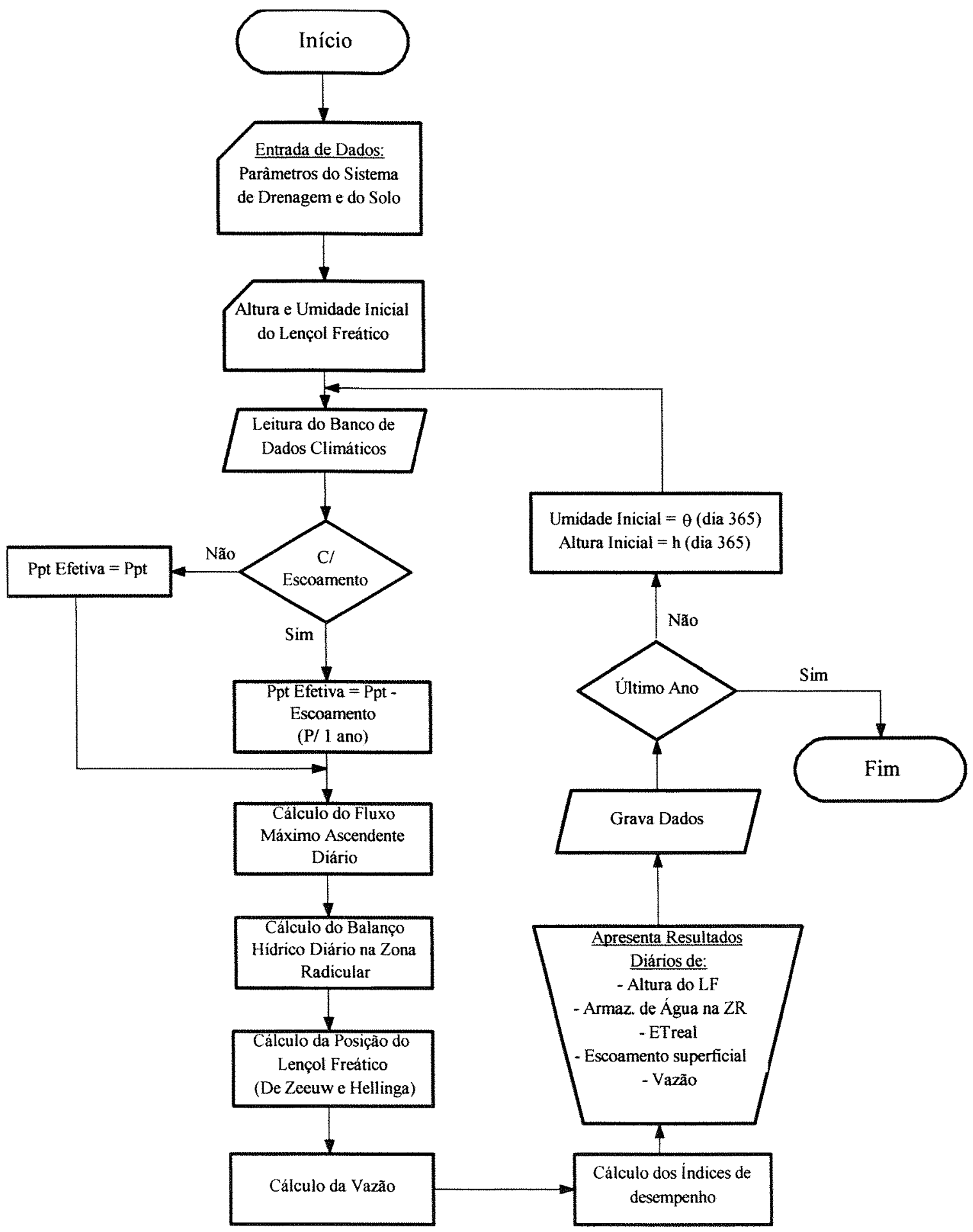

Figura 2 - Fluxograma do modelo proposto 


\subsection{Comparação das simulações realizadas com os modelos}

Os modelos SISDRENA e SIMDRENO (Duarte, 1997) foram comparados com o modelo norte-americano DRAINMOD (Skaggs, 1981).

Nas simulações realizadas pelo DRAINMOD a estimativa do escoamento da água em direção aos drenos ficou restrita ao emprego da equação de Hooghoudt. As comparações foram conduzidas em três etapas. Na primeira etapa foram calculados os erros padrões entre os valores diários simulados de altura do lençol freático, vazão escoada através dos drenos, armazenamento de água na zona radicular e evapotranspiração real, tomando o modelo DRAINMOD como padrão. O erro padrão é dado pela expressão:

$e=\frac{\sqrt{\sum_{i=1}^{N}\left((y m(i)-y s(i))^{2}\right.}}{N}$

em que:

$\mathrm{e}=$ erro padrão;

ym(i) $=$ valor simulado pelo modelo padrão;

ys(i) = valor simulado pelo modelo a ser aplicado; e

$\mathrm{N}=$ número de dias de comparação.

As simulações foram conduzidas utilizando dados meteorológicos de três períodos anuais com características diferentes: um chuvoso, um intermediário e um seco. Estes períodos anuais foram determinados analisando-se a série histórica de dados de chuva, sendo escolhidos os períodos: $1^{\circ}$ de julho de 1982 à 30 de junho de $1983,1^{\circ}$ de julho de 1984 à 30 de junho de 1985 e $1^{\circ}$ de julho de 1983 à 30 de junho de 1984 , respectivamente.

Foram utilizados três solos de perfil homogêneo, com texturas diferentes, cujos parâmetros fisico-hídricos são apresentados no Quadro 1. Estes dados foram obtidos por Duarte (1997) em uma várzea na região de Piracicaba-SP. 
Quadro 1 - Parâmetros físico-hídricos dos solos utilizados nas simulações.

\begin{tabular}{|c|c|c|l|}
\hline Solos & Textura & $\begin{array}{c}\text { Ko } \\
(\mathbf{m} / \mathbf{d i a})\end{array}$ & \multicolumn{1}{|c|}{ Equação de Infiltração } \\
\hline Solo 1 & Franco-argiloso & 1 & $\mathrm{VI}=11,295 \cdot \mathrm{T}_{\mathrm{e}}^{-0,4734}+23$ \\
\hline Solo 2 & Argila & 0.5 & $\mathrm{VI}=1,488 \cdot \mathrm{T}_{\mathrm{e}}^{-0,7400}+10$ \\
\hline Solo 3 & F.argilo-siltoso & 0.1 & $\mathrm{VI}=1,078 . \mathrm{T}_{\mathrm{e}}^{-0,8515}+5$ \\
\hline
\end{tabular}

VI $(\mathrm{mm} / \mathrm{h}), \mathrm{T}(\mathrm{min})$

Os parâmetros das curvas de retenção para os três tipos de solos, utilizando-se o modelo de van Genuchten (1980), seguem no Quadro 2.

Quadro 2 - Relação dos parâmetros dos três tipos de solos utilizados na simulação, para entrada no modelo de van Genuchten (1980).

\begin{tabular}{|c|c|c|c|c|}
\hline Solos & $\mathbf{n}$ & $\mathbf{m}$ & $\boldsymbol{\beta}$ & $\theta \mathbf{r}$ \\
\hline Solo 1 & 1,2685 & 0,2117 & 0,0538 & 0,112 \\
\hline Solo 2 & 1,1809 & 0,1532 & 0,0654 & 0,363 \\
\hline Solo 3 & 1,0676 & 0,0633 & 0,101 & 0,073 \\
\hline
\end{tabular}

As simulações foram realizadas supondo-se duas condições hidrológicas: ausência completa de escoamento superficial e existência de escoamento. Na primeira condição foram utilizados os solos 1 e 2, e na segunda os solos 1,2 e 3 . O fato de não se ter utilizado o solo 3 nas simulações de ausência de escoamento superficial decorre de problemas de operação do DRAINMOD quando utilizado nestas condições.

A opção de se simular sem escoamento superficial considera que toda a chuva que caiu infiltrou-se no solo. Para se realizar simulações considerando o escoamento superficial foram feitos vários testes prévios no sentido de se obter valores do parâmetro do Número da Curva $(\mathrm{CN})$ que apresentassem uma boa distribuição dos resultados quando comparados com os emitidos pelo DRAINMOD, considerando uma lâmina máxima de de armazenamento superficial para este modelo de $1,5 \mathrm{~cm}$. Os valores 
de $\mathrm{CN}$ obtidos para os 3 tipos de solos, respectivamente foram: 64, 85 e 90 para o SISDRENA e 59, 74 e 91 para o SIMDRENO. Os parâmetros geométricos do sistema de drenagem utilizados foram os seguintes: profundidade dos drenos de 1,2 metros, profundidade da camada de impedimento igual a 5,2 metros, raio efetivo do dreno de 0,05 metros e profundidade inicial do lençol freático de $0,7 \mathrm{~m}$. As simulações foram conduzidas para espaçamentos entre drenos de 20,50 e 80 metros.

$\mathrm{Na}$ segunda etapa foram comparados os parâmetros de saída $\mathrm{SEW}_{30}$, número de dias secos e produtividade relativa total, que são gerados anualmente pelos três modelos. Foi utilizada uma série de 21 anos de dados de chuva e evapotranspiração potencial para a região de Piracicaba englobando o período de 1974 a 1994. Os valores de espaçamentos utilizados variaram de 10 a 100 metros, de 10 em 10 metros, para os três tipos de solo, citados anteriormente. Considerou-se também condições de existência e ausência de escoamento superficial. Admitiu-se que anualmente uma cultura de milho que apresentasse um ciclo de 130 dias seria plantada no dia 8 de outubro e colhida em 14 de fevereiro. Os dados de sensibilidade da cultura ao excesso e falta de umidade e a variação da profundidade do sistema radicular foram obtidos de Skaggs (1991). Nos períodos de pousio assumiu-se que a umidade do solo seria afetada pela evaporação até uma profundidade de apenas $0,03 \mathrm{~m}$. Nestas comparações foram confeccionados gráficos de dispersão, calculadas as retas de regressão e os coeficientes de determinação $\left(r^{2}\right)$. Como o valor do $r^{2}$ analisado isoladamente pode levar a interpretações inadequadas da performance do modelo estudado, utilizou-se também o índice d (ID) de concordância (Willmott, 1981), descrito como:

$\mathrm{ID}=1-\frac{\sum(\mathrm{Pi}-\mathrm{Oi})^{2}}{\sum(|\mathrm{Pi}-\mathrm{O}|+|\mathrm{Oi}-\mathrm{O}|)^{2}}$

em que:

$\mathrm{Pi}=$ valores simulados pelos modelos;

$\mathrm{Oi}=$ valores simulados pelo padrão; $\mathrm{e}$

$\mathrm{O}=$ média dos valores simulados pelo padrão. 
O valor do índice d é mais sensível a erros sistemáticos e não sistemáticos dos modelos, e reflete uma tendência quando combinado com a análise do $\mathrm{r}^{2}$. Seu valor pode variar de 0 , para total discordância entre o simulado e o padrão, e 1 , para total concordância.

Numa terceira etapa foram calculadas as produtividades médias dos 21 anos para cada espaçamento e as produtividades esperadas com uma probabilidade de sucesso de $80 \%$. Para este cálculo os valores de produtividades anuais foram ajustados a uma distribuição normal.

Finalmente procedeu-se à análise econômica, realizada por intermédio do cálculo do índice valor presente. A receita anual gerada pela cultura foi estimada utilizando-se as produtividades médias e as produtividades prováveis com uma frequência de $80 \%$ (Skaggs, 1991).

Foram utilizados os seguintes valores estimados por Duarte (1997), com relação aos custos e benefícios da drenagem e da cultura:

- A produção potencial máxima para a cultura de milho foi de 200 sacos.ha ${ }^{-1}$;

- o preço de venda do saco de milho foi de R\$7,00.saco ${ }^{-1}$;

- o custo considerado para a produção da cultura foi estimado em R\$600,00.ha ${ }^{-1}$;

- o custo de implantação do projeto foi baseado considerando-se os custos de saneamento da área e abertura dos coletores e os custos de instalação dos drenos subterrâneos;

- os custos de saneamento e abertura dos coletores foram estimados em R\$350,00.ha ${ }^{-1}$;

- o custo do metro do dreno subterrâneo instalado foi de $\mathrm{R} \$ 5,00 . \mathrm{m}^{-1}$;

- a vida útil do projeto foi estimada em 25 anos; e

- a taxa de juros anual adotada foi de $12 \%$ a.a. 


\section{RESULTADOS E DISCUSSÃO}

\subsection{Comparações diárias sem escoamento superficial}

Os resultados apresentados a seguir referem-se aos valores diários simulados de altura do lençol freático (LF), vazão escoada através dos drenos, armazenamento de água na zona radicular e evapotranspiração real.

\subsubsection{Altura do lençol freático}

De um modo geral para espaçamentos de 20 e 50 metros tanto o SISDRENA quanto o SIMDRENO simularam a flutuação do LF igualmente bem quando comparado com o DRAINMOD (Figura 3). Com relação ao espaçamento de 80 metros o SIMDRENO apresentou os maiores erros, subestimando o rebaixamento do LF (Figura 4). O SIMDRENO calcula o valor da recarga efetiva do LF, somando a precipitação percolada com a lâmina proveniente do "seepage" vertical e subtraindo o valor da fração da evapotranspiração oriunda do LF. Em ausência de chuvas e de "seepage" a recarga efetiva assumiria um valor negativo, acarretando uma impossibilidade de cálculo. Para contornar este problema, o SIMDRENO considera a recarga efetiva nula sempre que esta assumir um valor negativo. Este artificio faz com que o efeito da evapotranspiração, sobre o rebaixamento do LF, não seja contabilizado. Como consequência, em situações em que a evapotranspiração proveniente do LF possui uma magnitude elevada, ou seja, quando o LF é rebaixado lentamente e portanto permanece mais tempo próximo à superficie do solo, este modelo passa a subestimar a queda do lençol freático. Esta situação ocorre sempre que o coeficiente de armazenamento $(J)$ assume valores elevados, ou seja, quando o espaçamento entre drenos é grande e a condutividade hidráulica do solo é baixa. 

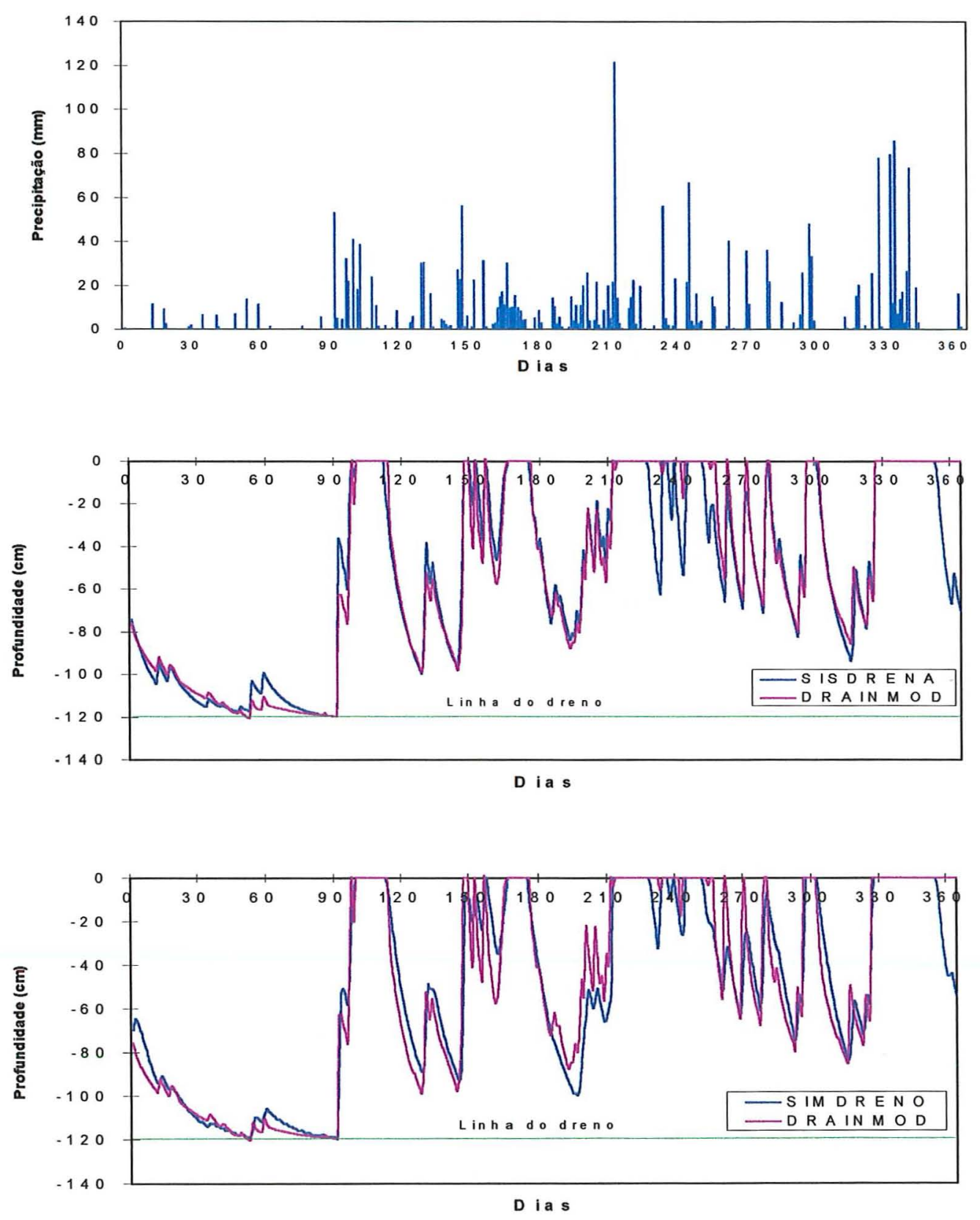

Figura 3 - Pluviograma e profundidades do lençol freático simuladas pelo SISDRENA e SIMDRENO comparadas com DRAINMOD, durante o período de julho de 1982 a julho de 1983, com espaçamento de $50 \mathrm{~m}$ para o solo 2 . 

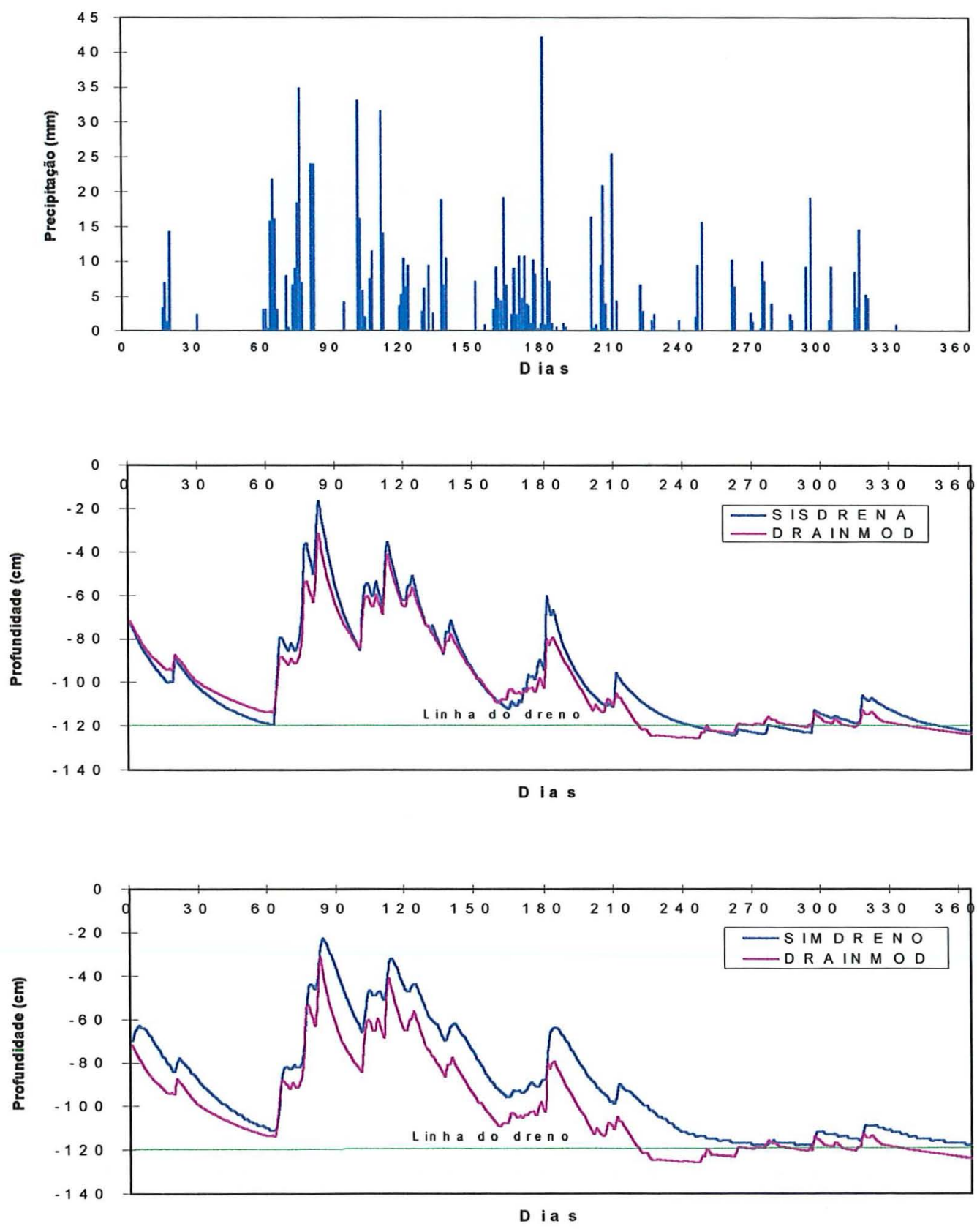

Figura 4 - Pluviograma e profundidades do lençol freático simuladas pelo SISDRENA e SIMDRENO comparadas com DRAINMOD, durante o período de julho de 1983 a julho de 1984, com espaçamento de $80 \mathrm{~m}$ para o solo 1. 
O modelo SISDRENA contabiliza o efeito da fração da evapotranspiração proveniente do LF corrigindo a sua posição, após esta ter sido estimada pela equação de De Zeeuw e Hellinga. Este artifício supera a limitação citada anteriormente e permite também que seja possível simular posições do LF abaixo da linha dos drenos, como pode ser observado na Figura 5. Verifica-se que neste caso, o SIMDRENO apresentou um desempenho inferior ao SISDRENA, quando comparado com o DRAINMOD, por não ser capaz de simular rebaixamentos abaixo da linha dos drenos.

A Tabela 1 apresenta os erros padrões entre as posições diárias do LF simuladas pelo SISDRENA e SIMDRENO em relação ao DRAINMOD. Verifica-se que houve uma tendência geral de ambos os modelos apresentarem erros-padrões maiores para o solo 2 e espaçamentos maiores. Nestes casos a velocidade de infiltração da água no solo é menor. O modelo DRAINMOD, por utilizar dados de chuva horária, contabiliza o tempo necessário para infiltração. Já o SISDRENA e o SIMDRENO, por utilizarem chuvas diárias, não são capazes de descrever o processo de infiltração e deste modo, apresentam maiores desvios em relação ao DRAINMOD à medida em que a duração deste processo aumenta. Na Tabela 1 pode-se verificar também que em média os erros padrões do SISDRENA foram menores que os do SIMDRENO.

\subsubsection{Vazão}

As vazões simuladas pelo SISDRENA, quando comparadas com o DRAINMOD apresentaram erros padrões que foram, em média, inferiores àqueles obtidos com o SIMDRENO (Tabela 2). As maiores diferenças entre os modelos foram obtidas para o espaçamento de $80 \mathrm{~m}$ conforme se observa na Figura 6. Em situações que o LF se posiciona acima da superficie do solo, tanto o SIMDRENO quanto o SISDRENA assumem a existência de solo acima da superficie do terreno. Para o cálculo da vazão o SISDRENA transforma estas camadas artificiais de solo que foram geradas na simulação em lâmina de água. Desta forma a carga hidráulica sobre os drenos, e consequentemente a vazão escoada pelos mesmos, se aproxima mais dos valores simulados pelo DRAINMOD. Por não realizar esta transformação o SIMDRENO simula 

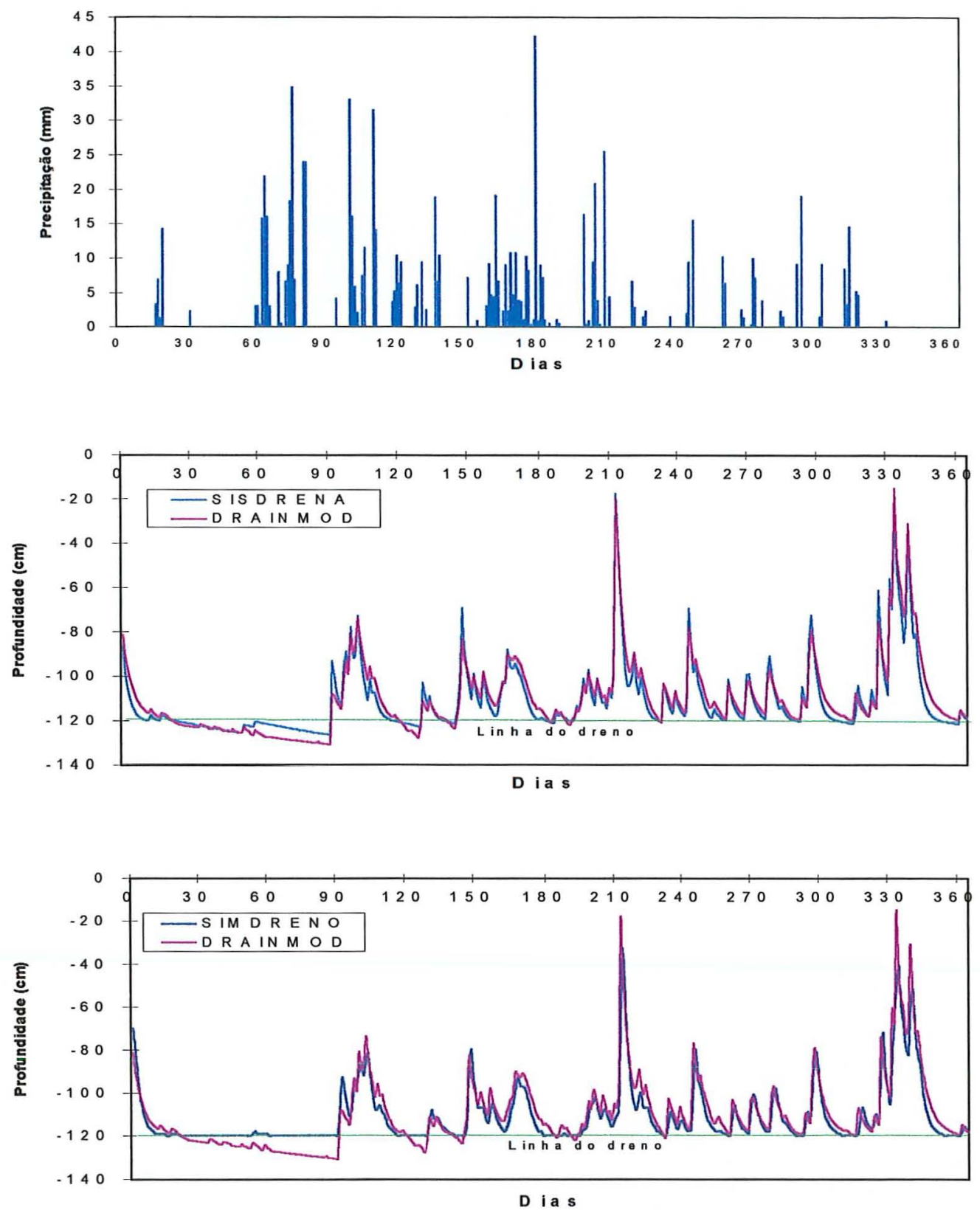

Figura 5 - Pluviograma e profundidades do lençol freático simuladas pelo SISDRENA e SIMDRENO comparadas com DRAINMOD, durante o período de julho de 1983 a julho de 1984, com espaçamento de $20 \mathrm{~m}$ para o solo 1. 
Tabela 1. Erros padrões entre as posições diárias do lençol freático simuladas pelo SISDRENA e SIMDRENO, em relação ao DRAINMOD, para diferentes períodos anuais, tipos de solo e espaçamentos, em condições de ausência de escoamento superficial.

\begin{tabular}{|c|c|c|c|}
\hline \multirow[t]{2}{*}{ Período anual } & \multirow{2}{*}{$\begin{array}{c}\text { ESPAÇAMENTO } \\
\text { (m) }\end{array}$} & \multicolumn{2}{|c|}{ ERRO PADRÃO (cm) } \\
\hline & & SISDRENA & SIMDRENO \\
\hline Solo $1(\mathrm{Ko}=1,0 \mathrm{~m} / \mathrm{dia})$ & 20 & 0,234 & 0,337 \\
\hline \multirow[t]{2}{*}{ chuvoso } & 50 & 0,400 & 0,431 \\
\hline & 80 & 0,470 & 1,169 \\
\hline Solo $1(\mathrm{Ko}=1,0 \mathrm{~m} / \mathrm{dia})$ & 20 & 0,233 & 0,506 \\
\hline \multirow[t]{2}{*}{ seco } & 50 & 0,240 & 0,340 \\
\hline & 80 & 0,306 & 0,686 \\
\hline Solo $1(\mathrm{Ko}=1,0 \mathrm{~m} /$ dia $)$ & 20 & 0,505 & 0,443 \\
\hline \multirow[t]{2}{*}{ intermediário } & 50 & 0,678 & 0,874 \\
\hline & 80 & 0,850 & 1,552 \\
\hline Solo $2(\mathrm{Ko}=0,5 \mathrm{~m} / \mathrm{dia})$ & 20 & 0,370 & 0,481 \\
\hline \multirow[t]{2}{*}{ chuvoso } & 50 & 0,699 & 0,690 \\
\hline & 80 & 0,280 & 0,387 \\
\hline Solo $2(\mathrm{Ko}=0,5 \mathrm{~m} / \mathrm{dia})$ & 20 & 0,387 & 0,396 \\
\hline \multirow[t]{2}{*}{ seco } & 50 & 0,438 & 0,395 \\
\hline & 80 & 0,523 & 1,825 \\
\hline Solo $2(\mathrm{Ko}=0,5 \mathrm{~m} / \mathrm{dia})$ & 20 & 0,973 & 0,862 \\
\hline \multirow[t]{2}{*}{ intermediário } & 50 & 1,170 & 1,170 \\
\hline & 80 & 1,075 & 2,41 \\
\hline Média & & 0,546 & $\mathbf{0 , 8 3 0}$ \\
\hline
\end{tabular}


Tabela 2. Erros padrões entre as vazões diárias simuladas pelo SISDRENA e SIMDRENO, em relação ao DRAINMOD, para diferentes períodos anuais, tipos de solo e espaçamentos, em condições de ausência de escoamento superficial.

\begin{tabular}{|c|c|c|c|}
\hline \multirow[t]{2}{*}{ Período anual } & \multirow{2}{*}{$\begin{array}{c}\text { ESPAÇAMENTO } \\
\text { (m) }\end{array}$} & \multicolumn{2}{|c|}{ ERRO PADRÃO (m/dia) } \\
\hline & & SISDRENA & SIMDRENO \\
\hline Solo $1(\mathrm{Ko}=1,0 \mathrm{~m} / \mathrm{dia})$ & 20 & 0,155 & 0,123 \\
\hline \multirow[t]{2}{*}{ chuvoso } & 50 & 0,055 & 0,076 \\
\hline & 80 & 0,027 & 0,071 \\
\hline Solo $1(\mathrm{Ko}=1,0 \mathrm{~m} / \mathrm{dia})$ & 20 & 0,056 & 0,061 \\
\hline \multirow[t]{2}{*}{ seco } & 50 & 0,020 & 0,033 \\
\hline & 80 & 0,013 & 0,025 \\
\hline Solo $1(\mathrm{Ko}=1,0 \mathrm{~m} / \mathrm{dia})$ & 20 & 0,167 & 0,161 \\
\hline \multirow[t]{2}{*}{ intermediário } & 50 & 0,061 & 0,066 \\
\hline & 80 & 0,037 & 0,045 \\
\hline Solo $2(\mathrm{Ko}=0,5 \mathrm{~m} / \mathrm{dia})$ & 20 & 0,143 & 0,124 \\
\hline \multirow[t]{2}{*}{ chuvoso } & 50 & 0,044 & 0,117 \\
\hline & 80 & 0,015 & 0,126 \\
\hline Solo $2\left(\mathrm{Ko}_{0}=0,5 \mathrm{~m} / \mathrm{dia}\right)$ & 20 & 0,058 & 0,050 \\
\hline \multirow[t]{2}{*}{ seco } & 50 & 0,022 & 0,027 \\
\hline & 80 & 0,012 & 0,020 \\
\hline Solo $2(\mathrm{Ko}=0,5 \mathrm{~m} / \mathrm{dia})$ & 20 & 0,185 & 0,172 \\
\hline \multirow[t]{2}{*}{ intermediário } & 50 & 0,064 & 0,070 \\
\hline & 80 & 0,031 & 0,053 \\
\hline Média & & 0,065 & 0,079 \\
\hline
\end{tabular}



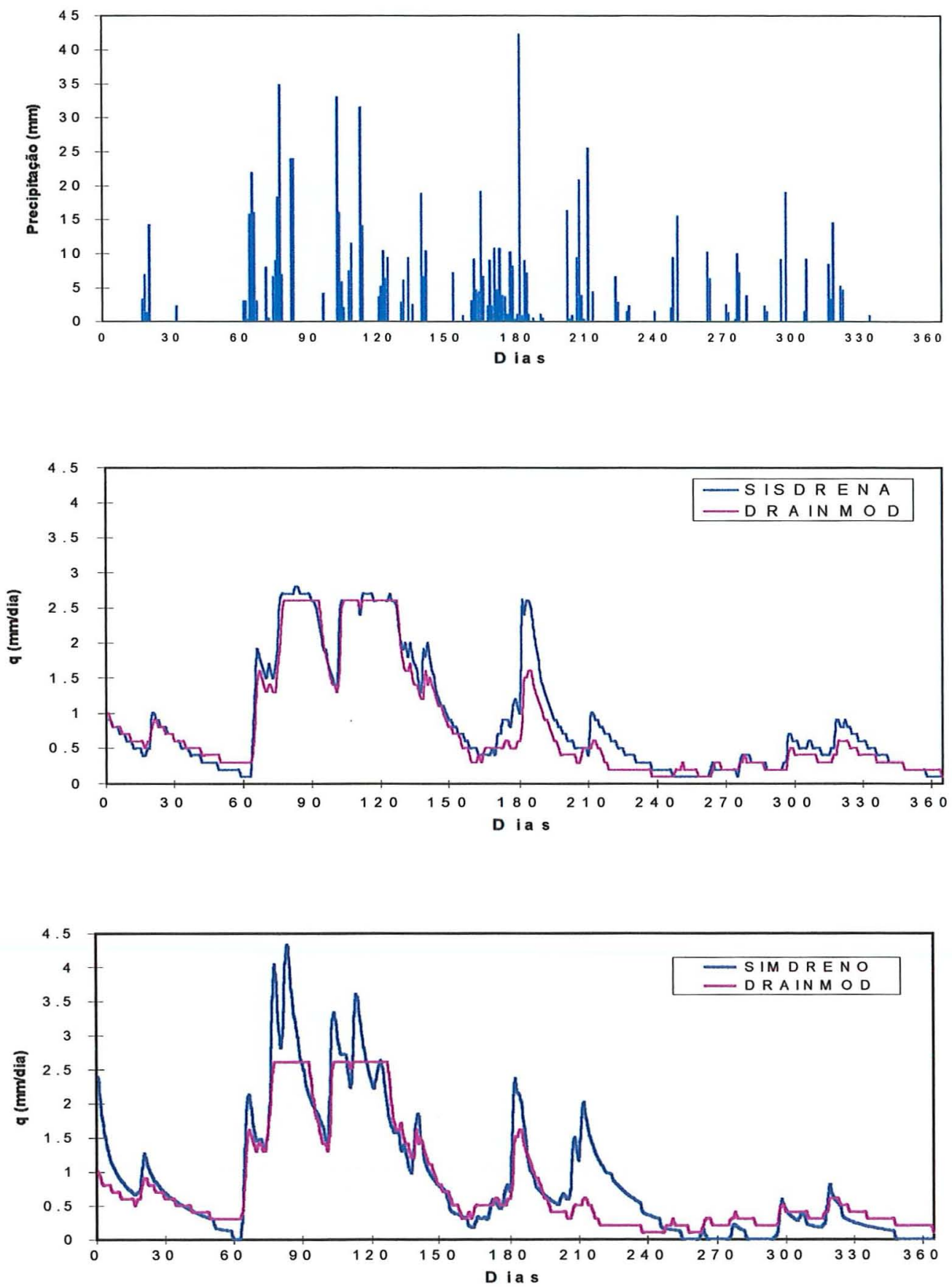

Figura 6 - Pluviograma e vazões diárias por unidade de área simuladas pelo SISDRENA e SIMDRENO comparadas com DRAINMOD, durante o período de julho de 1983 a julho de 1984, com espaçamento de $80 \mathrm{~m}$ para o solo 2. 
picos de vazão maiores quando o LF se posiciona acima da superficie do solo, o que ocorre mais frequentemente para espaçamentos maiores.

\subsubsection{Armazenamento de água na zona radicular}

A Tabela 3 apresenta os valores de erro padrão entre as simulações diárias de armazenamento de água na zona radicular obtidas com a utilização do SISDRENA e do SIMDRENO com relação ao DRAINMOD. Verifica-se que a ordem de grandeza dos erros foi semelhante para ambos os modelos. Pode-se notar também que para o solo $1 \mathrm{e}$ principalmente no caso de espaçamentos menores houve uma ligeira tendência do SIMDRENO apresentar erros menores do que o SISDRENA em relação ao DRAINMOD. Tanto o SIMDRENO quanto o SISDRENA consideram que após o LF ser rebaixado a umidade na zona radicular atinge o valor da capacidade de campo. Entretanto, o SIMDRENO considera a umidade na capacidade de campo como aquela correspondente a uma tensão de $6 \mathrm{kPa}$ enquanto o SISDRENA assume que esta corresponda a uma tensão igual ao comprimento da coluna que vai da superfície do LF à metade da profundidade da zona radicular. O DRAINMOD, por sua vez, considera que o solo na zona radicular permaneça saturado após o rebaixamento do LF. Assim, em situações em que o LF cai rapidamente a uma profundidade maior do que 0,6 metros, o SISDRENA passa a contabilizar uma umidade menor do que o SIMDRENO, e consequentemente, com um maior desvio em relação ao DRAINMOD.

A Figura 7 ilustra a variação do armazenamento para o solo 2 . $\mathrm{O}$ crescimento apresentado a partir do centésimo dia e decréscimo que se verifica a partir do dia de ordem 230 referem-se ao crescimento do sistema radicular.

\subsubsection{Evapotranspiração real}

Os desvios entre os valores simulados da evapotranspiração real pelo SISDRENA e SIMDRENO com relação aos valores obtidos pela simulação com o DRAINMOD, apresentaram a mesma ordem de grandeza, com exceção das simulações realizadas para o solo 2 com espaçamento de 80 metros. Neste caso o SISDRENA apresentou desvios ligeiramente inferiores possivelmente devido ao fato deste modelo ter 
simulado posições do LF com menores desvios em relação ao DRAINMOD, do que o SIMDRENO nesta situação (Tabela 4). A Figura 8 ilustra a comparação realizada para o solo 2 e espaçamento de 80 metros.

Tabela 3. Erros padrões do armazenamento de água na zona radicular simulado pelo SISDRENA e SIMDRENO, em relação ao DRAINMOD, para diferentes períodos anuais, tipos de solo e espaçamentos, em condições de ausência de escoamento superficial.

\begin{tabular}{c|c|c|c}
\hline \multicolumn{2}{c}{ Período anual } & ESPAÇAMENTO & \multicolumn{2}{c}{ ERRO PADRÃO (mm) } \\
\cline { 3 - 4 } \multicolumn{2}{c}{$(\mathbf{m})$} & SISDRENA & SIMDRENO \\
\hline Solo 1 (Ko=1,0 m/dia) & 20 & 1,247 & 1,056 \\
chuvoso & 50 & 1,005 & 0,998 \\
& 80 & 0,472 & 0,588 \\
\hline Solo 1 (Ko=1,0 m/dia) & 20 & 1,065 & 0,961 \\
seco & 50 & 1,014 & 0,950 \\
Solo 1 (Ko=1,0 m/dia) & 80 & 0,807 & 0,648 \\
intermediário & 50 & 1,326 & 1,137 \\
& 80 & 1,207 & 1,061 \\
\hline Solo 2 (Ko=0,5 m/dia) & 20 & 0,933 & 0,850 \\
chuvoso & 50 & 0,564 & 0,550 \\
& 80 & 0,280 & 0,448 \\
\hline Solo 2 (Ko=0,5 m/dia) & 20 & 0,051 & 0,046 \\
seco & 50 & 0,388 & 0,378 \\
& 80 & 0,300 & 0,363 \\
\hline Solo 2 (Ko=0,5 m/dia) & 20 & 0,214 & 0,556 \\
intermediário & 50 & 0,703 & 0,670 \\
\hline Média & 80 & 0,628 & 0,499 \\
\hline
\end{tabular}



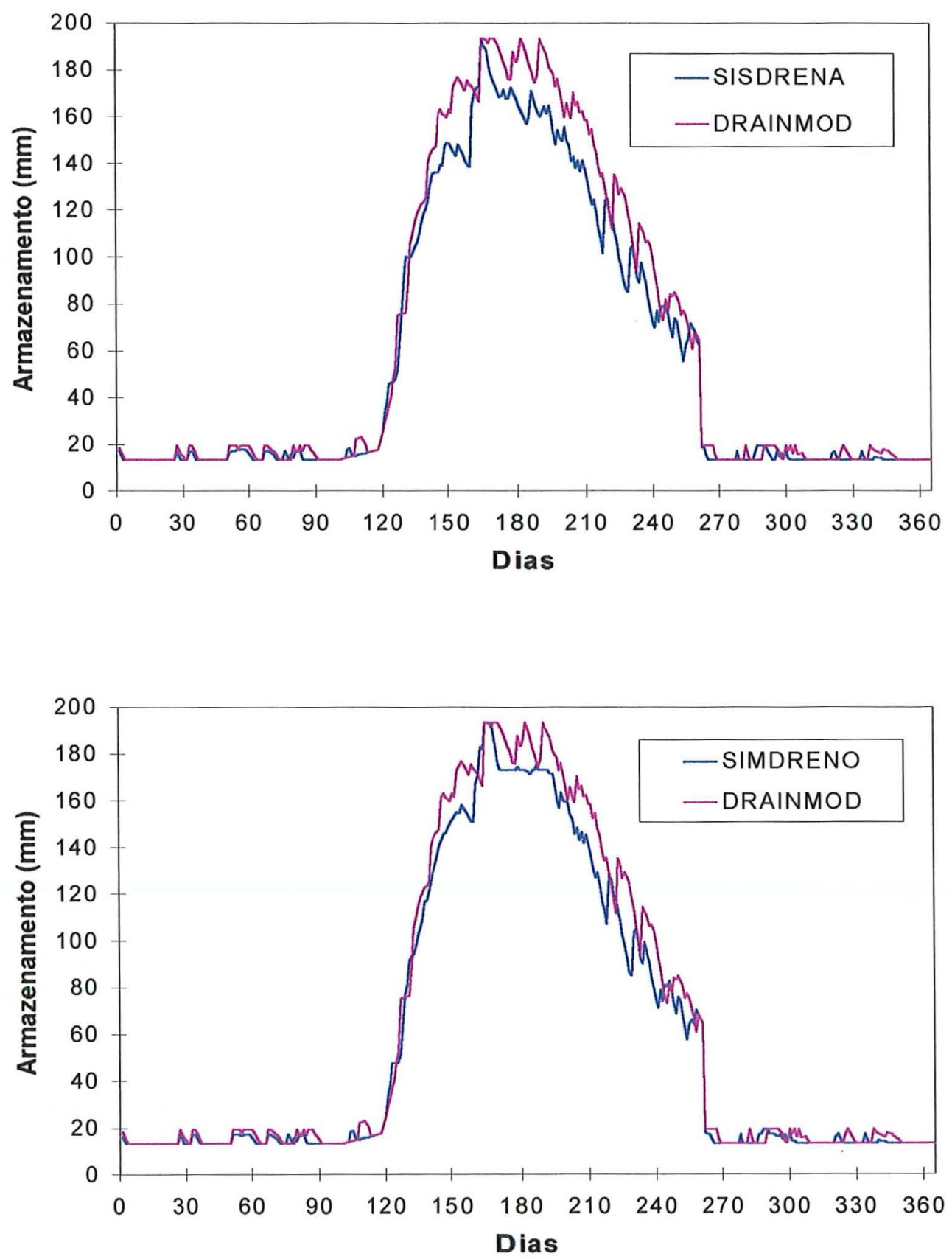

Figura 7 - Armazenamento de água na zona radicular simulado pelo SISDRENA e SIMDRENO comparado com DRAINMOD, durante o período de julho de 1984 a julho de 1985 , com espaçamento de $50 \mathrm{~m}$ para o solo 2 . 
Tabela 4. Erros padrões da evapotranspiração real simulada pelo SISDRENA e SIMDRENO, em relação ao DRAINMOD, para diferentes períodos anuais, tipos de solo e espaçamentos, em condições de ausência de escoamento superficial.

\begin{tabular}{|c|c|c|c|}
\hline \multirow[t]{2}{*}{ Período anual } & \multirow{2}{*}{$\begin{array}{c}\text { ESPAÇAMENTO } \\
\text { (m) }\end{array}$} & \multicolumn{2}{|c|}{ ERRO PADRÃO - ETR $\left(\mathrm{mm}^{\mathrm{d}} \mathrm{dia}^{-1}\right)$} \\
\hline & & SISDRENA & SIMDRENO \\
\hline Solo $1(\mathrm{Ko}=1,0 \mathrm{~m} / \mathrm{dia})$ & 20 & 0,045 & 0,045 \\
\hline \multirow[t]{2}{*}{ chuvoso } & 50 & 0,039 & 0,040 \\
\hline & 80 & 0,034 & 0,037 \\
\hline Solo $1(\mathrm{Ko}=1,0 \mathrm{~m} / \mathrm{dia})$ & 20 & 0,047 & 0,050 \\
\hline \multirow[t]{2}{*}{ seco } & 50 & 0,045 & 0,048 \\
\hline & 80 & 0,045 & 0,050 \\
\hline Solo $1(\mathrm{Ko}=1,0 \mathrm{~m} / \mathrm{dia})$ & 20 & 0,069 & 0,068 \\
\hline \multirow[t]{2}{*}{ intermediário } & 50 & 0,066 & 0,066 \\
\hline & 80 & 0,059 & 0,058 \\
\hline Solo $2(\mathrm{Ko}=0,5 \mathrm{~m} / \mathrm{dia})$ & 20 & 0,044 & 0,047 \\
\hline \multirow[t]{2}{*}{ chuvoso } & 50 & 0,040 & 0,050 \\
\hline & 80 & 0,033 & 0,037 \\
\hline Solo $2(\mathrm{Ko}=0,5 \mathrm{~m} / \mathrm{dia})$ & 20 & 0,059 & 0,052 \\
\hline \multirow[t]{2}{*}{ seco } & 50 & 0,054 & 0,050 \\
\hline & 80 & 0,051 & 0,066 \\
\hline Solo $2(\mathrm{Ko}=0,5 \mathrm{~m} / \mathrm{dia})$ & 20 & 0,069 & 0,069 \\
\hline \multirow[t]{2}{*}{ intermediário } & 50 & 0,069 & 0,068 \\
\hline & 80 & 0,059 & 0,067 \\
\hline Média & & 0,0515 & 0,0537 \\
\hline
\end{tabular}



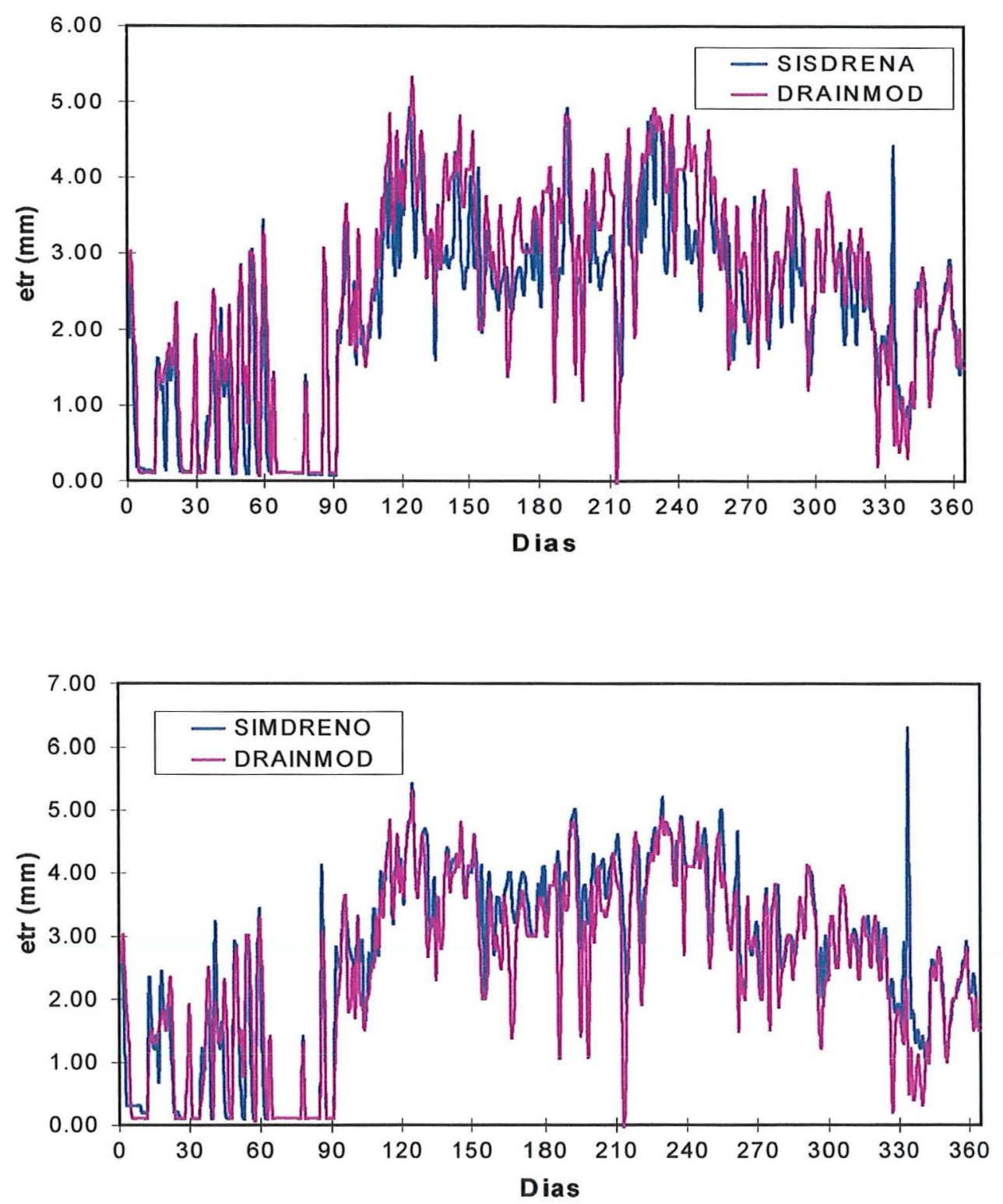

Figura 8 - Evapotranspiração real simulada pelo SISDRENA e SIMDRENO comparada com DRAINMOD, durante o período de julho de 1982 a julho de 1983, com espaçamento de $80 \mathrm{~m}$ para o solo 2. 


\subsection{Comparações diárias com escoamento superficial}

Os resultados apresentados a seguir são relativos a simulações de escoamento superficial, altura do lençol freático, vazão escoada através dos drenos, armazenamento na zona radicular e evapotranspiração real.

Nestas simulações tornou-se possível a utilização dos três tipos de solos $(1,2$ e 3), para os três modelos simulados.

\subsubsection{Escoamento superficial}

$\mathrm{O}$ volume de escoamento superficial é influenciado pela capacidade de infiltração e pela magnitude da precipitação anual. Assim, para ambos os modelos, os menores erros encontrados com relação ao DRAINMOD, foram obtidos nas simulações realizadas para o solo 1 e para o período anual mais seco (83/84). Os erros aumentaram em presença de maior escoamento superficial, ou seja, nos solos de menor capacidade de infiltração, conforme Tabela 5. Este resultado se deve ao fato do DRAINMOD contabilizar o escoamento superficial por um processo mais preciso, ou seja, realizando um balanço de água sobre a superfície do solo em intervalos de tempo menores do que uma hora. O SIMDRENO e o SISDRENA, por utilizarem chuvas diárias, contabilizam o escoamento superficial pelo método do Número da Curva.

Pode-se observar também que, em termos médios, o SISDRENA propiciou menores diferenças em relação ao DRAINMOD, principalmente no período anual mais úmido (82/83). Este resultado deve-se ao fato do SISDRENA considerar indiretamente o efeito da umidade do perfil do solo sobre o escoamento superficial. $\mathrm{O}$ SIMDRENO não considera o efeito da intensidade de drenagem subterrânea sobre o escoamento superficial. A Figura 9, mostra uma situação onde houve uma menor diferença entre os modelos e na Figura 10, pode-se observar que o SIMDRENO subestimou os valores de escoamento superficial, quando comparado com o DRAINMOD, enquanto que o SISDRENA acompanhou bem os valores simulados pelo modelo norte-americano. 
Tabela 5. Erros padrões do volume de escoamento superficial simulado pelo SISDRENA e SIMDRENO, em relação ao DRAINMOD, para diferentes períodos anuais, tipos de solo e espaçamentos, em condições de presença de escoamento superficial.

\begin{tabular}{c|c|c|c}
\hline \multicolumn{2}{c}{ Período anual } & ESPAÇAMENTO & \multicolumn{2}{c}{ ERRO PADRÃO } \\
\cline { 3 - 4 } & $(\mathbf{m})$ & SISDRENA & SIMDRENO \\
\hline Solo 1 (Ko=1,0 m/dia) & 20 & 0,081 & 0,074 \\
chuvoso & 50 & 0,124 & 0,218 \\
& 80 & 0,145 & 0,337 \\
\hline Solo 1 (Ko=1,0 m/dia) & 20 & 0,000 & 0,007 \\
seco & 50 & 0,000 & 0,007 \\
& 80 & 0,000 & 0,007 \\
\hline Solo 1 (Ko=1,0 m/dia) & 20 & 0,009 & 0,031 \\
intermediário & 50 & 0,016 & 0,031 \\
& 80 & 0,028 & 0,031 \\
\hline Solo 2 (Ko=0,5 m/dia) & 20 & 0,112 & 0,167 \\
chuvoso & 50 & 0,102 & 0,383 \\
& 80 & 0,090 & 0,474 \\
\hline Solo 2 (Ko=0,5 m/dia) & 20 & 0,018 & 0,016 \\
seco & 50 & 0,037 & 0,030 \\
& 80 & 0,039 & 0,072 \\
\hline Solo 2 (Ko=0,5 m/dia) & 20 & 0,081 & 0,030 \\
intermediário & 50 & 0,134 & 0,075 \\
& 80 & 0,236 & 0,166 \\
\hline Solo 3 (Ko=0,1 m/dia) & 20 & 0,103 & 0,458 \\
chuvoso & 50 & 0,113 & 0,574 \\
& 80 & 0,116 & 0,602 \\
\hline Solo 3 (Ko=0,1 m/dia) & 20 & 0,052 & 0,041 \\
seco & 50 & 0,068 & 0,122 \\
& 80 & 0,065 & 0,135 \\
\hline Solo 3 (Ko=0,1 m/dia) & 20 & 0,212 & 0,139 \\
intermediário & 50 & 0,383 & 0,274 \\
& 80 & 0,425 & 0,302 \\
\hline Média & & $\mathbf{0 , 1 0 3}$ & $\mathbf{0 , 1 7 7}$ \\
\hline
\end{tabular}



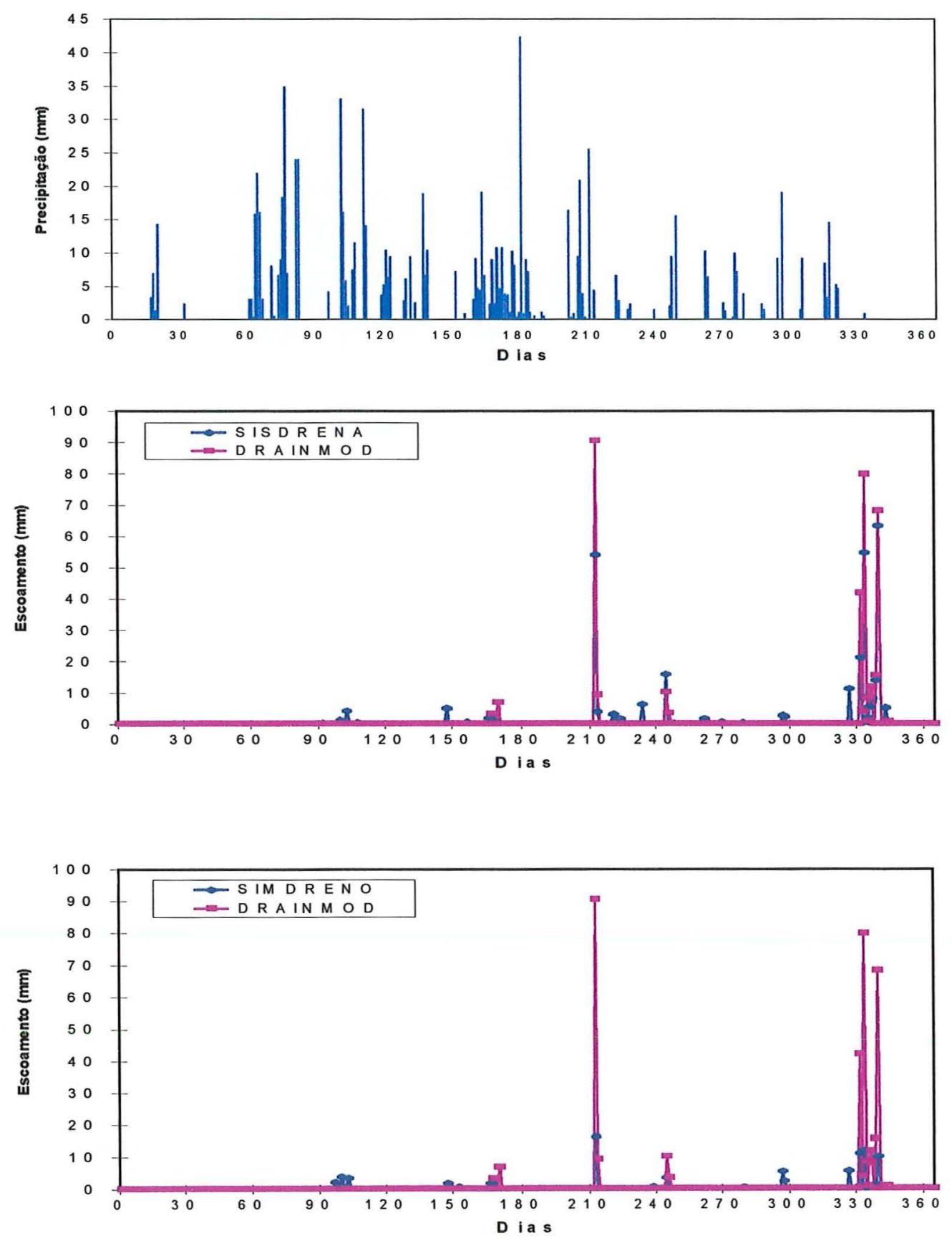

Figura 9 - Pluviograma e escoamento superficial simulado pelo SISDRENA e SIMDRENO comparado com DRAINMOD, durante o período de julho de 1983 a julho de 1984, com espaçamento de $80 \mathrm{~m}$ para o solo 1 . 

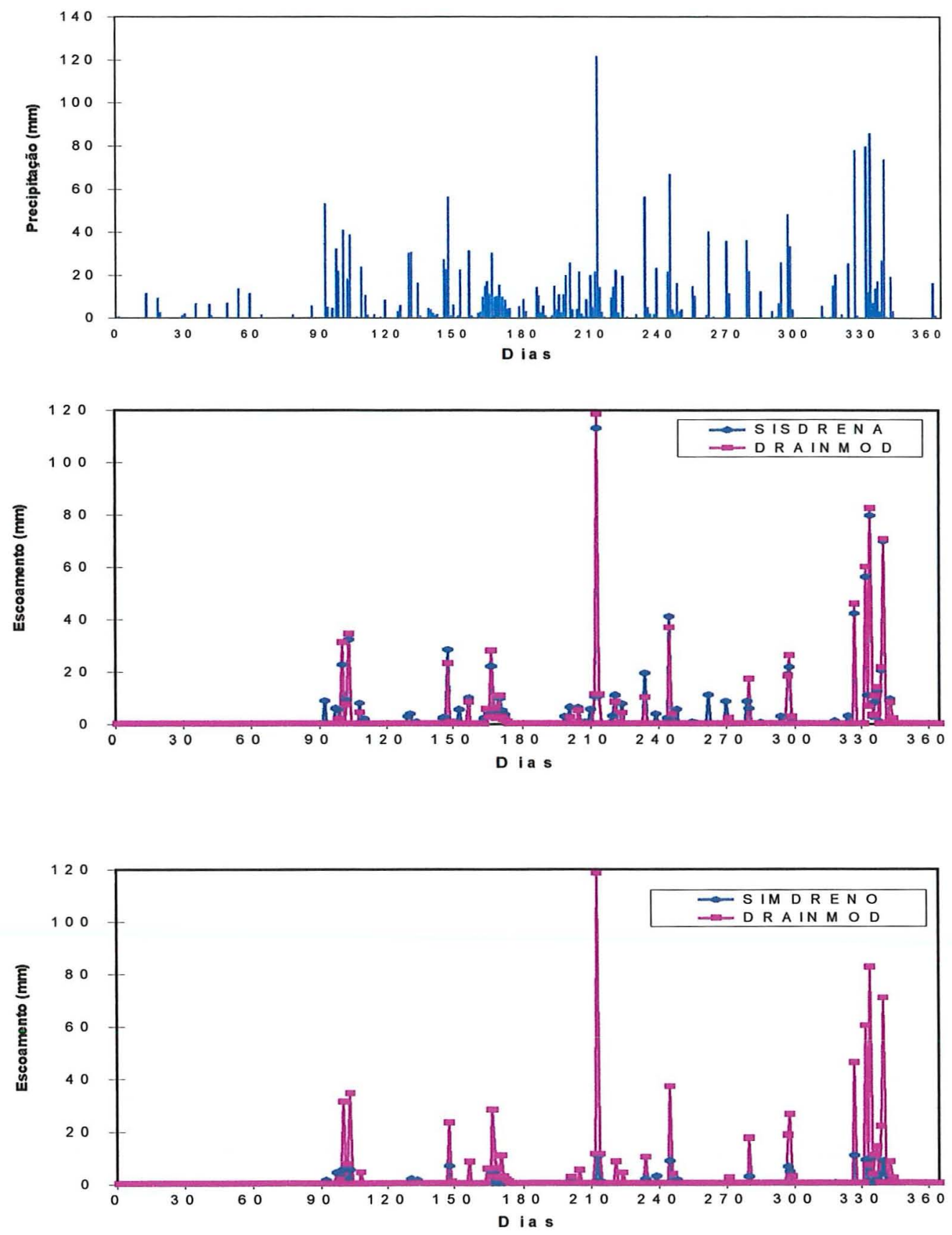

Figura 10 - Pluviograma e escoamento superficial simulado pelo SISDRENA e SIMDRENO comparado com DRAINMOD, durante o período de julho de 1982 a julho de 1983, com espaçamento de $80 \mathrm{~m}$ para o solo 2 . 


\subsubsection{Altura do lençol freático considerando o escoamento superficial}

Foi verificado que na maioria das simulações o SISDRENA propiciou menores desvios em relação ao DRAINMOD do que o modelo SIMDRENO. Os valores das alturas do lençol seguiram basicamente a mesma tendência observada quando se considerou a infiltração total da precipitação. O SIMDRENO subestimou o rebaixamento do LF, quando comparado com os valores simulados pelo DRAINMOD, em espaçamentos maiores e em solos com condutividade hidráulica baixa (Tabela 6).

A Figura 11 ilustra a comparação das simulações realizadas para o espaçamento de 50 metros com o solo 2, situação em que ambos os modelos apresentaram desvios semelhantes. Na Figura 12 verifica-se que para o solo $3 \mathrm{e}$ espaçamento de 80 metros o SIMDRENO previu que o LF permaneceria praticamente durante todo o período sobre a superfície do solo, destoando consideravelmente do DRAINMOD.

\subsubsection{Vazão considerando o escoamento superficial}

De um modo geral, principalmente para o solo 2 , as vazões obtidas pelo modelo SISDRENA considerando o escoamento superficial, apresentaram um erro padrão menor, em relação ao DRAINMOD, do que as que foram obtidas em ausência do escoamento superficial. Em condições de ausência total de escoamento superficial formase uma lâmina de água sobre a superfície do solo durante os períodos mais chuvosos, principalmente em solos de menor condutividade hidráulica. O modelo DRAINMOD, utilizando a equação de Hooghoudt, não considera o efeito do aumento da carga hidráulica proporcionado pela lâmina superficial sobre a vazão dos drenos. Já no SISDRENA este efeito é considerado. Em condições de existência de escoamento superficial a lâmina d'água que se forma sobre a superficie do terreno é menor e, consequentemente, a diferença entre as vazões estimadas pelos dois modelos diminui.

As maiores diferenças entre o desempenho do SISDRENA e do SIMDRENO foram observadas nas simulações conduzidas para o solo de condutividade hidráulica mais baixa. 
Tabela 6. Erros padrões entre as posições diárias do lençol freático simuladas pelo SISDRENA e SIMDRENO, em relação ao DRAINMOD, para diferentes períodos anuais, tipos de solo e espaçamentos, em condições de presença de escoamento superficial.

\begin{tabular}{c|c|c|c}
\hline \multicolumn{2}{c}{ Período anual } & ESPAÇAMENTO & \multicolumn{2}{c}{ ERRO PADR O - h (cm) } \\
\cline { 3 - 4 } & $(\mathbf{m})$ & SISDRENA & SIMDRENO \\
\hline Solo 1 $(\mathrm{Ko}=1,0 \mathrm{~m} /$ dia $)$ & 20 & 0,276 & 0,458 \\
chuvoso & 50 & 0,312 & 0,474 \\
& 80 & 0,640 & 1,535 \\
\hline Solo 1 $(\mathrm{Ko}=1,0 \mathrm{~m} /$ dia $)$ & 20 & 0,232 & 0,507 \\
seco & 50 & 0,240 & 0,336 \\
& 80 & 0,305 & 0,644 \\
\hline Solo 1 $(\mathrm{Ko}=1,0 \mathrm{~m} /$ dia $)$ & 20 & 0,501 & 0,427 \\
intermediário & 50 & 0,667 & 0,519 \\
& 80 & 0,818 & 1,412 \\
\hline Solo 2 (Ko=0,5 m/dia) & 20 & 0,380 & 0,789 \\
chuvoso & 50 & 0,320 & 0,792 \\
& 80 & 0,348 & 1,716 \\
\hline Solo 2 (Ko=0,5 m/dia) & 20 & 0,384 & 0,419 \\
seco & 50 & 0,393 & 0,384 \\
& 80 & 0,480 & 1,953 \\
\hline Solo 2 (Ko=0,5 m/dia) & 20 & 0,902 & 0,811 \\
intermediário & 50 & 1,087 & 0,989 \\
& 80 & 1,066 & 2,213 \\
\hline Solo 3 (Ko=0,1 m/dia) & 20 & 0,479 & 1,478 \\
chuvoso & 50 & 0,502 & 1,209 \\
& 80 & 0,539 & 0,982 \\
\hline Solo 3 (Ko=0,1 m/dia) & 20 & 0,481 & 0,736 \\
seco & 50 & 0,497 & 2,496 \\
& 80 & 0,584 & 2,509 \\
\hline Solo 3 (Ko=0,1 m/dia) & 20 & 1,217 & 1,554 \\
intermediário & 50 & 0,996 & 1,750 \\
& 80 & 0,827 & 1,114 \\
\hline Média & & $\mathbf{0 , 5 7 3}$ & $\mathbf{1 , 1 1 8}$ \\
\hline
\end{tabular}



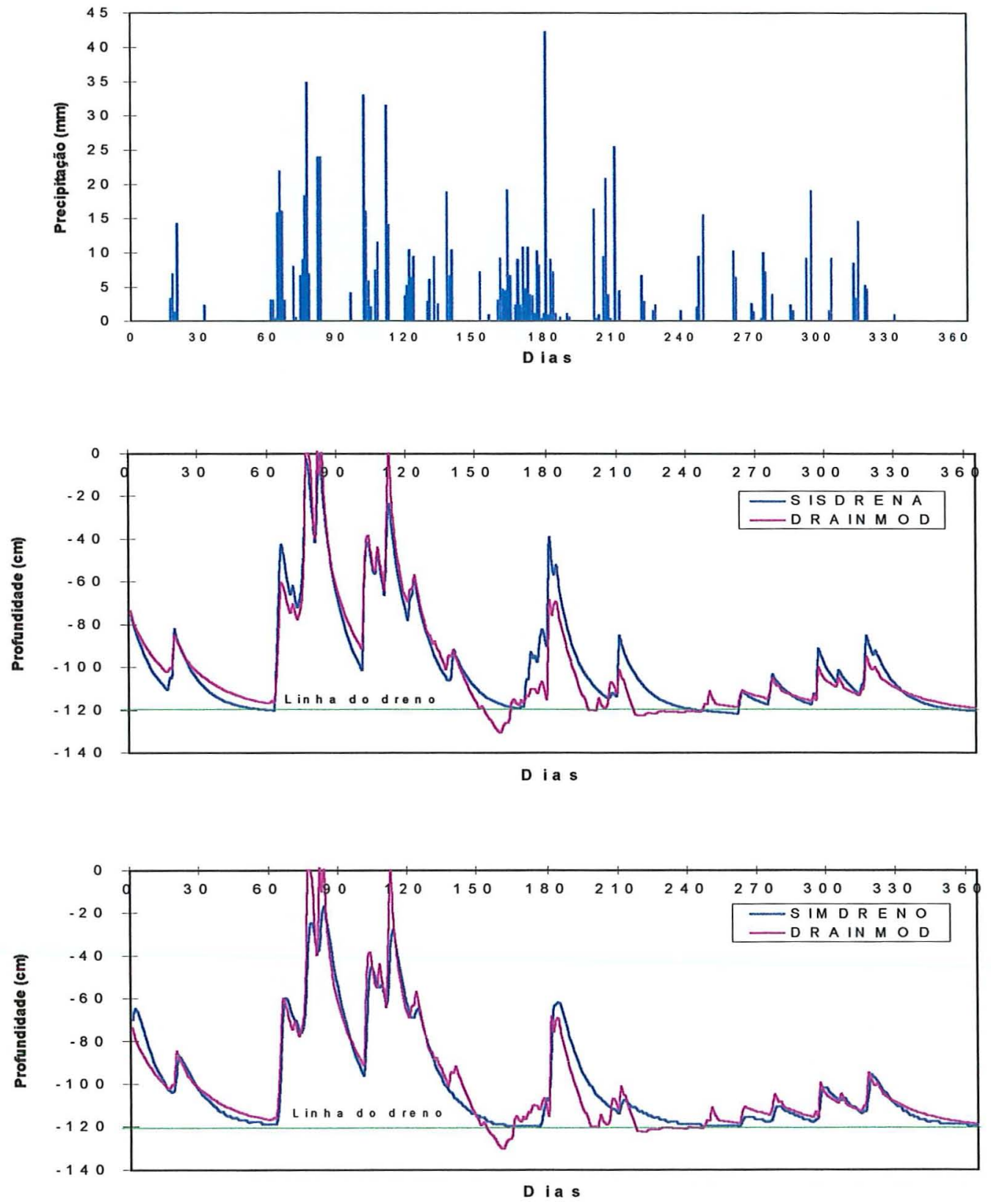

Figura 11 - Pluviograma e profundidades do lençol freático simuladas pelo SISDRENA e SIMDRENO comparadas com DRAINMOD, durante o período de julho de 1983 a julho de 1984 , com espaçamento de $50 \mathrm{~m}$ para o solo 2 

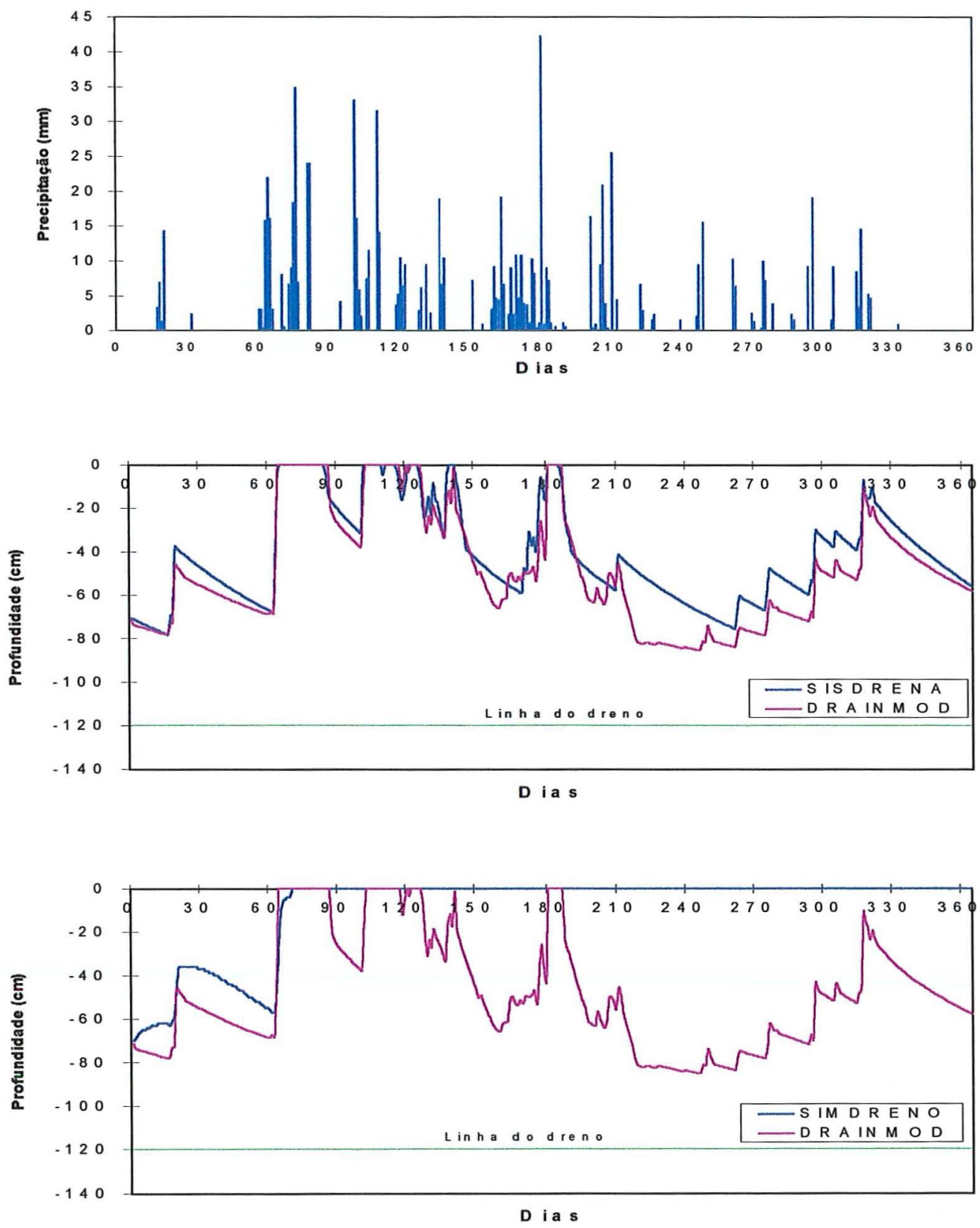

Figura 12 - Pluviograma e profundidades do lençol freático simuladas pelo SISDRENA e SIMDRENO comparadas com DRAINMOD, durante o período de julho de 1983 a julho de 1984, com espaçamento de $80 \mathrm{~m}$ para o solo 3. 
Estas diferenças relativas à vazão, considerando o escoamento superficial, devem-se ao fato do SIMDRENO subestimar o rebaixamento do LF, nestas condições, principalmente para espaçamentos maiores (Tabela 7).

A Figura 13 ilustra uma situação onde houve uma superioridade sensível do SISDRENA em relação ao SIMDRENO, tomando o DRAINMOD como padrão. Nesta figura pode ser observado também que os picos de vazão ocorridos durante 0 período mais chuvoso, quando simulados pelo SISDRENA e pelo SIMDRENO apresentam-se adiantados quando comparados com aqueles simulados pelo DRAINMOD. Como já comentado anteriormente, este resultado deve-se ao fato do DRAINMOD permitir que o tempo necessário para que a recarga pluvial infiltre no solo seja contabilizado.

\subsubsection{Armazenamento de água na zona radicular considerando o escoamento superficial}

O modelo SISDRENA apresentou menores erros padrões em relação ao DRAINMOD do que o SIMDRENO, na maioria dos casos. Para os solos de condutividade hidráulica mais baixa, o desempenho superior do SISDRENA, tomando o DRAINMOD como padrão, foi mais sensível (Tabela 8).

A Figura 14 representa o resultado de simulações onde ambos os modelos tiveram um bom desempenho enquanto na Figura 15 ilustra um caso onde o SISDRENA apresentou-se melhor. Nesta figura observa-se que o SIMDRENO simulou um armazenamento menor do que aquele previsto pelo DRAINMOD. Este resultado possivelmente decorre do efeito da estimativa do escoamento superficial. Como o SIMDRENO calcula este escoamento independente do espaçamento entre drenos, há uma tendência do deflúvio superficial ser superestimado para menores espaçamentos e subestimado para espaçamentos maiores, quando comparado com modelos que contabilizam o efeito da drenagem subterrânea sobre a superficial, tal como o SISDRENA e o DRAINMOD. Na figura em questão a superestimativa do escoamento acarreta uma diminuição da fração da precipitação que infiltra no solo e, consequentemente, um menor armazenamento. 
Tabela 7. Erros padrões entre as vazões diárias simuladas pelo SISDRENA e SIMDRENO, em relação ao DRAINMOD, para diferentes períodos anuais, tipos de solo e espaçamentos, em condições de presença de escoamento superficial.

\begin{tabular}{|c|c|c|c|}
\hline \multirow[t]{2}{*}{ Período anual } & \multirow{2}{*}{$\begin{array}{l}\text { ESPAÇAMENTO } \\
(\mathrm{m})\end{array}$} & \multicolumn{2}{|c|}{ ERRO PADRÃO - q $\left(\mathrm{mm}^{\left.-\mathrm{dia}^{-1}\right)}\right.$} \\
\hline & & SISDRENA & SIMDRENO \\
\hline \multirow{3}{*}{$\begin{array}{l}\text { Solo } 1(\mathrm{Ko}=1,0 \mathrm{~m} / \mathrm{dia}) \\
\text { chuvoso }\end{array}$} & 20 & 0,156 & 0,154 \\
\hline & 50 & 0,042 & 0,055 \\
\hline & 80 & 0,032 & 0,051 \\
\hline \multirow{3}{*}{$\begin{array}{c}\text { Solo } 1(\mathrm{Ko}=1,0 \mathrm{~m} / \mathrm{dia}) \\
\text { seco }\end{array}$} & 20 & 0,056 & 0,060 \\
\hline & 50 & 0,020 & 0,033 \\
\hline & 80 & 0,010 & 0,025 \\
\hline \multirow{3}{*}{$\begin{array}{l}\text { Solo } 1(\mathrm{Ko}=1,0 \mathrm{~m} / \mathrm{dia}) \\
\text { intermediário }\end{array}$} & 20 & 0,165 & 0,151 \\
\hline & 50 & 0,060 & 0,063 \\
\hline & 80 & 0,030 & 0,041 \\
\hline \multirow{3}{*}{$\begin{array}{c}\text { Solo } 2(\mathrm{Ko}=0,5 \mathrm{~m} / \mathrm{dia}) \\
\text { chuvoso }\end{array}$} & 20 & 0,119 & 0,154 \\
\hline & 50 & 0,025 & 0,050 \\
\hline & 80 & 0,010 & 0,057 \\
\hline \multirow{3}{*}{$\begin{array}{c}\text { Solo } 2\left(\begin{array}{c}\mathrm{Ko}=0,5 \mathrm{~m} / \mathrm{dia}) \\
\text { seco }\end{array}\right.\end{array}$} & 20 & 0,055 & 0,055 \\
\hline & 50 & 0,020 & 0,028 \\
\hline & 80 & 0,010 & 0,015 \\
\hline \multirow{3}{*}{$\begin{array}{l}\text { Solo } 2(\mathrm{Ko}=0,5 \mathrm{~m} / \mathrm{dia}) \\
\text { intermediário }\end{array}$} & 20 & 0,166 & 0,157 \\
\hline & 50 & 0,058 & 0,068 \\
\hline & 80 & 0,024 & 0,038 \\
\hline \multirow{3}{*}{$\begin{array}{c}\text { Solo } 3(\mathrm{Ko}=0,1 \mathrm{~m} / \mathrm{dia}) \\
\text { chuvoso }\end{array}$} & 20 & 0,029 & 0,103 \\
\hline & 50 & 0,006 & 0,018 \\
\hline & 80 & 0,002 & 0,015 \\
\hline \multirow{3}{*}{$\begin{array}{c}\text { Solo } 3\left(\begin{array}{c}\mathrm{Ko}=0,1 \mathrm{~m} / \mathrm{dia}) \\
\text { seco }\end{array}\right.\end{array}$} & 20 & 0,021 & 0,052 \\
\hline & 50 & 0,005 & 0,018 \\
\hline & 80 & 0,003 & 0,010 \\
\hline \multirow{3}{*}{$\begin{array}{l}\text { Solo } 3(\mathrm{Ko}=0,1 \mathrm{~m} / \mathrm{dia}) \\
\text { intermediário }\end{array}$} & 20 & 0,053 & 0,080 \\
\hline & 50 & 0,011 & 0,024 \\
\hline & 80 & 0,003 & 0,010 \\
\hline Média & & 0,044 & 0,058 \\
\hline
\end{tabular}



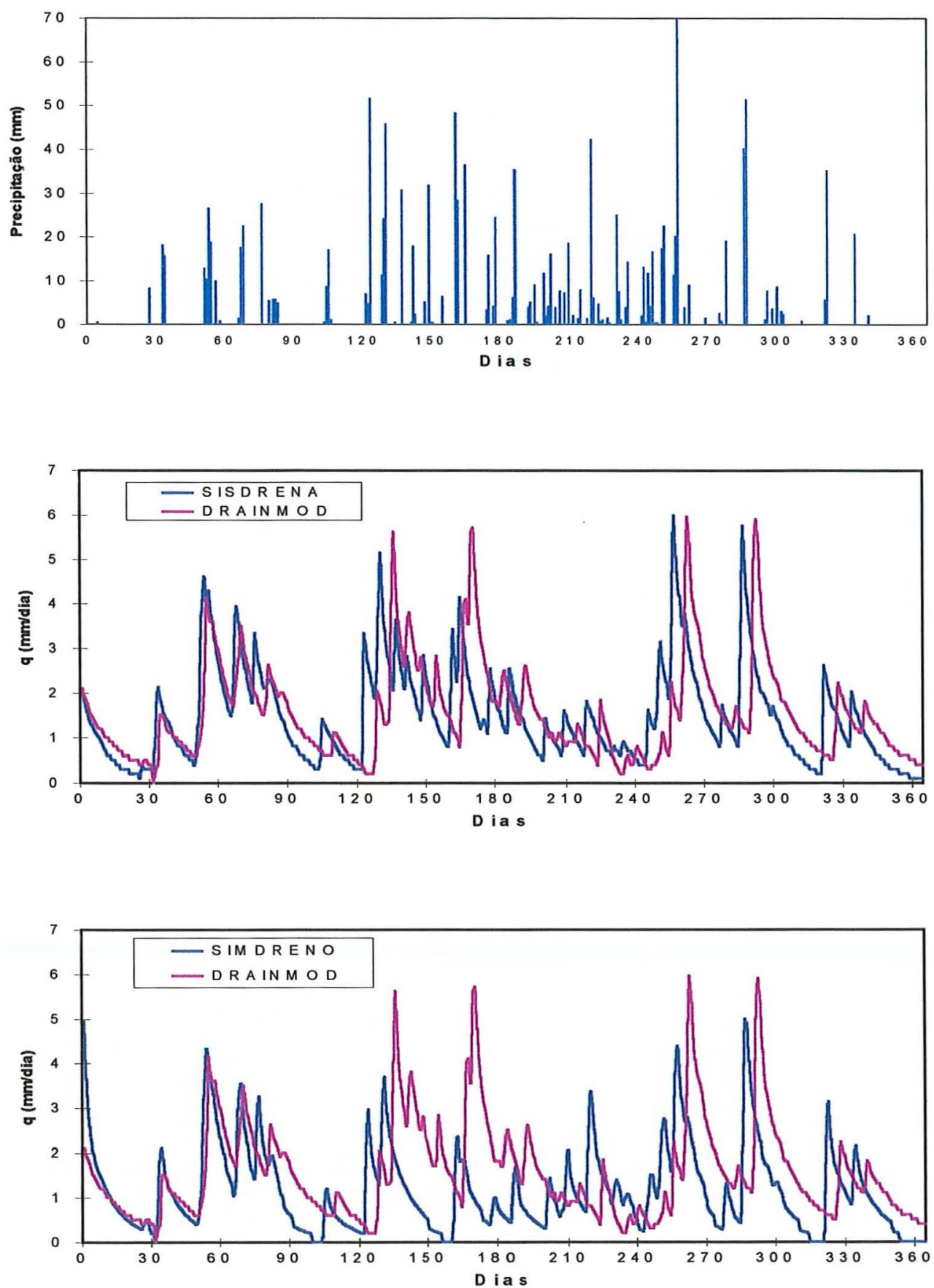

Figura 13 - Pluviograma e vazões diárias por unidade de área simuladas pelo SISDRENA e SIMDRENO comparadas com DRAINMOD, durante o período de julho de 1984 a julho de 1985, com espaçamento de $50 \mathrm{~m}$ para o solo 2 . 
Tabela 8. Erros padrões de armazenamento de água na zona radicular simulado pelo SISDRENA e SIMDRENO, em relação ao DRAINMOD, para diferentes períodos anuais, tipos de solo e espaçamentos, em condições de presença de escoamento superficial.

\begin{tabular}{c|c|c|c}
\hline \multicolumn{2}{c}{ Período anual } & ESPAÇAMENTO & \multicolumn{2}{c}{ ERRO PADRÃO - Armaz. (mm) } \\
\cline { 2 - 4 } & $(\mathbf{m})$ & SISDRENA & SIMDRENO \\
\hline Solo 1 (Ko=1,0 m/dia) & 20 & 1,258 & 1,058 \\
chuvoso & 50 & 1,015 & 1,019 \\
& 80 & 0,504 & 0,616 \\
\hline Solo 1 (Ko=1,0 m/dia) & 20 & 1,065 & 0,961 \\
seco & 50 & 1,013 & 0,950 \\
& 80 & 0,807 & 0,654 \\
\hline Solo 1 (Ko=1,0 m/dia) & 20 & 1,326 & 1,138 \\
intermediário & 50 & 1,208 & 1,068 \\
& 80 & 0,937 & 0,870 \\
\hline Solo 2 (Ko=0,5 m/dia) & 20 & 0,604 & 0,589 \\
chuvoso & 50 & 0,352 & 0,440 \\
& 80 & 0,168 & 0,222 \\
\hline Solo 2 (Ko=0,5 m/dia) & 20 & 0,390 & 0,377 \\
seco & 50 & 0,329 & 0,364 \\
& 80 & 0,208 & 0,560 \\
\hline Solo 2 (Ko=0,5 m/dia) & 20 & 0,710 & 0,676 \\
intermediário & 50 & 0,618 & 0,533 \\
& 80 & 0,382 & 0,270 \\
\hline Solo 3 (Ko=0,1 m/dia) & 20 & 0,281 & 0,484 \\
chuvoso & 50 & 0,098 & 0,210 \\
& 80 & 0,051 & 0,186 \\
\hline Solo 3 (Ko=0,1 m/dia) & 20 & 0,267 & 0,310 \\
seco & 50 & 0,165 & 0,813 \\
& 80 & 0,170 & 0,818 \\
\hline Solo 3 (Ko=0,1 m/dia) & 20 & 0,542 & 0,595 \\
intermediário & 50 & 0,291 & 0,278 \\
& 80 & 0,244 & 0,230 \\
\hline Média & & $\mathbf{0 , 5 5 5}$ & $\mathbf{0 , 6 0 3}$ \\
\hline & & & \\
\hline
\end{tabular}



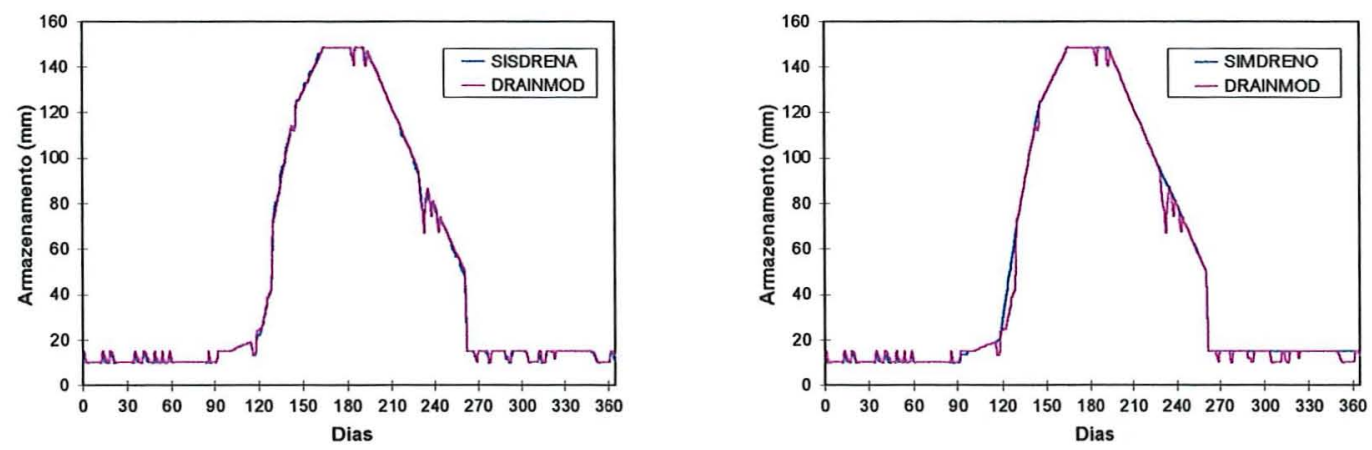

Figura 14 - Armazenamento de água na zona radicular simulado pelo SISDRENA e SIMDRENO comparado com DRAINMOD, durante o período de julho de 1982 a julho de 1983, com espaçamento de $80 \mathrm{~m}$ para o solo 3.
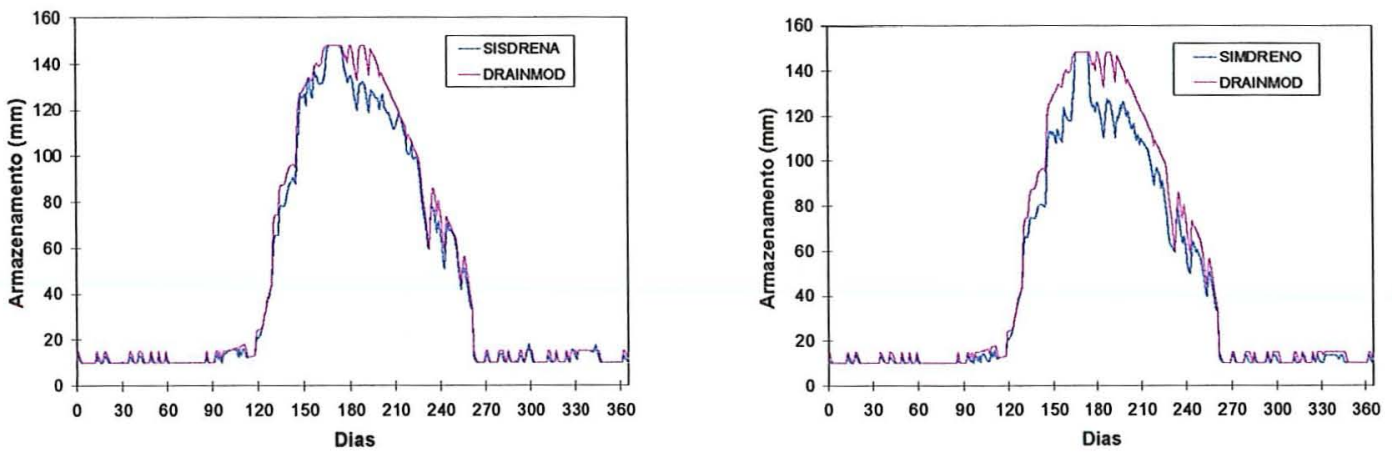

Figura 15 - Armazenamento de água na zona radicular simulado pelo SISDRENA e SIMDRENO comparado com DRAINMOD, durante o período de julho de 1982 a julho de 1983, com espaçamento de $20 \mathrm{~m}$ para o solo 3. 


\subsubsection{Evapotranspiração real considerando o escoamento superficial}

Praticamente não houve diferença sensível entre o SISDRENA e o SIMDRENO, com relação ao DRAINMOD. A maior diferença ocorrida para o parâmetro evapotranspiração foi observada quando utilizou-se espaçamentos maiores no solo de condutividade hidráulica menor, o que possivelmente deve-se ao fato do SISDRENA simular posições do LF e escoamento superficial com menores desvios em relação ao DRAINMOD, nestas condições.

A Tabela 9 e a Figura 16 mostram respectivamente os valores de erros padrões e o resultado gráfico de uma das simulações.

\section{3 Índices anuais de desempenho em condições de ausência de escoamento superficial}

Foram realizadas comparações de comportamento dos modelos SISDRENA e SIMDRENO em relação ao DRAINMOD, simulando-se os índices $\mathrm{SEW}_{30}$, número de dias secos e produtividade total anual, usando a série de dados meteorológicos de 21 anos para o município de Piracicaba-SP, dados de sensibilidade da cultura de milho considerando-se ausência de escoamento superficial.

A Figura 17 mostra as dispersões dos pontos que representam o índice $\mathrm{SEW}_{30}$, simulados com o SISDRENA e o SIMDRENO, quando comparados com o DRAINMOD, em torno da reta $\mathrm{X}=\mathrm{Y}$, assim como as equações de regressão, o coeficiente de determinação e o índice ID.

Pode-se observar que as simulações realizadas com o SISDRENA apresentaram menor dispersão do que aquelas obtidas com o SIMDRENO quando comparadas com o DRAINMOD para os dois tipos de solo. O SIMDRENO apresentou uma tendência de superestimar valores mais altos de $\mathrm{SEW}_{30}$, principalmente no solo 2, que apresenta uma condutividade hidráulica menor. Este resultado decorre do fato do SIMDRENO subestimar o rebaixamento do LF quando comparado com o DRAINMOD quando o coeficiente de armazenamento $(\mathrm{J})$ é elevado, conforme relatado anteriormente. Nestas condições a drenagem é mais lenta e o índice $\mathrm{SEW}_{30}$ tende a ser elevado. 
Tabela 9. Erros padrões da evapotranspiração real simulada pelo SISDRENA e SIMDRENO, em relação ao DRAINMOD, para diferentes períodos anuais, tipos de solo e espaçamentos, em condições de presença de escoamento superficial.

\begin{tabular}{c|c|c|c}
\hline Período anual & ESPAÇAMENTO & \multicolumn{2}{c}{ ERRO PADRÃO-ETR (mm) } \\
\cline { 3 - 4 } & $(\mathbf{m})$ & SISDRENA & SIMDRENO \\
\hline Solo 1 $(\mathrm{Ko}=1,0 \mathrm{~m} /$ dia $)$ & 20 & 0,045 & 0,046 \\
chuvoso & 50 & 0,039 & 0,042 \\
& 80 & 0,034 & 0,037 \\
\hline Solo 1 $(\mathrm{Ko}=1,0 \mathrm{~m} /$ dia) & 20 & 0,047 & 0,050 \\
seco & 50 & 0,057 & 0,061 \\
& 80 & 0,045 & 0,049 \\
\hline Solo 1 (Ko=1,0 m/dia) & 20 & 0,074 & 0,073 \\
intermediário & 50 & 0,066 & 0,065 \\
& 80 & 0,060 & 0,058 \\
\hline Solo 2 (Ko=0,5 m/dia) & 20 & 0,044 & 0,047 \\
chuvoso & 50 & 0,040 & 0,042 \\
& 80 & 0,040 & 0,049 \\
\hline Solo 2 (Ko=0,5 m/dia) & 20 & 0,059 & 0,052 \\
seco & 50 & 0,055 & 0,050 \\
& 80 & 0,052 & 0,069 \\
\hline Solo 2 (Ko=0,5 m/dia) & 20 & 0,068 & 0,069 \\
intermediário & 50 & 0,067 & 0,068 \\
& 80 & 0,060 & 0,065 \\
\hline Solo 3 (Ko=0,1 m/dia) & 20 & 0,043 & 0,055 \\
chuvoso & 50 & 0,042 & 0,057 \\
& 80 & 0,036 & 0,053 \\
\hline Solo 3 (Ko=0,1 m/dia) & 20 & 0,053 & 0,054 \\
seco & 50 & 0,044 & 0,098 \\
& 80 & 0,047 & 0,117 \\
\hline Solo 3 (Ko=0,1 m/dia) & 20 & 0,070 & 0,072 \\
intermediário & 50 & 0,065 & 0,082 \\
& 80 & 0,068 & 0,078 \\
\hline Média & & $\mathbf{0 , 0 5 2}$ & $\mathbf{0 , 0 6 1}$ \\
\hline & & & \\
\hline & & & \\
\hline
\end{tabular}



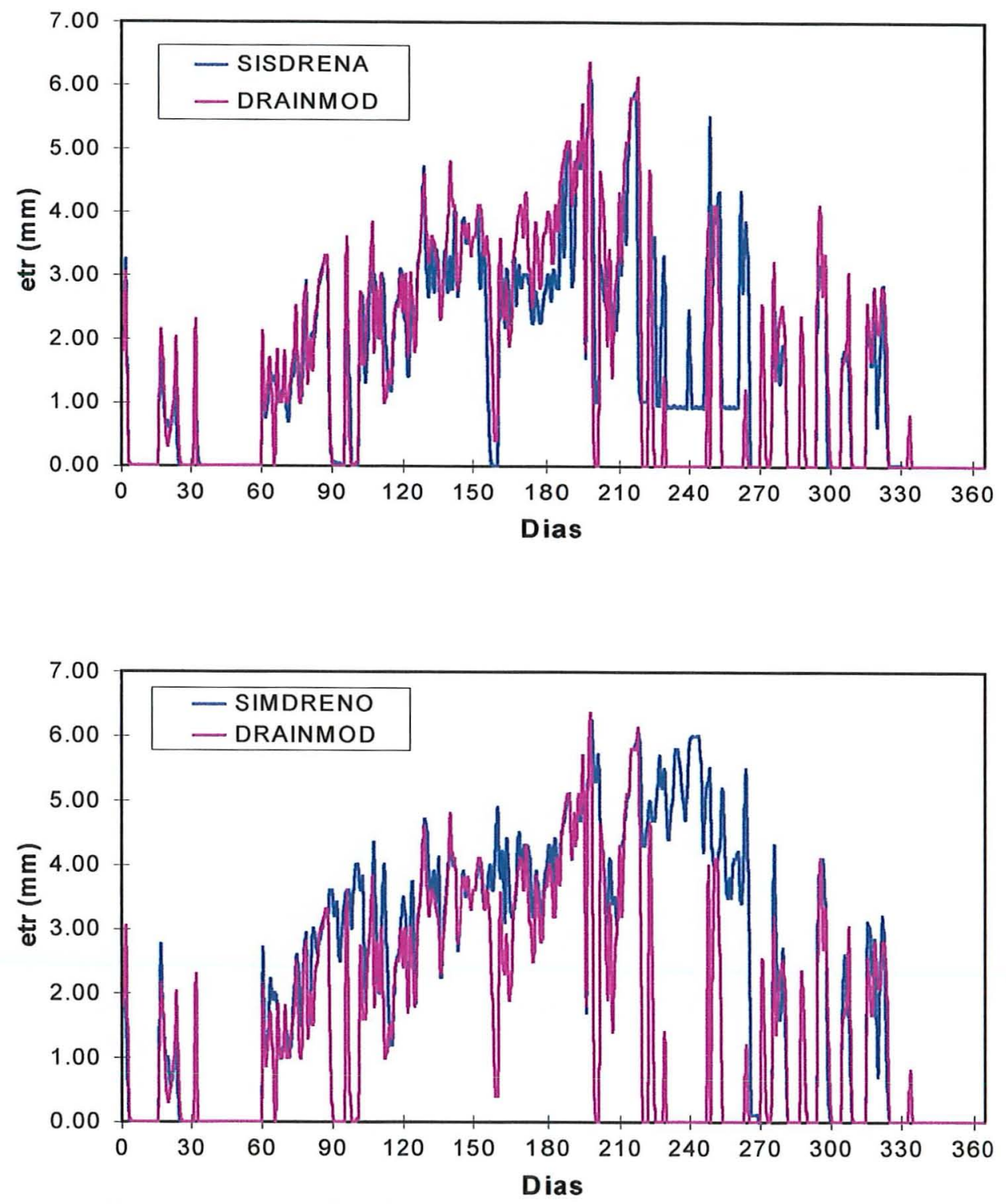

Figura 16 - Evapotranspiração real simulada pelo SISDRENA e SIMDRENO comparada com DRAINMOD, durante o período de julho de 1983 a julho de 1984, com espaçamento de $50 \mathrm{~m}$ para o solo 3. 
SOLO 1 - SISDRENA

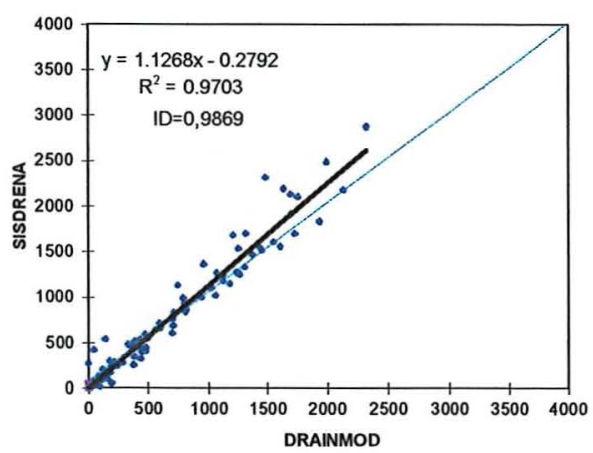

SOLO 2 - SISDRENA

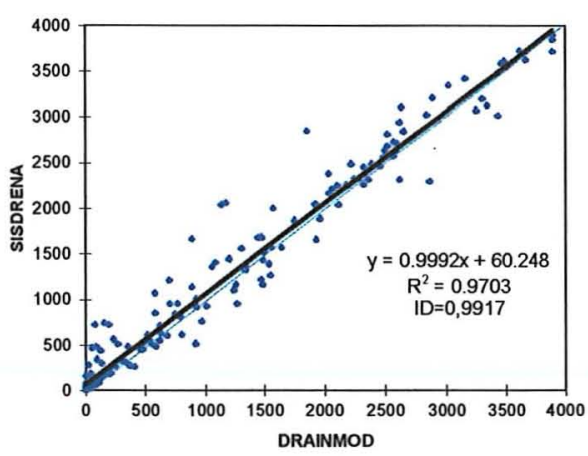

SOLO 1 - SIMDRENO

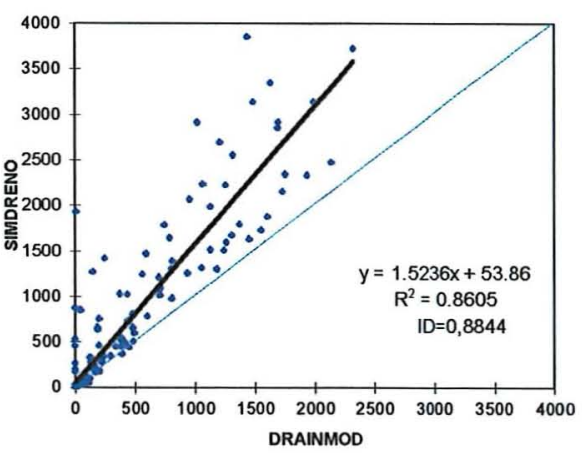

SOLO 2 - SIMDRENO

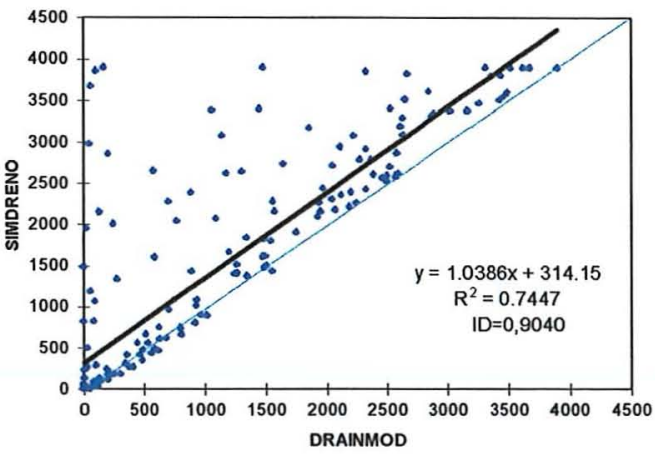

Figura 17 - Gráficos de dispersão do índice $\mathrm{SEW}_{30}$ (cm.dia) em torno da reta $\mathrm{X}=\mathrm{Y}$, mostrando o desempenho dos modelos SISDRENA e SIMDRENO em relação ao DRAINMOD, para as simulações realizadas com os solos 1 e 2 . 
A Figura 18 apresenta a dispersão dos pontos representativos do número de dias secos em torno da reta $\mathrm{X}=\mathrm{Y}$, simulados com o SISDRENA e o SIMDRENO, quando comparado com o DRAINMOD.

Verifica-se que para ambos os modelos os coeficientes de determinação foram menores do que aqueles obtidos nas comparações do índice $\mathrm{SEW}_{30}$. Este resultado possivelmente se deve ao fato do DRAINMOD considerar que o solo permanece saturado após o rebaixamento do LF (Rogers, 1985), enquanto que o SISDRENA e o SIMDRENO consideram que este atinge a capacidade de campo, conforme discutido anteriormente.

Pode-se observar também que de um modo geral os números de dias secos simulados pelo SISDRENA apresentaram menor dispersão do que os simulados pelo modelo SIMDRENO, quando comparado com o DRAINMOD, principalmente para o solo 2. Este resultado possivelmente é consequência da estimativa das posições do LF.

$\mathrm{Na}$ Figura 19 pode ser observada a dispersão dos pontos representativos da produtividade relativa anual para a cultura do milho simulada pelo SISDRENA e pelo SIMDRENO quando comparada com o DRAINMOD. Como consequência do fato do SISDRENA ter simulado as condições de excesso de umidade $\left(\mathrm{SEW}_{30}\right)$ e déficit hídrico (número de dias secos) com menores desvios em relação ao DRAINMOD, a produtividade relativa anual, que é influenciada por ambos efeitos, também seguiu a mesma tendência.

\section{4 Índices anuais de desempenho em condições de existência de escoamento superficial.}

As Figuras 20, 21 e 22 apresentam as dispersões dos pontos relativos às comparações do $\mathrm{SEW}_{30}$, número de dias secos e produtividade relativa anual, respectivamente, considerando a existência de escoamento superficial.

Observa-se que, tomando o DRAINMOD como padrão, a superioridade do SISDRENA em relação ao SIMDRENO aumentou, quando se compara com a condição de ausência de escoamento superficial. Este resultado se deve ao fato do SIMDRENO não considerar o efeito da variação do espaçamento entre drenos sobre a 
SOLO 1 - SISDRENA

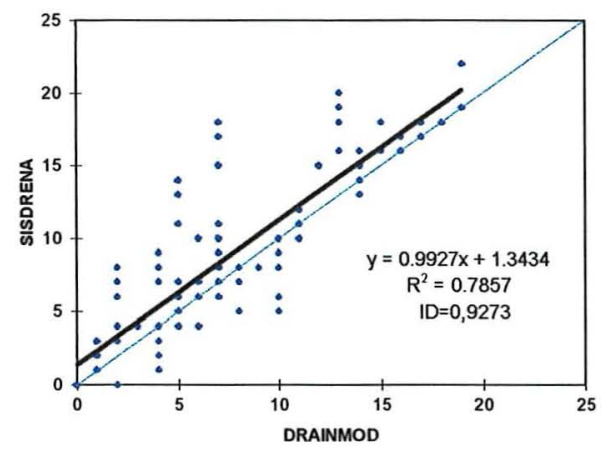

SOLO 2 - SISDRENA

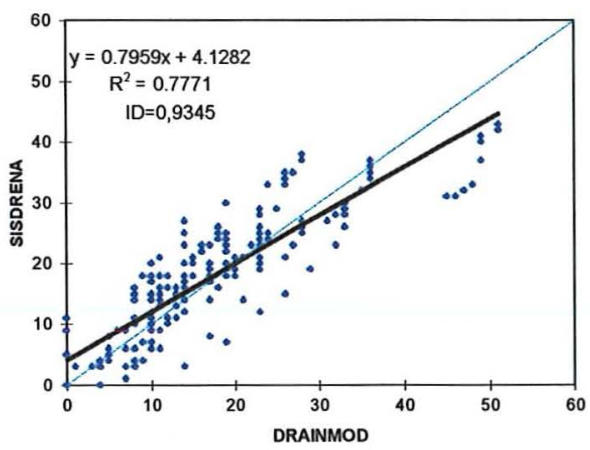

SOLO 1 - SIMDRENO

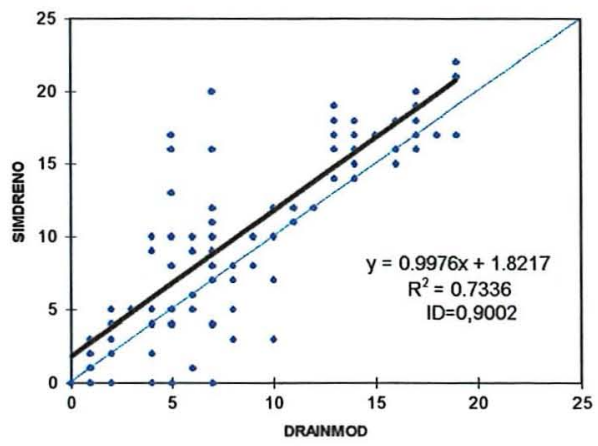

SOLO 2 - SIMDRENO

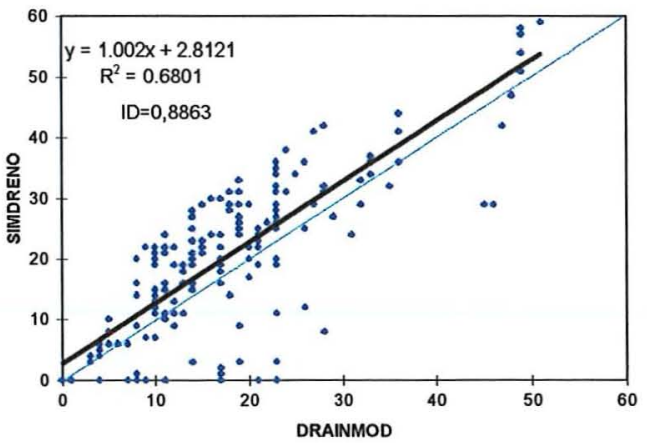

Figura 18- Gráficos de dispersão do índice número de dias secos em torno da reta $\mathrm{X}=\mathrm{Y}$, mostrando o desempenho dos modelos SISDRENA e SIMDRENO em relação ao DRAINMOD, para as simulações realizadas com os solos 1 e 2 . 
SOLO 1 - SISDRENA

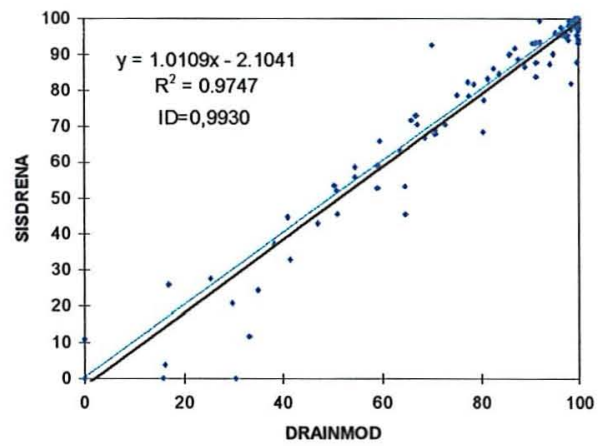

SOLO 2 - SISDRENA

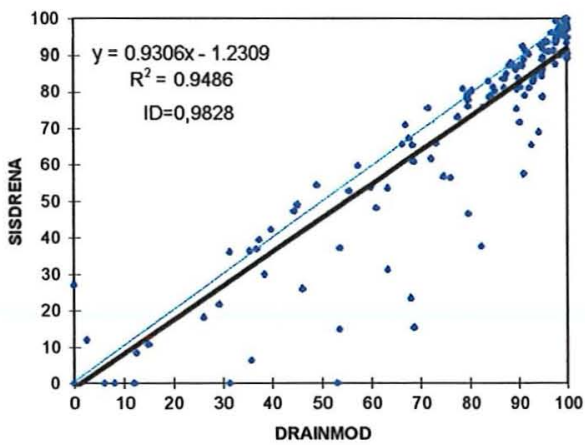

SOLO 1 - SIMDRENO

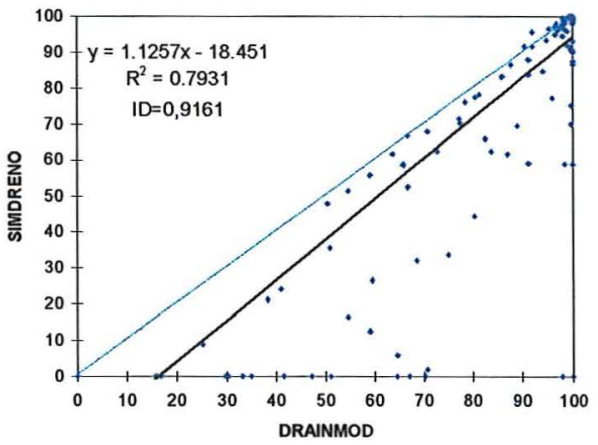

SOLO 2 - SIMDRENO

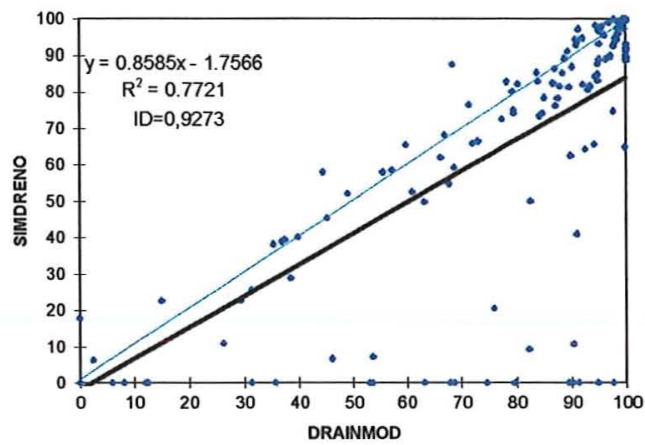

Figura 19 - Gráficos de dispersão da produtividade relativa anual (\%), para a cultura do milho, em torno da reta $\mathrm{X}=\mathrm{Y}$, mostrando o desempenho dos modelos SISDRENA e SIMDRENO em relação ao DRAINMOD, para as simulações realizadas com os solos 1 e 2 . 
SOLO 1 - SISDRENA

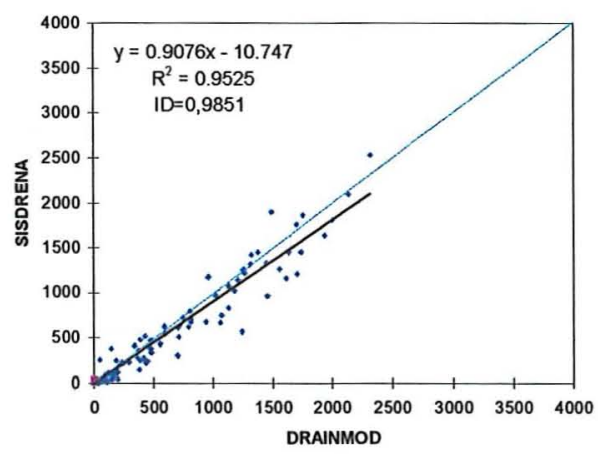

SOLO 2 - SISDRENA

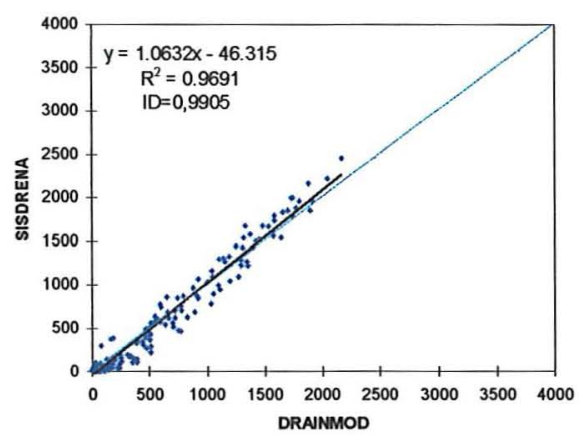

SOLO 3 - SISDRENA

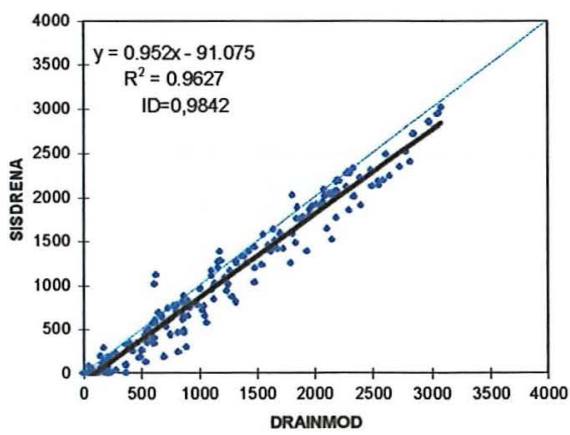

SOLO 1 - SIMDRENO

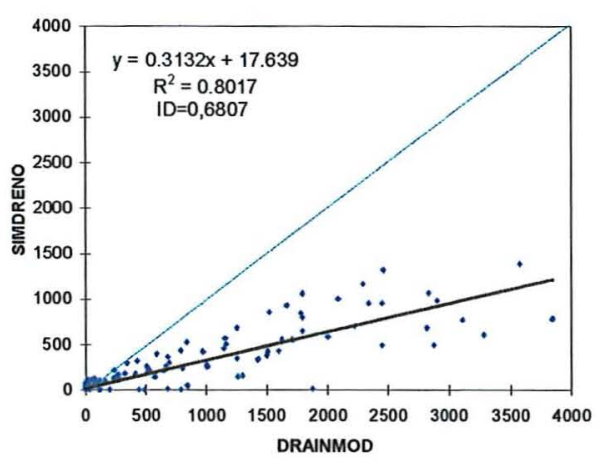

SOLO 2 - SIMDRENO

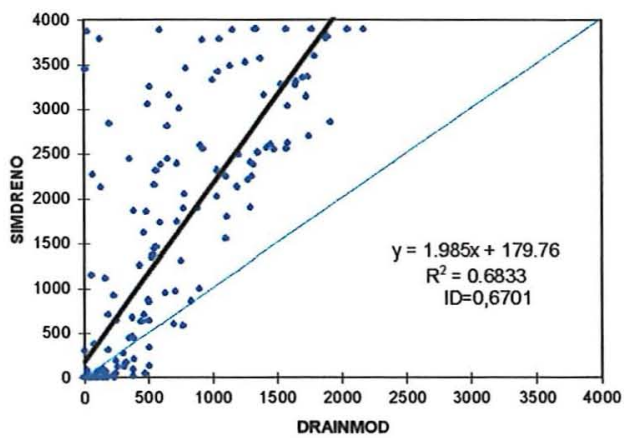

SOLO 3 - SIMDRENO

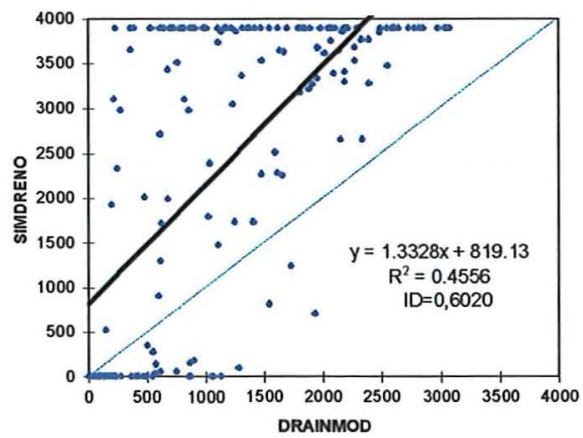

Figura 20 - Gráficos de dispersão do índice $\mathrm{SEW}_{30}$ em torno da reta $\mathrm{X}=\mathrm{Y}$, mostrando o desempenho dos modelos SISDRENA e SIMDRENO em relação ao DRAINMOD, para as simulações realizadas com os solos 1,2 e 3. 
SOLO 1 - SISDRENA

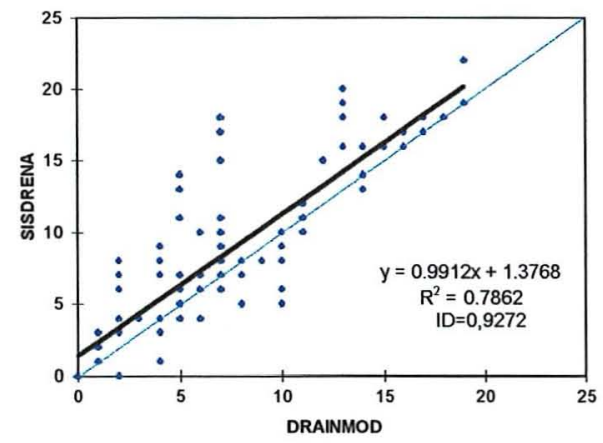

SOLO 2 - SISDRENA

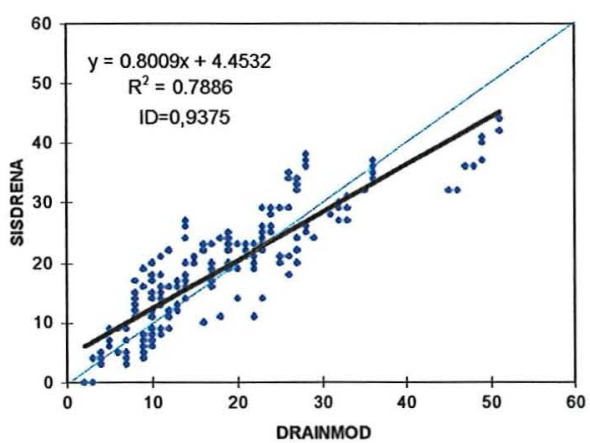

SOLO 3 - SISDRENA

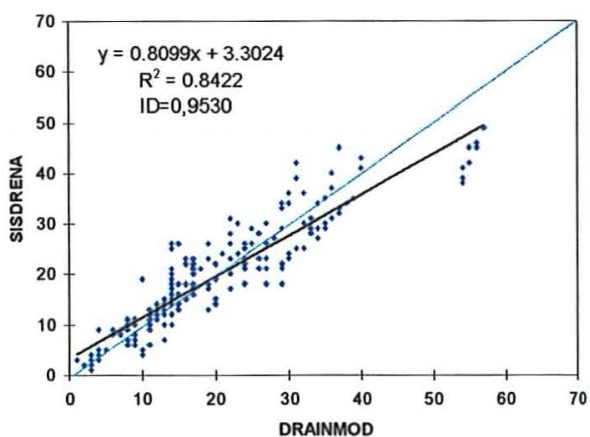

SOLO 1 - SIMDRENO

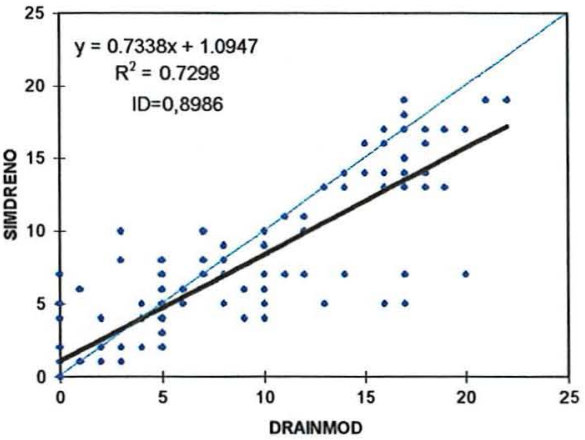

SOLO 2 - SIMDRENO

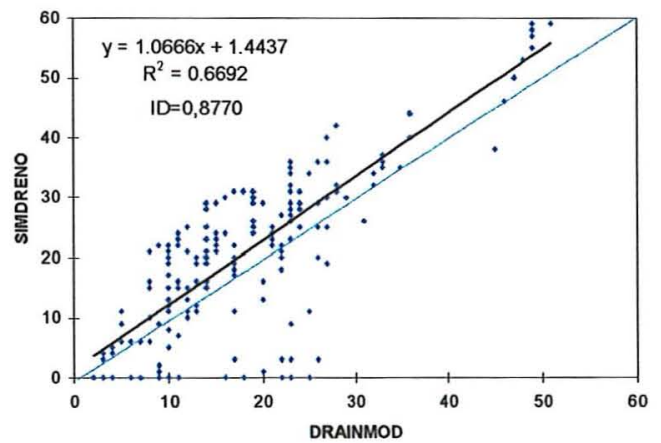

SOLO 3 - SIMDRENO

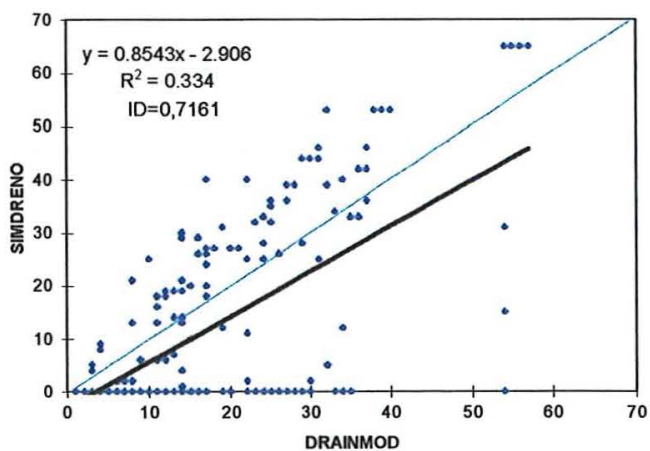

Figu ra 21 - Gráficos de dispersão do índice número de dias secos em torno da reta $\mathrm{X}=\mathrm{Y}$, mostrando o desempenho dos modelos SISDRENA e SIMDRENO em relação ao DRAINMOD,para as simulações realizadas com os solos 1,2 e 3 . 
SOLO 1 - SISDRENA

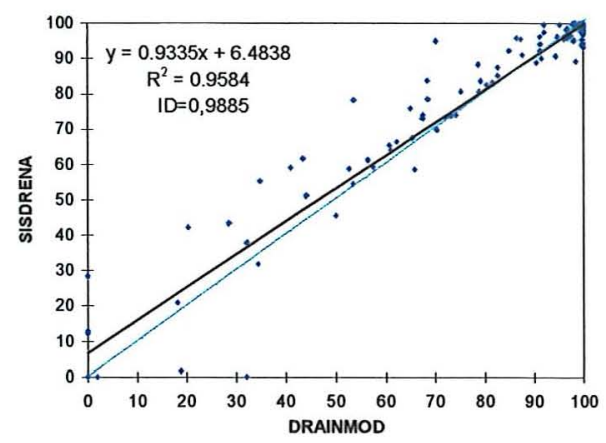

SOLO 2 - SISDRENA

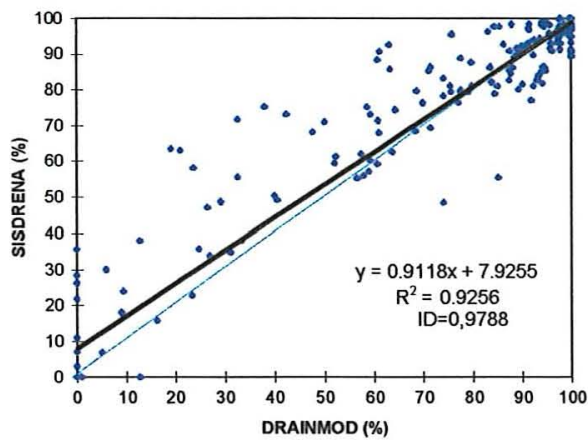

SOLO 3 - SISDRENA

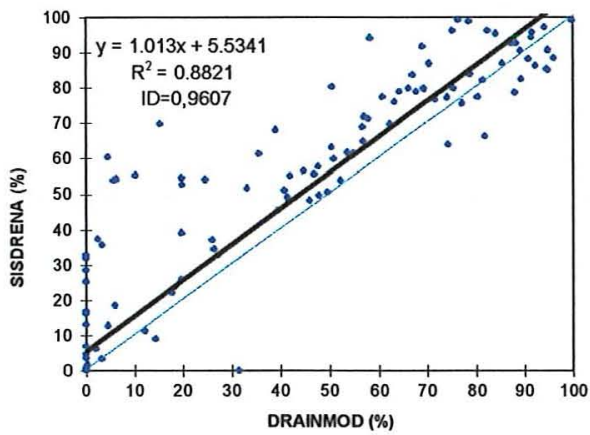

SOLO 1 - SIMDRENO

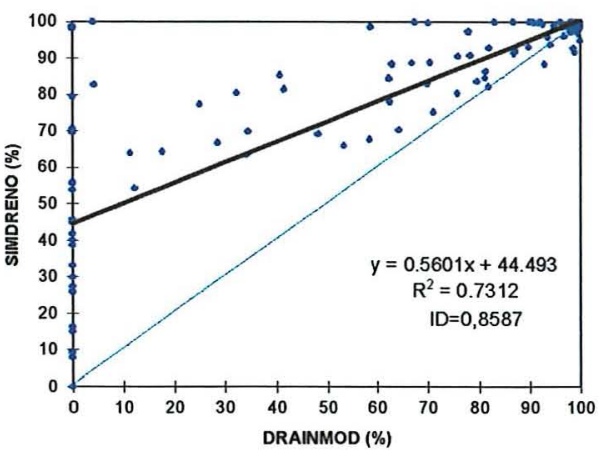

SOLO 2 - SIMDRENO

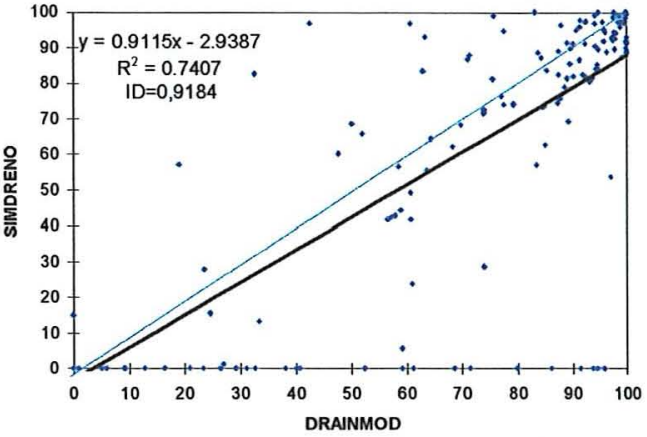

SOLO 3 - SIMDRENO

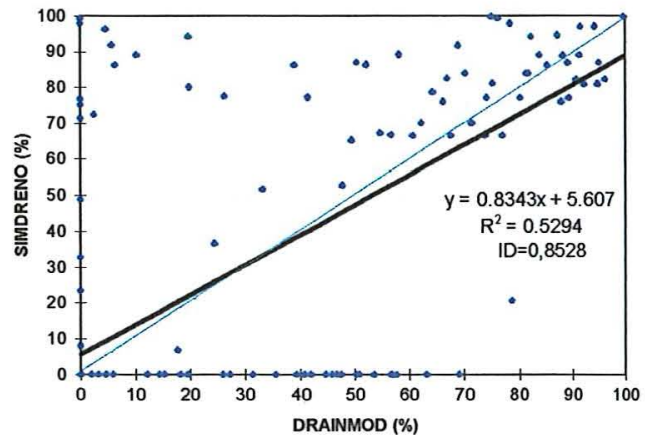

Figura 22 - Gráficos de dispersão da produtividade relativa anual (\%), para a cultura do milho, em torno da reta $\mathrm{X}=\mathrm{Y}$, mostrando o desempenho dos modelos SISDRENA e SIMDRENO em relação ao DRAINMOD, para as simulações realizadas com os solos 1,2 e 3 . 
magnitude do escoamento superficial, conforme discutido anteriormente. Pode-se observar também que houve um ligeiro aumento da dispersão para ambos os modelos quando comparada com a condição de ausência de escoamento. Este resultado é consequência do fato do SISDRENA e do SIMDRENO estimarem o escoamento superficial de forma diferente daquela empregada pelo DRAINMOD, conforme observações já comentadas.

Verifica-se ainda que quanto menor a condutividade hidráulica do solo, maior é a dificuldade dos modelos que utilizam chuvas de um dia em acompanharem as simulações do DRAINMOD devido ao aumento de ocorrência de escoamento superficial e de situações em que o LF se posiciona sobre a superficie do solo, pois nestes casos os modelos utilizam processos de simulação diferentes.

\subsection{Dimensionamento econômico do sistema de drenagem}

O dimensionamento econômico visa principalmente determinar qual o espaçamento que propiciará o maior retorno financeiro para o produtor, o qual é função principalmente da possibilidade da cultura atingir altas produtividades, da receita gerada pela produção e do custo do sistema de drenagem necessário para obtê-las.

Normalmente, na prática, os produtores vêm utilizando espaçamentos maiores do que aqueles obtidos por critérios de drenagem tradicionais, como os preconizados por Pizarro (1978) e Cruciani (1987).

\subsubsection{Estimativa das produtividades médias e prováveis para a cultura do milho em condições de ausência de escoamento superficial.}

As Tabelas 10 e 11 apresentam os valores de produtividade média dos 21 anos de simulação, para cada espaçamento entre drenos, para a cultura do milho, estimadas para o solo 1 e 2, respectivamente, pelo SISDRENA, SIMDRENO e DRAINMOD. A Figura 23 mostra a representação gráfica destes resultados. 
Tabela 10.Valores de produtividade relativa média (Ytm), para a cultura do milho, em função do espaçamento entre drenos, obtidos pelos três modelos para o solo $1(\mathrm{Ko}=1 \mathrm{~m} / \mathrm{dia})$ em condições de ausência de escoamento superficial.

\begin{tabular}{cccccc}
\hline \multicolumn{2}{c}{ SISDRENA } & \multicolumn{2}{c}{ DRAINMOD } & \multicolumn{2}{c}{ SIMDRENO } \\
\hline Espaçamento & YTm \% & Espaçamento & YTm \% & Espaçamento & YTm \% \\
\hline 10 & 99.11 & 10 & 100 & 10 & 99.28 \\
20 & 99.14 & 20 & 99.97 & 20 & 99.28 \\
30 & 98.88 & 30 & 99.72 & 30 & 99.08 \\
40 & 98.15 & 40 & 98.54 & 40 & 97.98 \\
50 & 94.98 & 50 & 95.47 & 50 & 94.52 \\
60 & 89.26 & 60 & 90.46 & 60 & 83.50 \\
70 & 77.70 & 70 & 79.08 & 70 & 65.03 \\
80 & 65.53 & 80 & 67.73 & 80 & 52.10 \\
90 & 58.61 & 90 & 61.50 & 90 & 43.94 \\
100 & 53.50 & 100 & 54.19 & 100 & 33.84 \\
\hline
\end{tabular}

Tabela 11.Valores de produtividade relativa média (Ytm), para a cultura do milho, em função do espaçamento entre drenos, obtidos pelos três modelos para o solo $2(\mathrm{Ko}=0,5 \mathrm{~m} / \mathrm{dia})$ em condições de ausência de escoamento superficial.

\begin{tabular}{cccccc}
\hline \multicolumn{2}{c}{ SISDRENA } & \multicolumn{2}{c}{ DRAINMOD } & \multicolumn{2}{c}{ SIMDRENO } \\
\hline Espaçamento & YTm \% & Espaçamento & YTm \% & Espaçamento & YTm \% \\
\hline 10 & 91.88 & 10 & 96.36 & 10 & 91.02 \\
20 & 89.85 & 20 & 93.90 & 20 & 89.77 \\
30 & 80.77 & 30 & 84.25 & 30 & 83.32 \\
40 & 58.93 & 40 & 62.36 & 40 & 60.17 \\
50 & 44.75 & 50 & 48.30 & 50 & 41.55 \\
60 & 35.04 & 60 & 39.85 & 60 & 32.15 \\
70 & 28.35 & 70 & 31.56 & 70 & 23.15 \\
80 & 22.63 & 80 & 28.93 & 80 & 11.24 \\
90 & 17.50 & 90 & 25.77 & 90 & 5.26 \\
100 & 13.92 & 100 & 21.62 & 100 & 2.32 \\
\hline
\end{tabular}




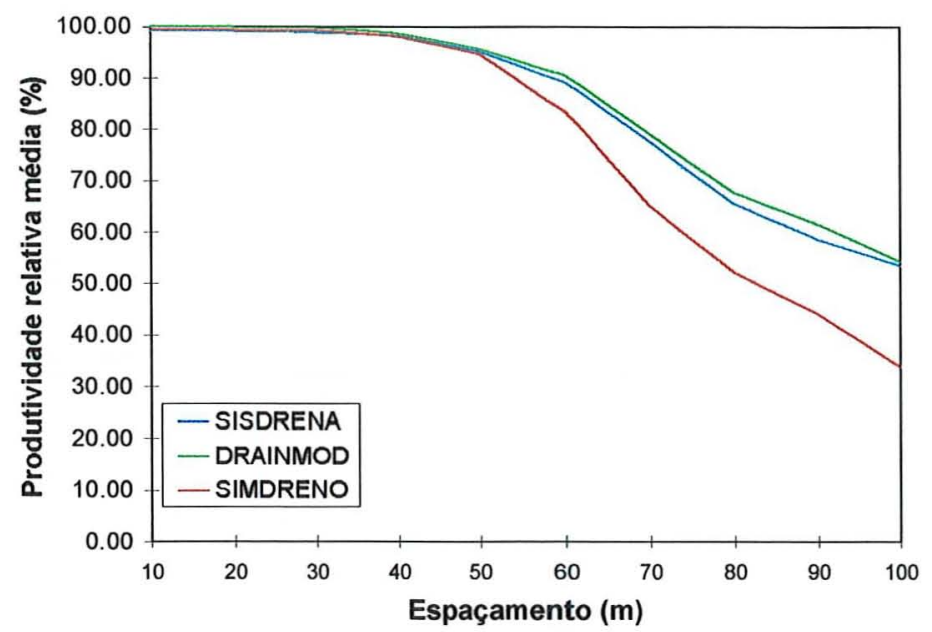

Solo 1

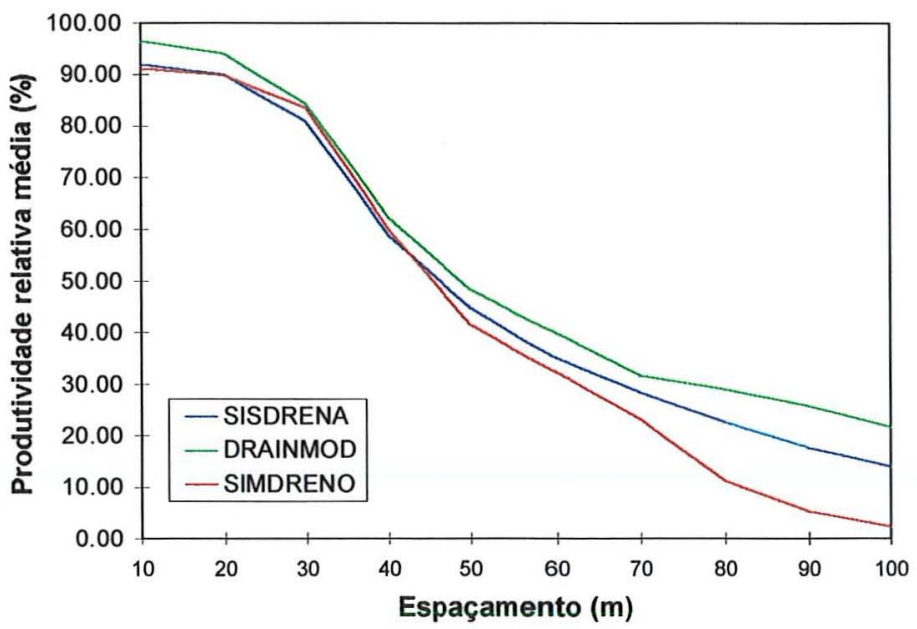

Solo 2

Figura 23 - Produtividades relativas médias para a cultura do milho em função do espaçamento entre drenos, obtidas pelo SISDRENA, SIMDRENO e DRAINMOD para os solos 1 e 2 em condições de ausência de escoamento superficial.

Observa-se que para o solo 1, que apresenta condutividade hidráulica mais alta, produtividades relativas médias maiores ou iguais a cerca de 90 \% são esperadas para espaçamentos de até 50 metros. Já para o solo 2, que apresenta menor condutividade hidráulica, este valor de espaçamento cai para cerca de 20 metros. 
Verifica-se também que o SIMDRENO tendeu a subestimar as produtividades, em relação ao DRAINMOD, quando foram utilizados espaçamentos maiores nas simulações, o que é uma consequência da subestimativa do rebaixamento do LF. As Tabelas 12 e 13 apresentam os valores das produtividades esperadas com $80 \%$ de probabilidade de sucesso, estimadas para o solo 1 e 2, respectivamente, pelo SISDRENA, SIMDRENO e DRAINMOD. A Figura 24 mostra a representação gráfica destes resultados.

Tabela 12. Valores de produtividade provável, para a cultura do milho, em função do espaçamento entre drenos, obtidos pelos três modelos para o solo 1 $(\mathrm{Ko}=1 \mathrm{~m} / \mathrm{dia})$ em condições de ausência de escoamento superficial.

\begin{tabular}{cccccc}
\hline \multicolumn{2}{c}{ SISDRENA } & \multicolumn{2}{c}{ DRAINMOD } & \multicolumn{2}{c}{ SIMDRENO } \\
\hline Espaçamento & YT 80\% & Espaçamento & YT 80\% & Espaçamento & YT 80\% \\
\hline 10 & 97,68 & 10 & 100,00 & 10 & 97,43 \\
20 & 97,78 & 20 & 99,86 & 20 & 97,44 \\
30 & 97,45 & 30 & 99,08 & 30 & 97,27 \\
40 & 95,65 & 40 & 96,13 & 40 & 95,04 \\
50 & 88,80 & 50 & 88,42 & 50 & 87,20 \\
60 & 77,15 & 60 & 78,14 & 60 & 65,49 \\
70 & 55,46 & 70 & 58,03 & 70 & 32,75 \\
80 & 33,91 & 80 & 37,12 & 80 & 16,00 \\
90 & 23,99 & 90 & 27,84 & 90 & 7,81 \\
100 & 17,36 & 100 & 18,19 & 100 & 0,00 \\
\hline
\end{tabular}

Tabela 13. Valores de produtividade provável, para a cultura do milho, em função do espaçamento entre drenos, obtidos pelos três modelos para o solo 2 $(\mathrm{Ko}=0,5 \mathrm{~m} / \mathrm{dia})$ em condições de ausência de escoamento superficial.

\begin{tabular}{cccccc}
\hline \multicolumn{2}{c}{ SISDRENA } & \multicolumn{2}{c}{ DRAINMOD } & \multicolumn{2}{c}{ SIMDRENO } \\
\hline Espaçamento & YT 80\% & Espaçamento & YT 80\% & Espaçamento & YT 80\% \\
\hline 10 & 86,22 & 10 & 91,82 & 10 & 84,18 \\
20 & 83,91 & 20 & 88,97 & 20 & 82,71 \\
30 & 68,89 & 30 & 71,64 & 30 & 73,37 \\
40 & 30,83 & 40 & 32,98 & 40 & 33,70 \\
50 & 11,35 & 50 & 12,55 & 50 & 8,61 \\
60 & 1,82 & 60 & 4,69 & 60 & 0 \\
70 & 0 & 70 & 0 & 70 & 0 \\
80 & 0 & 80 & 0 & 80 & 0 \\
90 & 0 & 90 & 0 & 90 & 0 \\
100 & 0 & 100 & 0 & 100 & 0 \\
\hline
\end{tabular}


Comparando as Figuras 23 e 24 verifica-se que para espaçamentos maiores a produtividade provável é consideravelmente menor que a média, o que é um reflexo de se ter exigido uma maior probabilidade de sucesso. Para o solo 1 pode-se identificar a tendência do SIMDRENO subestimar as produtividades à medida em que os espaçamentos aumentam. No caso do solo 2 os espaçamentos maiores propiciaram produtividades nulas para os três modelos.

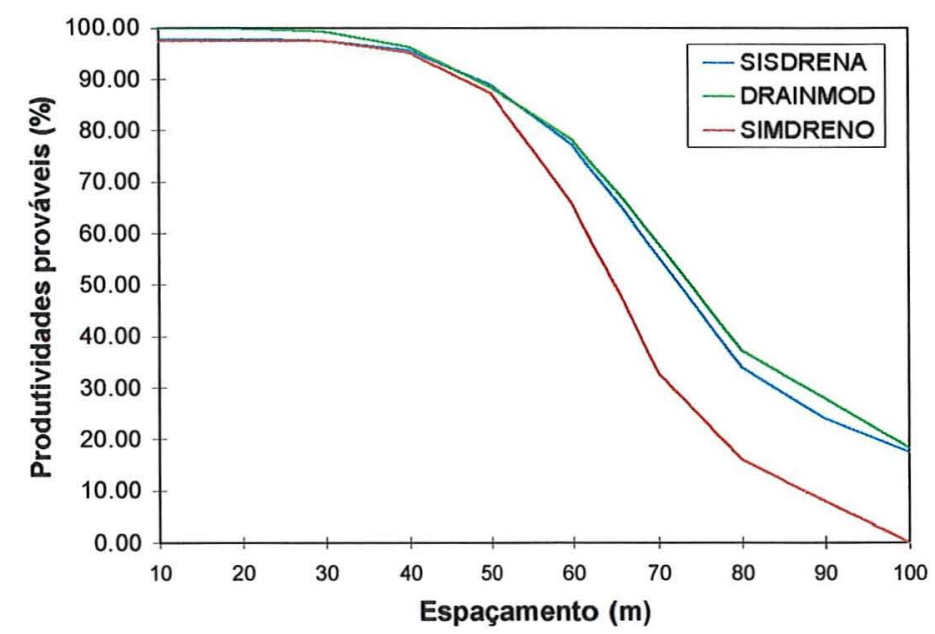

Solo 1

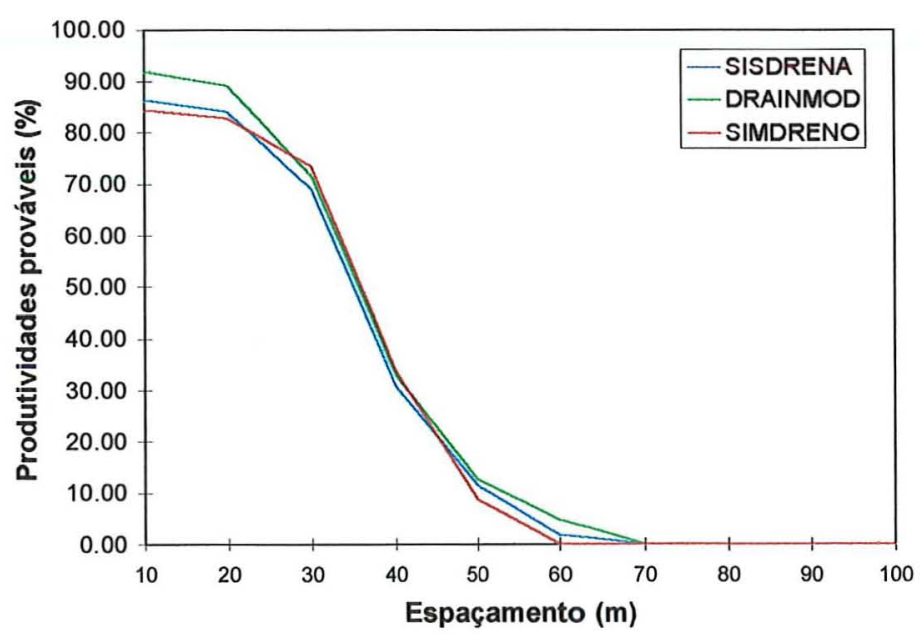

Solo 2

Figura 24 - Produtividades prováveis para a cultura do milho em função do espaçamento entre drenos, obtidas pelo SISDRENA, SIMDRENO e DRAINMOD para os solos 1 e 2 em condições de ausência de escoamento superficial. 


\subsubsection{Estimativa das produtividades médias e prováveis para a cultura do milho em condições de existência de escoamento superficial}

Os valores de produtividade relativa média em função do espaçamento entre drenos podem ser observados pelas Tabelas 14, 15 e 16, e visualizados na Figura 25. Pode-se notar que as produtividades aumentaram com relação ao item anterior. Este resultado é devido a uma menor recarga do LF, propiciando um menor encharcamento da zona radicular, fazendo com que estresses por excesso de água, sejam minimizados. Este fato reflete a importância da drenagem superficial em um sistema de drenagem agrícola.

Outro aspecto é que manteve-se a tendência do SIMDRENO subestimar as produtividades obtidas nas simulações realizadas com espaçamentos maiores, quando se compara com os resultados obtidos com o SISDRENA em relação ao DRAINMOD.

As Tabelas 17, 18 e 19 apresentam os valores das produtividades esperadas com $80 \%$ de probabilidade de sucesso, estimadas para os solos 1, 2 e 3, respectivamente, pelo SISDRENA, SIMDRENO e DRAINMOD. A Figura 26 mostra a representação gráfica deste resultado. Observando-se esta figura, verifica-se que para o solo 1 o desempenho do SISDRENA foi melhor que o do SIMDRENO, quando comparado com o DRAINMOD. Para o solo 2 e 3 ambos os modelos apresentaram desempenho semelhante. Isto porque nestes casos, para espaçamentos maiores, as produtividades relativas foram nulas.

\subsubsection{Análise econômica baseada no valor presente}

Os Quadros 3 e 4 apresentam os espaçamentos mais econômicos e os respectivos valores presentes, calculados em função da produtividade média e da produtividade provável, respectivamente, para a condição de ausência de escoamento superficial. Os Quadros 5 e 6 apresentam os resultados obtidos para a condição de existência de escoamento superficial.

Quando a análise econômica foi realizada tomando como base a produtividade média, o SISDRENA e o DRAINMOD estipularam os espaçamentos iguais para cada um dos 3 tipos de solos analisados, sob a condição de existência ou ausência de escoamento superficial. 
Tabela 14.Valores de produtividade relativa média (YTm) em função do espaçamento entre drenos, obtidos pelos três modelos para o solo $1(\mathrm{Ko}=1,0 \mathrm{~m} / \mathrm{dia})$.

\begin{tabular}{cccccc}
\hline \multicolumn{2}{c}{ SISDRENA } & \multicolumn{2}{c}{ DRAINMOD } & \multicolumn{2}{c}{ SIMDRENO } \\
\hline Espaçamento & YTm \% & Espaçamento & YTm \% & Espaçamento & YTm \% \\
\hline 10 & 99.11 & 10 & 100.00 & 10 & 99.28 \\
20 & 99.19 & 20 & 100.00 & 20 & 99.28 \\
30 & 99.18 & 30 & 99.81 & 30 & 99.28 \\
40 & 98.70 & 40 & 98.87 & 40 & 99.14 \\
50 & 96.74 & 50 & 97.30 & 50 & 96.99 \\
60 & 92.41 & 60 & 93.88 & 60 & 90.27 \\
70 & 83.34 & 70 & 85.25 & 70 & 70.45 \\
80 & 71.06 & 80 & 77.26 & 80 & 53.88 \\
90 & 62.63 & 90 & 70.40 & 90 & 45.51 \\
100 & 56.26 & 100 & 63.86 & 100 & 34.50 \\
\hline
\end{tabular}

Tabela 15.Valores de produtividade relativa média (YTm) em função do espaçamento entre drenos, obtidos pelos três modelos para o solo $2(\mathrm{Ko}=0,5 \mathrm{~m} / \mathrm{dia})$.

\begin{tabular}{cccccc}
\hline \multicolumn{2}{c}{ SISDRENA } & \multicolumn{2}{c}{ DRAINMOD } & \multicolumn{2}{c}{ SIMDRENO } \\
\hline Espaçamento & YTm \% & Espaçamento & YTm \% & Espaçamento & YTm \% \\
\hline 10 & 91.94 & 10 & 96.53 & 10 & 90.99 \\
20 & 92.23 & 20 & 94.69 & 20 & 91.17 \\
30 & 90.64 & 30 & 88.09 & 30 & 90.72 \\
40 & 83.39 & 40 & 73.71 & 40 & 83.72 \\
50 & 68.53 & 50 & 58.81 & 50 & 53.32 \\
60 & 54.76 & 60 & 47.69 & 60 & 36.09 \\
70 & 44.31 & 70 & 39.48 & 70 & 28.91 \\
80 & 35.34 & 80 & 34.02 & 80 & 16.85 \\
90 & 30.13 & 90 & 30.36 & 90 & 9.37 \\
100 & 26.50 & 100 & 27.27 & 100 & 7.87 \\
\hline
\end{tabular}

Tabela 16.Valores de produtividade relativa média (YTm) em função do espaçamento entre drenos, obtidos pelos três modelos para o solo $3(\mathrm{Ko}=0,1 \mathrm{~m} / \mathrm{dia})$.

\begin{tabular}{cccccc}
\hline \multicolumn{2}{c}{ SISDRENA } & \multicolumn{2}{c}{ DRAINMOD } & \multicolumn{2}{c}{ SIMDRENO } \\
\hline Espaçamento & YTm \% & Espaçamento & YTm \% & Espaçamento & YTm \% \\
\hline 10 & 88.98 & 10 & 84.30 & 10 & 86.66 \\
20 & 65.03 & 20 & 45.52 & 20 & 84.31 \\
30 & 37.43 & 30 & 27.30 & 30 & 43.50 \\
40 & 25.55 & 40 & 20.00 & 40 & 19.52 \\
50 & 19.40 & 50 & 15.00 & 50 & 9.37 \\
60 & 15.48 & 60 & 12.32 & 60 & 3.52 \\
70 & 11.74 & 70 & 9.27 & 70 & 0.00 \\
80 & 9.62 & 80 & 6.12 & 80 & 0.00 \\
90 & 7.44 & 90 & 4.93 & 90 & 0.00 \\
100 & 6.34 & 100 & 3.94 & 100 & 0.00 \\
\hline
\end{tabular}




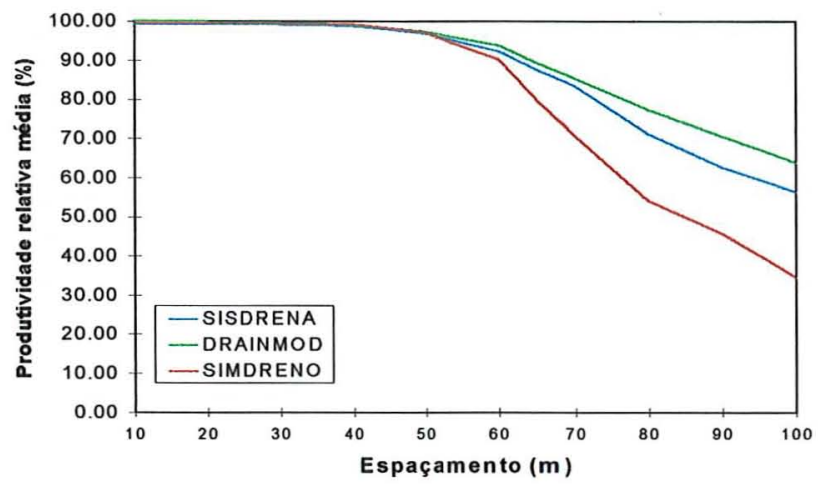

Solo 1

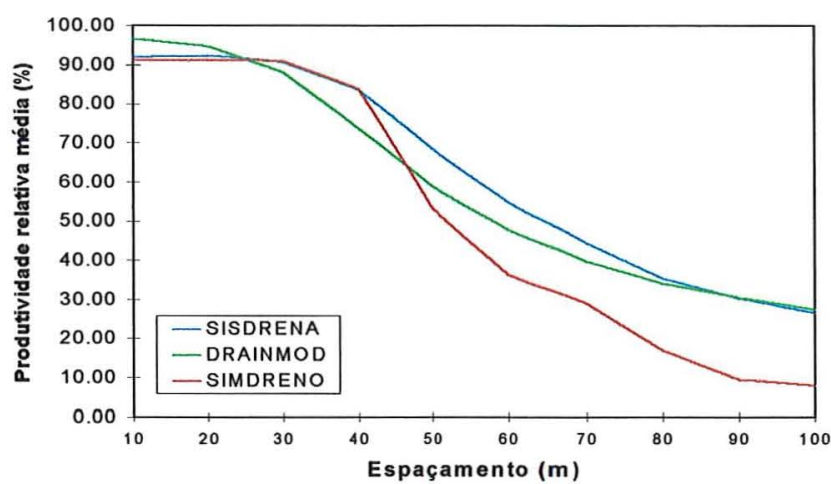

Solo 2

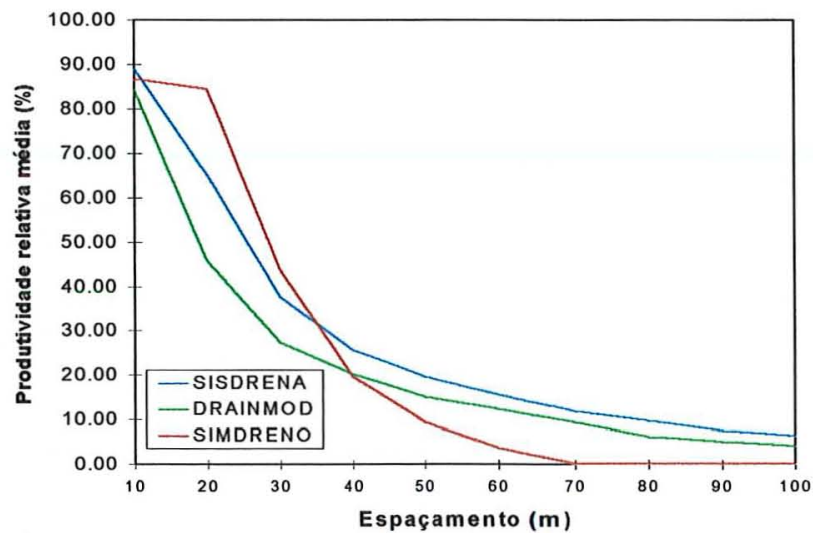

Solo 3

Figura 25 - Produtividades relativas médias para a cultura do milho em função do espaçamento entre drenos, obtidas pelo SISDRENA, SIMDRENO e DRAINMOD para os solos 1, 2 e 3 em condições de existência de escoamento superficial. 
Tabela 17. Valores de produtividade provável em função do espaçamento entre drenos, obtidos pelos três modelos para o solo $1(\mathrm{Ko}=1,0 \mathrm{~m} / \mathrm{dia})$.

\begin{tabular}{cccccc}
\hline \multicolumn{2}{c}{ SISDRENA } & \multicolumn{2}{c}{ DRAINMOD } & \multicolumn{2}{c}{ SIMDRENO } \\
\hline Espaçamento & YT 80\% & Espaçamento & YT 80\% & Espaçamento & YT 80\% \\
\hline 10 & 97,68 & 10 & 100 & 10 & 97,43 \\
20 & 97,83 & 20 & 99,98 & 20 & 97,44 \\
30 & 97,89 & 30 & 99,43 & 30 & 97,47 \\
40 & 96,99 & 40 & 96,89 & 40 & 97,45 \\
50 & 92,06 & 50 & 93,18 & 50 & 92,36 \\
60 & 83,93 & 60 & 86,05 & 60 & 77,70 \\
70 & 67,32 & 70 & 70,22 & 70 & 41,89 \\
80 & 42,04 & 80 & 54,83 & 80 & 17,94 \\
90 & 29,75 & 90 & 41,28 & 90 & 9,39 \\
100 & 20,71 & 100 & 31,08 & 100 & 0 \\
\hline
\end{tabular}

Tabela 18. Valores de produtividade provável em função do espaçamento entre drenos, obtidos pelos três modelos para o solo $2(\mathrm{Ko}=0,5 \mathrm{~m} / \mathrm{dia})$.

\begin{tabular}{cccccc}
\hline \multicolumn{2}{c}{ SISDRENA } & \multicolumn{2}{c}{ DRAINMOD } & \multicolumn{2}{c}{ SIMDRENO } \\
\hline Espaçamento & YT 80\% & Espaçamento & YT 80\% & Espaçamento & YT 80\% \\
\hline 10 & 86,25 & 10 & 91,91 & 10 & 84,16 \\
20 & 86,68 & 20 & 90,03 & 20 & 84,33 \\
30 & 85,16 & 30 & 79,12 & 30 & 84,09 \\
40 & 74,05 & 40 & 54,05 & 40 & 74,23 \\
50 & 47,15 & 50 & 29,10 & 50 & 23,37 \\
60 & 24,84 & 60 & 15,14 & 60 & 2,30 \\
70 & 10,91 & 70 & 5,09 & 70 & 0 \\
80 & 1,20 & 80 & 0 & 80 & 0 \\
90 & 0 & 90 & 0 & 90 & 0 \\
100 & 0 & 100 & 0 & 100 & 0 \\
\hline
\end{tabular}

Tabela 19. Valores de produtividade provável em função do espaçamento entre drenos, obtidos pelos três modelos para o solo $3(\mathrm{Ko}=0,1 \mathrm{~m} / \mathrm{dia})$.

\begin{tabular}{cccccc}
\hline \multicolumn{2}{c}{ SISDRENA } & \multicolumn{2}{c}{ DRAINMOD } & \multicolumn{2}{c}{ SIMDRENO } \\
\hline Espaçamento & YT 80\% & Espaçamento & YT 80\% & Espaçamento & YT 80\% \\
\hline 10 & 67,40 & 10 & 61,93 & 10 & 66,41 \\
20 & 5,58 & 20 & 0,82 & 20 & 1,23 \\
30 & 0 & 30 & 0 & 30 & 0 \\
40 & 0 & 40 & 0 & 40 & 0 \\
50 & 0 & 50 & 0 & 50 & 0 \\
60 & 0 & 60 & 0 & 60 & 0 \\
70 & 0 & 70 & 0 & 70 & 0 \\
80 & 0 & 80 & 0 & 80 & 0 \\
90 & 0 & 90 & 0 & 90 & 0 \\
100 & 0 & 100 & 0 & 100 & 0 \\
\hline
\end{tabular}




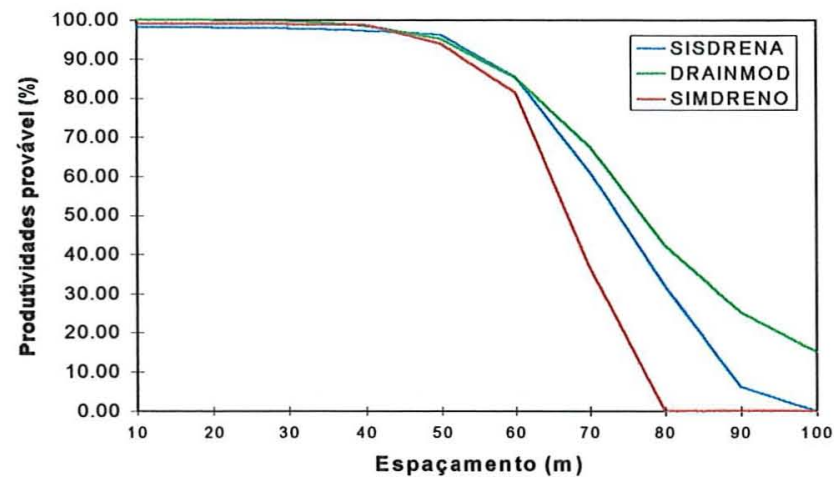

Solo 1

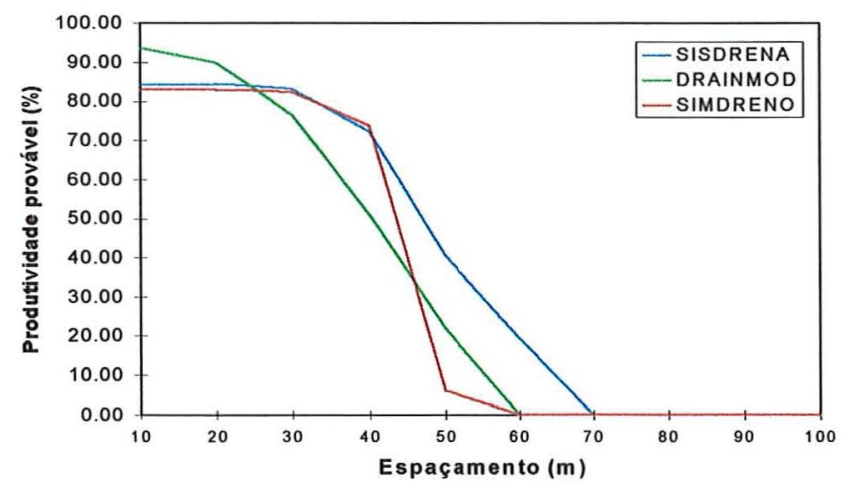

Solo 2

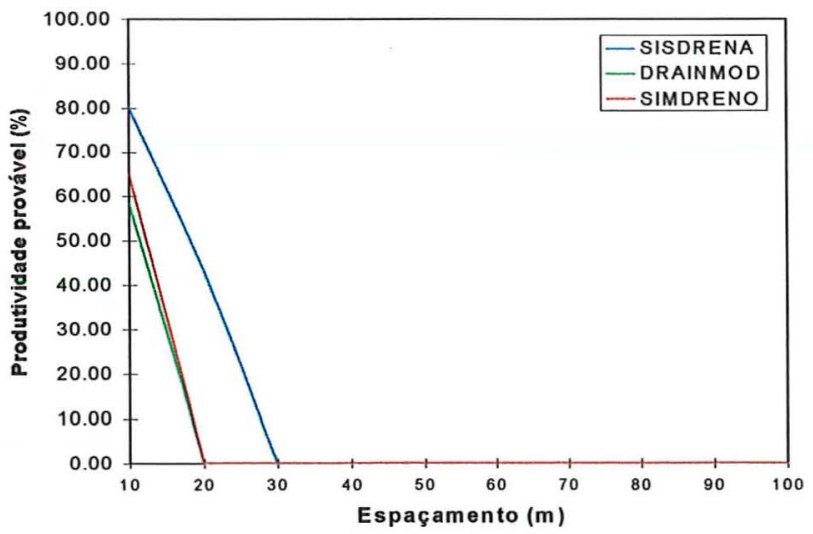

Solo 3

Figura 26 - Produtividades prováveis para a cultura do milho em função do espaçamento entre drenos, obtidas pelo SISDRENA, SIMDRENO e DRAINMOD para os solos 1, 2 e 3 em condições de existência de escoamento superficial. 
Quadro 3: Valores presentes $\left(\mathrm{R} \$ . h \mathrm{~h}^{-1}\right)$ obtidos usando-se produtividades médias para os solos 1 e 2 em ausência de escoamento superficial.

\begin{tabular}{|c|c|c|c|c|c|c|c|c|}
\hline \multicolumn{3}{|c|}{ SISDRENA } & \multicolumn{3}{c|}{ DRAINMOD } & \multicolumn{3}{c|}{ SIMDRENO } \\
\hline Solos & Esp. & VP & Solos & Esp. & VP & Solos & Esp. & VP \\
\hline $\mathbf{1}$ & 40 & $5.097,35$ & $\mathbf{1}$ & 40 & $5.145,63$ & $\mathbf{1}$ & 40 & $5.076,3$ \\
\hline $\mathbf{2}$ & 20 & $2.764,51$ & $\mathbf{2}$ & 20 & $3.265,92$ & $\mathbf{2}$ & 30 & $2.826,25$ \\
\hline
\end{tabular}

Quadro 4: Valores presentes $\left(\mathrm{R} \$ . \mathrm{ha}^{-1}\right)$ obtidos usando-se produtividades prováveis para os solos 1 e 2 em ausência de escoamento superficial.

\begin{tabular}{|c|c|c|c|c|c|c|c|c|}
\hline \multicolumn{3}{|c|}{ SISDRENA - Y80\% } & \multicolumn{3}{c|}{ DRAINMOD - Y80\% } & \multicolumn{3}{c|}{ SIMDRENO - Y80\% } \\
\hline Solos & Esp. & VP & Solos & Esp. & VP & Solos & Esp. & VP \\
\hline $\mathbf{1}$ & 40 & $4.787,84$ & $\mathbf{1}$ & 40 & $4.847,27$ & $\mathbf{1}$ & 40 & $4.712,32$ \\
\hline $\mathbf{2}$ & 20 & $2.029,11$ & $\mathbf{2}$ & 20 & $2.655,56$ & $\mathbf{2}$ & 20 & $1.880,55$ \\
\hline
\end{tabular}

Quadro 5: Valores presentes ( $\mathrm{R} \$ \mathrm{ha}^{-1}$ ) obtidos usando-se produtividades médias para os solos 1, 2 e 3, na presença de escoamento superficial.

\begin{tabular}{|c|c|c|c|c|c|c|c|c|}
\hline \multicolumn{3}{|c|}{ SISDRENA } & \multicolumn{3}{c|}{ DRAINMOD } & \multicolumn{3}{c|}{ SIMDRENO } \\
\hline Solos & Esp. & VP & Solos & Esp. & VP & Solos & Esp. & VP \\
\hline $\mathbf{1}$ & 50 & $5.183,84$ & $\mathbf{1}$ & 50 & $5.253,17$ & $\mathbf{1}$ & 40 & $5.219,92$ \\
\hline $\mathbf{2}$ & 30 & $3.732,49$ & $\mathbf{2}$ & 30 & $3.416,79$ & $\mathbf{2}$ & 30 & $3.742,4$ \\
\hline $\mathbf{3}$ & 10 & 46,26 & $\mathbf{3}$ & 10 & $-533,14$ & $\mathbf{3}$ & 10 & $-2.078,64$ \\
\hline
\end{tabular}

Quadro 6: Valores presentes ( $\left.\mathrm{R} \$ . \mathrm{ha}^{-1}\right)$ obtidos usando-se produtividades prováveis para os solos 1, 2 e 3, na presença de escoamento superficial.

\begin{tabular}{|c|c|c|c|c|c|c|c|c|}
\hline \multicolumn{3}{|c|}{ SISDRENA } & \multicolumn{3}{c|}{ DRAINMOD } & \multicolumn{3}{c|}{ SIMDRENO } \\
\hline Solos & Esp. & VP & Solos & Esp. & VP & Solos & Esp. & VP \\
\hline $\mathbf{1}$ & 40 & $4.953,74$ & $\mathbf{1}$ & 40 & $4.941,36$ & $\mathbf{1}$ & 40 & $5.010,69$ \\
\hline $\mathbf{2}$ & 30 & $3.054,05$ & $\mathbf{2}$ & 20 & $2.786,79$ & $\mathbf{2}$ & 30 & $2.921,58$ \\
\hline $\mathbf{3}$ & 10 & $-2.625,43$ & $\mathbf{3}$ & 10 & $-3.302,64$ & $\mathbf{3}$ & 10 & $-2.747,99$ \\
\hline
\end{tabular}


Ao se calcular o valor presente utilizando-se os dados de produtividade provável, os espaçamentos obtidos como mais econômicos pelo SISDRENA e DRAINMOD foram idênticos apenas na condição de ausência de escoamento superficial. Quando este escoamento foi considerado, o valor obtido pelo SISDRENA para o solo 2 foi ligeiramente superior. O SIMDRENO também forneceu espaçamentos semelhantes àqueles obtidos com o DRAINMOD. Este resultado se deve ao fato deste modelo apresentar desempenho razoável para faixas de espaçamentos não muito elevadas, faixas estas onde geralmente estão incluídas as opções mais econômicas.

Observa-se também que a condição de existência de escoamento superficial permite o uso de espaçamentos maiores. Outro aspecto a ser levado em consideração é que a produtividade com $80 \%$ de probabilidade de ocorrência, por ser menor que a média, leva a obtenção de valores presentes menores. Finalizando, pode-se constatar que a drenagem para a implantação da cultura do milho, na região de Piracicaba, mostrou-se economicamente viável para os solos 1 e 2 . 


\section{CONCLUSÕES}

Os resultados obtidos pelas simulações dos modelos, SISDRENA e SIMDRENO em relação ao DRAINMOD, permitiram as seguintes conclusões:

- O SISDRENA quando comparado com o SIMDRENO, apresentou menores erros padrões nas simulações de posição diária do lençol freático, principalmente para espaçamentos maiores e na condição de presença de escoamento superficial e em situações que o LF se posiciona abaixo da linha dos drenos.

- Nas simulações de vazão e evapotranspiração real diária, o SISDRENA apresentou menores erros em relação ao SIMDRENO, em condições de presença e ausência do escoamento superficial.

- Nas simulações do armazenamento diário de água na zona radicular os resultados obtidos pelos dois modelos foram semelhantes.

- O volume de escoamento superficial diário foi simulado melhor pelo SISDRENA, com relação ao SIMDRENO.

- Os valores do índice $\mathrm{SEW}_{30}$ simulados pelo SISDRENA apresentaram-se mais próximos do que os simulados pelo SIMDRENO.

- Na simulação do número de dias secos na condição de ausência de escoamento superficial, os desempenhos do SISDRENA e do SIMDRENO, foram semelhantes. Na condição de presença de escoamento superficial o SISDRENA apresentou um desempenho melhor.

- As produtividades médias e prováveis simuladas pelo SISDRENA, aproximaram-se mais daquelas obtidas pelo DRAINMOD, do que as simuladas com o SIMDRENO principalmente para espaçamentos entre drenos maiores e em condições de ausência de escoamento superficial. Para espaçamentos menores, as produtividades simuladas pelos três modelos, foram semelhantes.

- Os espaçamentos econômicos obtidos pelos três modelos foram semelhantes. 


\section{REFERÊNCIAS BIBLIOGRÁFICAS}

BATISTA, M.J. Drenagem subterrânea e recuperação de solos salinizados no trópico semi-árido brasileiro. Irrigação e Tecnologia Moderna, n.47, p.3-6, 1992.

BELMANS, C.; WESSELING, J.G.; FEDDES R. A. Simulation model of the water of a cropped soil: SWATRE. Journal of Hydrology, v.63, n.3, p.271-286, 1983.

BENGSTON, R.L.; GARZON, R.S.; FOUSS, J.L. A fluctuating watertable model for the management of a controlled-drainage/subirrigation system. Transactions of the ASAE, v.36, n.2, p.437-443, 1993.

BERNARDO, S. Manual de irrigação. 4.ed. Viçosa, UFV, Impr. Univ., 1986. 488p.

BORNSTEIN, J.; SKINNER, S.P.; REILING, S.D. Economics of subfurface drainage systems for alfafa hay. Transactions of the ASAE, v.29, n.2, p.484-488, 1986.

BOUMANS, J.H.; SMEDEMA, L.K. Derivation of cost-minimizing depth for lateral pipe drains. Agricultural Water Management, v.12, n.1, p.41-51, 1986.

BOWER, H., JACKSON, R.D. Determinig soil properties. In: SCHILFGAARDE, J. van. Drainage for agriculture. Madison: American Society of Agronomy, 1974. p.611666. 
BRANDYK, T.; WESSELING, J.G. Soil moisture flow in drainage -subirrigation system. Journal of Hidrology, v.113, n.1, p86-97, 1987.

BURAS, N. Water management systems. In: SCHILFGAARDE, J. van. Drainage for agriculture. Madison: American Society of Agronomy, 1974. p.675-693.

CAPECE, J.C.; CAMPBELL, K.L.; BALDWIN, L.B.; KONYHA, K.D. Estimating runoff volumes from flat, high-water table watersheds. Transactions of the ASAE, v.30, n.5, p.1397-1402, 1987.

CARTER, C.E.; CAMP, C.R. Drain spacing effects on water table control and cane sugar yields. Transactions of the ASAE, v.37, n.5, p.1509-1513, 1994.

COSTA, R.N.T. Espaçamento econômico de drenos laterais e a dinâmica do lençol freático sobre o rendimento da cultura de milho (zea mays, L.). Piracicaba, 1994. 88 p. Tese (Doutorado) - Escola Superior de Agricultura Luiz de Queiroz, Universidade de São Paulo.

CRUCIANI, D.E. A drenagem na agricultura. 4. ed. São Paulo: Nobel, 1987. 337p.

DUARTE, S.N. Modelo para avaliação de desempenho de sistemas de drenagem subterrânea e cálculo de espaçamento de drenos. Viçosa, 1997. 143 p. Tese (Doutorado) - Universidade Federal de Viçosa.

ESTADOS UNIDOS. Department of Agriculture. Soil Conservation Service. National engineering handbook: IV. Hydrology. s.l, Washington, 1972, 1 v.

FAO. Drainage design factors; 28 questions and answers. Rome, 1986. 52p. (FAO. Irrigation and Drainage Paper, 38). 
FEDDES, R.A. Effects of drainage on crops and farm management. Agricultural and Water Management, v.14, n.1, p.3-18, 1988.

FERREIRA, P.A. Curso de engenharia de irrigação: XI. Drenagem. Brasilia: Associação Brasileira de Educação Agrícola Superior. 1987. 86p.

GENUCHTEN, M. T. van. A closed-form equation for predicting the hydraulic conductivity of unsaturated soils. Soil Science Society of America Journal, v.44, n.3, p.892-898, 1980.

JARVIS, N.J.; LEEDS-HARRISON, P.B. Modelling water movement in drained clay soil. I. Description of the model, sample output and sensitivity analysis. Journal of Soil Science, v.38, n.3, p.487-498, 1987.

JORJANI, H.; VUUREN, W. van. Physical and economics benefits of subsurface drainage by soil type in eastern Ontario. Agricultural and Water Management, v.19, n.3, p.235-251, 1991.

KANWAR, R.S.; JOHNSON, H.P.; SCHULT, D. et al. Transactions of the ASAE, v.26, n.2, p.457-464, 1983.

LEITCH, J.A. Economics of prairie wetland drainage. Transactions of the ASAE, v.26, n.5, p.1465-1475, 1983.

MINDERHOUND, P. A model for the design of drainage in flat agricultural. Agricultural and Water Management, v.5, n.2, p.95-125, 1982.

MOODY, W.T. Nonlinear differential equation of drainage spacing. Journal of the Irrigation and Drainage Division, v.92, n.2, p.1-9, 1967. 
MUALEM, Y. A new model for predicting the hydraulic conductivity of unsaturated porus media. Water Resources Research, v.12, n.3, p.513-522, 1976.

PIZARRO, F. Drenaje agrícola y recuperación de suelos salinos. Madrid: Agrícola Española, 1978. 521p.

ROGERS, J.S. Water management model evaluation for shallow sandy soils. Transactions of the ASAE, v.28, n.3, p.785-790, 1985.

SABBAGH, G.J.; FOUSS,J.L.; BENGSTON, R.L. Comparison of EPIC-WT and DRAINMOD simulated performance of land drainage sistems. Transactions of the ASAE, v.36, n.1, p.73-79, 1993.

SCHILFGAARDE, J. van. Transient design of drainage systems. Journal of the Irrigation and Drainage Division, v.91, n.3, p.9-22, 1965.

SCHILGAARDE, J. van. Nonsteady flow to drains In: SCHILFGAARDE, J. van. Drainage for agriculture. Madison: American Society of Agronomy, 1974. p.245270.

SKAGGS, R.W. The effect of surface drainage on water table response to rainfall. Transactions of the ASAE, v.17, n.2, p.406-411, 1974.

SKAGGS, R.W. DRAINMOD - Reference report: methods for design and evaluation of drainage-water management systems for soils with high water tables. Raleigh: USDA,SCS, 1981.329 p.

SKAGGS, R.W. DRAINMOD: user's manual. Raleigh: North Carolina State University, 1990. 101p. 
SKAGGS, R.W. Drainage. In: Modeling plant and soil systems. Madison: American Society of Agronomy, 1991. p.205-243: Drainage (Agronomy Monograph, 31).

SMEDEMA, L.K.; RYCROFT, D.W. Land drainage. Ithaca: Cornell University Press, 1983. 377p.

TOVEY, R. Alfafa growth as influenced by static and fluctuating water tables. Transactions of the ASAE, v.7, n.3, p.310-312, 1964.

WILLMOTT, C.J. On the validation of models. Physical Geography, v.2, p.184-194, 1981.

WISER, E.H.; WARD, R.C.; LINK, D.A. Optimized design of a subsurface drainage system. Transactions of the ASAE, v.15, n.1, p.175-182, 1974.

WORKMAN, S.R.; SKAGGS, R.W. Comparison of two drainage simulation models using field data. Transactions of the ASAE, v.32, n.6, p.1933-1938, 1989.

YOUNG, T.C.; LIGON, J.T. Water table and soil moisture probabilities with tile drainage. Transactions of the ASAE, v.15, n.2, p.448-451, 1972. 